Florida International University FIU Digital Commons

$11-3-2002$

\title{
Implications of adolescent development upon transracial adoptees
}

Anthony L. Burrow

Florida International University

DOI: $10.25148 /$ etd.FI14051891

Follow this and additional works at: https://digitalcommons.fiu.edu/etd

Part of the Psychology Commons

\section{Recommended Citation}

Burrow, Anthony L., "Implications of adolescent development upon transracial adoptees" (2002). FIU Electronic Theses and Dissertations. 1868.

https://digitalcommons.fiu.edu/etd/1868

This work is brought to you for free and open access by the University Graduate School at FIU Digital Commons. It has been accepted for inclusion in FIU Electronic Theses and Dissertations by an authorized administrator of FIU Digital Commons. For more information, please contact dcc@fiu.edu. 


\section{FLORIDA INTERNATIONAL UNIVERSITY}

Miami, Florida

\section{IMPLICATIONS OF ADOLESCENT DEVELOPMENT UPON TRANSRACIAL ADOPTEES}

A thesis submitted in partial fulfillment of the

requirements for the degree of

MASTER OF SCIENCE

in

PSYCHOLOGY

by

Anthony L. Burrow

2002 
To: Dean Arthur W. Herriott

College of Arts and Sciences

This thesis, written by Anthony L. Burrow, and entitled Implications of Adolescent Development Upon Transracial Adoptees, having been approved in respect to style and intellectual content, is referred to you for judgment.

We have read this thesis and recommend that it be approved.

Marvin Dunn

Jonathan Tubman

Paulette Johnson

Gordon E. Finley, Major Professor

Date of Defense: November 3, 2002

The thesis of Anthony L. Burrow is approved.

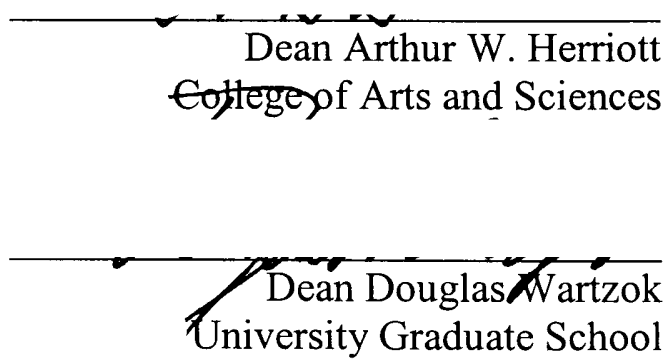

Florida International University, 2002 


\section{DEDICATION}

I dedicate this thesis to my grandmother. Through her expectations, encouragement, and love, the completion of this work was possible. 


\section{ACKNOWLEDGMENTS}

I would like to thank all of my committee members for their guidance and support of my work on this thesis. Each offered motivation, mentoring, and insight towards helping me complete this thesis. I would like to thank my major professor, Dr. Finley for helping me turn a conceptual interest into a professional product. 
ABSTRACT OF THE THESIS

IMPLICATIONS OF ADOLESCENT DEVELOPMENT UPON TRANSRACIAL

ADOPTEES

by

Anthony L. Burrow

Florida International University, 2002

Miami, Florida

Professor Gordon E. Finley, Major Professor

The aim of the present investigation was to examine the implications of adoption status upon the adjustment of adolescents, with a focus on transracial adoptees. Based upon secondary analyses of a nationally collected data set, three levels of analyses were undertaken to investigate group differences between: (a) adoptees and non-adoptees, (b) transracially adopted adolescents and same-race adopted adolescents and, (c) specific racial groupings of adopted children and their parents across a broad range of adjustment measures. The results indicated some evidence supporting increased maladjustment of adoptees compared to their non-adopted counterparts. Yet, when comparing groups of adopted adolescents, the results suggested that racial differences between adoptees and their adoptive parents do not exacerbate developmental risks related to adjustment. Support was also found for significant age and gender influences upon adjustment variables. The implications of the findings are discussed. 


\section{TABLE OF CONTENTS}

CHAPTER

PAGE

I. INTRODUCTION

II. LITERATURE REVIEW 9

Adoption $\quad 9$

Transracial Adoption $\quad 12$

Adolescence $\quad 21$

$\begin{array}{ll}\text { Adolescence and Adoption } & 22\end{array}$

$\begin{array}{ll}\text { III. METHODOLOGY } & 27\end{array}$

Description of Database $\quad 27$

$\begin{array}{ll}\text { Participants } & 28\end{array}$

Independent Variables $\quad 28$

Dependent Variables $\quad 30$

Statistical Analyses $\quad 35$

$\begin{array}{lll}\text { IV. RESULTS } & 37\end{array}$

Analysis One: Adoption Status X Adolescent Age X Gender 37

Analysis Two: Adoption Type X Adolescent Age X Gender 44

Analysis Three: Exploratory Analyses $\quad 47$

Tables $\quad 53$

$\begin{array}{lll}\text { V. DISCUSSION } & 86\end{array}$

Summary of Results $\quad 86$

Synthesis of Literature Review and Results $\quad 89$

Limitations $\quad 97$

Directions for Future Research $\quad 98$

$\begin{array}{lr}\text { LIST OF REFERENCES } & 100\end{array}$ 
Table 1. Analysis One: MANOVA for Academic Variables by Adoption Status, Adolescent Age, and Gender

Table 2. Analysis One: Means and Standard Deviations for Academic Variables by Adoption Status, Adolescent Age, and Gender

Table 3. Analysis One: ANOVA Main Effects of Adoption Status on Academic Variables

Table 4. Analysis One: ANOVA Main Effects of Adolescent Age on Academic Variables

Table 5. Analysis One: ANOVA Main Effects of Gender on Academic Variables

Table 6. Analysis One: Means and Standard Deviations for Academic Variables by Adolescent Age X Gender

Table 7. Analysis One: ANOVA Interaction Effects of Adolescent Age by Gender on Academic Variables

Table 8. Analysis One: MANOVA for Familial Relationship Variables by Adoption Status, Adolescent Age, and Gender

Table 9. Analysis One: Means and Standard Deviations for Familial Relationship Variables by Adoption Status, Adolescent Age, and Gender

Table 10. Analysis One: ANOVA Main Effects of Adoption Status on Familial Relationship Variables

Table 11. Analysis One: ANOVA Main Effects of Adolescent Age on Familial Relationship Variables

Table 12. Analysis One: ANOVA Main Effects of Gender on Familial Relationship Variables

Table 13. Analysis One: MANOVA for Psychological Adjustment Variables by Adoption Status, Adolescent Age, and Gender 
Table 14. Analysis One: Means and Standard Deviations for Psychological Adjustment Variables by Adoption Status, Adolescent Age, and Gender

Table 15. Analysis One: ANOVA Main Effects of Adolescent Age on Psychological Adjustment Variables

Table 16. Analysis One: ANOVA Main Effects of Gender on Psychological Adjustment Variables

Table 17. Analysis One: MANOVA for Physical Health Variables by Adoption Status, Adolescent Age, and Gender

Table 18. Analysis One: Means and Standard Deviations for Physical Health Variables by Adoption Status, Adolescent Age, and Gender

Table 19. Analysis One: ANOVA Main Effects of Gender on Physical Health Variables

Table 20. Analysis Two: MANOVA for Academic Variables by Adoption Type, Adolescent Age, and Gender

Table 21. Analysis Two: Means and Standard Deviations for Academic Variables by Adoption Type, Adolescent Age, and Gender

Table 22. Analysis Two: ANOVA Main Effects of Gender on Academic Variables

Table 23. Analysis Two: MANOVA for Familial Relationship Variables by Adoption Type, Adolescent Age, and Gender

Table 24. Analysis Two: Means and Standard Deviations for Familial Relationship Variables by Adoption Type, Adolescent Age, and Gender

Table 25. Analysis Two: MANOVA for Psychological Adjustment Variables by Adoption Type, Adolescent Age, and Gender

Table 26. Analysis Two: Means and Standard Deviations for Psychological Adjustment Variables by Adoption Type, Adolescent Age, and Gender

Table 27. Analysis Two: ANOVA Main Effects of Gender on Psychological Adjustment Variables 
Table 28. Analysis Two: MANOVA for Physical Health Variables by Adoption Type, Adolescent Age, and Gender

Table 29. Analysis Two: Means and Standard Deviations for Physical Health Variables by Adoption Type, Adolescent Age, and Gender

Table 30. Analysis Two: ANOVA Main Effects of Gender on Physical Health Variables

Table 31. Analysis Three: Means, Standard Deviations, and Significance Tests by Specific Racial Groupings

Table 32. Analysis Three: Means, Standard Deviations, and Significance Tests by Adolescent Age

Table 33. Analysis Three: Means, Standard Deviations, and Significance Tests by Gender 
This study centers on adoption. As a primary focus, this study investigated implications of adolescent development upon the adjustment of transracial adoptees.

\section{Background Information}

\section{$\underline{\text { Adoption }}$}

The practice of providing permanent families for children whose parents are unable to care for them has generated significant discussion in American society (Finley, 2002). National estimates suggest that approximately one million children are currently living with adoptive parents (Stolley, 1993). As a result, adoption has become a socially acceptable alternative to biological child rearing. Within the context of this low frequency family form, ensuring positive developmental experiences of children has continuously been at issue by those involved in adoption placements. Accordingly, many researchers have raised questions about the implications of adoption on adolescent development. For the most part, empirical research conducted in this area has reported positive outcomes (or similar outcomes as non-adopted counterparts) for adopted individuals (Brodzinksy, Smith, \& Brodzinsky, 1998; Finley, 1999; McRoy \& Zurcher, 1983; Silverman, 1993; Simon \& Alstein, 1992), particularly compared to forms of institutional care (Feigelman and Silverman, 1984; Schorr, 2000; Burrow and Finley, 2001).

\section{$\underline{\text { Transracial Adoption }}$}

Before World War II, the practice of adopting children of different racial backgrounds from the adopting parents was relatively uncommon. However, through 
specific changes in American society, transracial placements (TRA) became a more widely accepted form of adoption (Brodzinksy, Smith, \& Brodzinsky, 1998). Over the past two decades, a number of studies have examined developmental outcomes of transracially adopted children (e.g., Brooks \& Barth, 1999; Feigelman, 2000, Grow \& Shapiro, 1974; Hollingsworth, 1997; McRoy \& Zurcher, 1983; Simon \& Alstien, 1996). Insofar as same race adoptions have been used in comparison with transracial adoptions, empirical research has generally indicated that these two groups do not significantly differ with regards to adjustment issues (McRoy \& Zurcher, 1983; Triseliotis, Shireman, \& Hundleby, 1997; Silverman, 1993; Simon \& Alstein, 1992). Despite these findings, however, significant criticism remains within the literature regarding the purported inability of parents of one race to facilitate positive developmental outcomes for their adopted children of a different race. For instance, more than once the National Association of Black Social Workers (NABSW) has contended that the healthy development of black children requires black parents. Accordingly, the NABSW and others who support their claims have criticized empirical data that suggests otherwise. Although much of this criticism has been heavily ideological, (i.e., not empirically supported), it continues to be a prominent position within academic, legal, and adoption placement settings.

Within the context of empirical research, the argument against TRA centers on purported methodological shortcomings that deny researchers the ability to accurately assess adoptee adjustment (e.g., Park \& Green, 2000). Additionally, critics assert that too much of the relevant literature investigating transracially adopted children focuses on academic performance and global psychological adjustment (Vonk \& Angaran, 2001). 
Consequently, opponents of TRA maintain that other measures of adjustment, such as knowledge of how to survive in a race-salient society and understanding of cultural heritage are neglected (Courtney, 1997). Many critics of TRA argue that placing children of one race with parents of a different race condemns those children to develop a maladaptive racial identity (Chestang, 1972; Chemezie, 1975; NABSW, 1994).

In contrast to this criticism, some researchers have maintained that the racial identity of black children adopted by white parents is not harmed (Simon \& Alstein, 1996; Vroegh, 1997). Concurrently, other scholars have suggested that for adolescent adoptees, there are many domains that should be considered important beyond racial identity (e.g., Hayes, 1993). These include, academic performance, number and quality of familial relationships, and problem behaviors have been deemed paramount to adaptive adolescent development (Brodzinsky \& Brodzinsky, 1992; Verhulst \& Versliuis-den Bierman, 1995; McRoy, Zurcher, Lauderdale, \& Anderson, 1982).

Although these domains have been identified, attempts to empirically examine their implications have been met with methodological disdain. Namely, the usage of small sample sizes has been considered a consistent shortcoming of nearly all studies investigating transracial adoption. Effectively identifying and sustaining comparative populations of adopted children has proven to be a difficult task. Furthermore, identifying transracially adopted children has traditionally presented an even larger obstacle as issues surrounding racial classification have confounded many efforts to distinguish these particular types of adoption. Thus, it is common that many studies on adoption (specifically TRA) utilize very small samples. As a result, empirical and 
ideological assessments have been curtailed in their ability to provide a generally acceptable resolution to questions regarding the adjustment of transracial adoptees.

\section{Adolescence}

Adolescence is often depicted as a time of marked personal distress and disturbance in human development. For many individuals, negotiating oneself through this period can be a difficult process, resulting in various kinds of problems. In support of this, some researchers have argued that significant adjustment problems are most likely to be observed during this time more so than any other stage of the life-cycle (Howe, 1997; Rosenthal, 1993; Tizard, 1991). While the types of problems manifested are not universal, there are typical issues that emerge as one progresses through adolescence. Of significant concern, maladaptive adolescent adjustment has commonly been associated with poor academic performance (Berdnt \& Keefe, 1992), negative social behaviors (Fergusson \& Lynskey, 1996), and poor familial relationships (Corbett \& Pertersilia, 1994; Werner, 1989).

\section{Adolescence and Adoption}

Few studies investigating adoption have specifically looked at adjustment as a function of adolescent development. Of this limited body of research, the results are inconclusive. For instance, according to some, the above realities of adolescence are exacerbated for adopted children (Brodzinsky, Smith, \& Brodzinsky, 1998; Howe, 1997; Rosenthal, 1993; Tizard, 1991). As an explanation, Verhulst (2000) contended that a decline in familial supervisory factors (associated with normative adolescent development) have more negative implications for adopted individuals than for their nonadopted peers. Contrary to these findings, some researchers failed to find any significant 
differences between adolescent adoptees and non-adoptees (e.g., Bohman \& Sigvardsson, 1980; Tizard \& Rees, 1974). However, these studies involved same-race adoptees. Interestingly, Verhulst's (2000) study involving international adoptees who were racially different than their adoptive parents reported significant differences in adjustment between adopted adolescents and the non-adopted adolescents. Also, another empirical study of international adolescent adoptees found them to have significantly worse psychological adjustment compared to their non-adopted siblings (Cohen \& Westhues, 1995). Despite negative findings reported by some researchers, adolescents tend to show less maladjustment as they reach middle to late adolescence (Brodzinsky, Smith, and Brodzinsky, 1998).

To relate these findings to transracial adoptions, Feigelman and Silverman (1984) suggested that international adoptees and domestic transracial adoptees share similarities in separation from birth parents and culture, physical differences from parents, and prejudice. In this way, a possible conclusion to be drawn from these findings is that adoptions wherein the parent and child do not share a race can be an additional risk factor for maladaptive developmental outcomes, specifically within adolescence for the adoptee. In sum, these findings indicate that while adolescence seems to be a critical developmental period for most individuals (adopted and non-adopted), it might be particularly more challenging for transracially adopted individuals.

\section{Purpose of Study}

The purpose of the current study was to examine adolescent transracial adoptee adjustment with a large comparative population represented in the National Longitudinal Study of Adolescent Health database (1997). Thus, this study addressed important 
methodological critiques present in the current literature, through investigating adjustment issues of adolescent transracial adoptees. Specifically, the various areas of inquiry regarded by this study, (e.g., academic performance, familial relationships, and problematic social behaviors.) were used as variables to represent aspects of adjustment.

As adolescence is considered a critical period of development for individuals, the current study investigated the influence of adoption, transracial adoption, adolescent age groups (12-13, 14-16 or 17-19), and gender has upon normative adolescent development. $\underline{\text { Research Hypothesis }}$

Based upon the existing literature suggesting that progress through adolescence presents adjustment challenges to individuals, and that perhaps racial differences between parent and child may exacerbate these challenges, this study hypothesized the following interaction effect: a) transracial adoptees in the young ages (12-13), will not significantly differ from their same-race adopted counterparts regarding normative adolescent development as measured by academic performance, familial relationships, psychological adjustment, and physical health domains selected. However, b) transracial adoptees in the middle ages (14-16), and old ages (17-19) will significantly differ from their samerace adopted counterparts regarding normative adolescent development along such variables.

\section{Methodology}

\section{$\underline{\text { Instrumentation }}$}

The present study conducted secondary analyses of a nationally collected data set. The data set consisted of sections of the National Longitudinal Study of Adolescent Health. This data set is a compilation of questionnaires and interviews administered to 
adolescents in their schools and homes. The items selected to measure by this study correspond to the most common measures utilized within the existing literature regarding adolescent development, adoptee development, and transracial adoptee development.

\section{$\underline{\text { Data Analysis }}$}

The data were analyzed using SPSS for windows. The research design involved three levels of analysis. Analysis One and Analysis Two both fit a 2 X 3 X 2 model of independent variables. Specifically, Analysis One involved 2 (adopted versus nonadopted) X 3 (ages 12-13, 14-16, and 17-19) X 2 (males versus females). Analysis Two involved 2 (transracially adopted versus same-race adopted) X 3 (ages 12-13, 14-16, and 17-19) X 2 (males versus females). The statistical procedures used in Analyses One and Two were MANOVAs. Analysis Three involved investigating specific racial groupings, adolescent age, and gender separately. Therefore, One-way ANOVAs were used. Each analysis investigated the following four dependent variables: a) academic outcomes, b) familial relationships, c) psychological adjustment, and d) physical health.

\section{$\underline{\text { Significance of Study }}$}

Analyzing the National Longitudinal Study of Adolescent Health data contributes to the existing knowledge on adoptions and its implications for adolescents. While previous research has offered a great deal to our knowledge of the experiences and outcomes of adopted children, questions surrounding the usage of small samples have left researchers unable to generalize their results. However, the data represented in the National Longitudinal Study of Adolescent Health offers a large sample of adoptees to investigate. In addition, the large set of adoptees represented in this database can be refined to identify persons who were transracially adopted. Therefore, the study will 
specifically evaluate variables investigated in several past studies of transracial adoption, however, through the scope of a much larger sample size and with comparative samples of same-race adoptees and non-adopted adolescents.

As the primary focus, the study addresses issues related to the adjustment of transracially adopted children. Specifically, this study concentrates on factors central to adolescent development. As research questions, the study addresses: What factors influence TRA adjustment? Are the factors that influence TRA adjustment different than those that influence intraracial adoptee adjustment? How do transracial adoptees compare to intraracial adoptees across academic, familial relationship, and problem behavioral variables? What roles, if any, do age and gender play in adolescent development for transracial adoptees, same-race adoptees, and non-adopted adolescents? 


\section{Chapter II Literature Review}

Adoption

The concept of family is continuously changing within our society. Traditional views concerning family are continuously replaced by unique examples of diverse family forms. (Brodzinsky, 1998) One such family form which consistently deems itself relevant to investigation across disciplines is that of adoption. In contemporary society, adoption serves to provide permanent homes for children whose biological parents are unable to care for them (Brooks \& Barth, 1999; Finley, 2002). Correspondingly, national estimates suggest that approximately one million children are currently living with adoptive parents (Stolley, 1993). Accordingly, adoption has become a socially accepted alternative to biological child-rearing.

Nevertheless, as adoption has become relatively common, it, like other family forms has been subjected to various criticisms. Specifically, these criticisms center on the effects that the adoption experience has upon parents, children, and family functioning. Within this context, the growing social emphasis placed upon the welfare of children prompted regulated assessments of conditions that are in the best interest of the children (Brodzinsky, Lang, \& Smith 1988, Finley, 2002). To ensure this well-being, qualitative and quantitative evaluations of a wide range various psychological factors require measurement. Thus, scientific investigations have been conducted to describe and measure the influence of adoption upon the normative development of children Adoptee versus non-adoptee empirical research

To better understand normative adoption experience, numerous researchers have sought to investigate its implications upon children. Accordingly, for the nearly the past 
40 years, extensive research has been conducted on various aspects of children's development to investigate psychological outcomes associated with adoption (Brodzinsky, Lang, \& Smith 1995). Much of this interest was directed by Kirk's (1964) notion of shared fate suggested that adopted children were subjected to pathology due to experiencing a deep sense of loss, produced by losing their biological parents and being placed with adoptive parents. In this way, researchers have believed that this negative sense of loss and stress are significant contributors to maladaptive adoptee development (Brodzinsky, Smith \& Brodzinsky, 1998). Hence, many investigators seek empirical evidence to delineate the underlying developmental processes associated with adoption.

To this end, some researchers have contended that adoption is associated with increased pathology for children. Some researchers assert that familial closeness is compromised by adoption, due to adopted children being less attached to their parents than are non-adopted children (Yarrow \& Goodwin, 1973; Yarrow, Goodwin, Manheimer, \& Milowe, 1973). As a result of this decreased attachment, investigators hypothesised that maladaptive outcomes would result for adoptees. Some investigations of specific developmental aspects confirmed this hypothesis. For instance, Sharma, McGue, and Benson (1998) found that adoptees demonstrated more school adjustment problems, increased substance abuse, and greater reports of delinquency than nonadopted children. Also, other problems have been associated with the adoption experience for children as well. For instance, Brodzinsky $(1990,1993)$ argued that adoptees were at greater risk to display more externalizing behaviors than non-adoptees. Correspondingly, to exacerbate the concern of increased psychological risk for adoptees, 
research consistently suggests that adopted children are over-represented in mental health settings (Wierzbicki, 1993).

In contrast, some studies have failed to show negative implications of adoption upon children. Accordingly, several studies comparing adopted children to non-adopted children did not find significant differences between the two groups along several psychological indices such as emotional, social, and academic functioning (Stein \& Hoopes, 1985; Bohman \& Sigvardsson, 1990; Maughan \& Pickles, 1990). Also, Weiss (1985) investigated comparative rates of substance abuse, and concluded that adoptees did not have significantly higher rates of substance abuse than their non-adopted counterparts.

What is more, according to some scholars the comparatively high rate of adoptee clinical referrals may not reflect actual psychiatric need. As an alternative explanation, adoptive parents may be more likely to refer their children to a mental health agency, due to their own insecurities and anxieties, or because they are more familiar with mental health institutions than non-adoptive parents (Warren, 1992; Brodzinsky, Smith \& Brodzinsky, 1998; Brodzinsky, Lang, \& Smith 1988). In this way, adoption is considered by most investigators to be a viable means of ensuring adaptive outcomes; certainly compared to adverse institutional or foster care (Feigelman \& Silverman, 1984; Schorr, 2000; Burrow \& Finley, 2001).

Hence, within adoption research literature, uniform conclusions remain to be found. (Finley, 1999c). To rationalize the purported inconsistencies, some scholars assert that methodological shortcomings have diluted the adoption literature (Brodzinsky, 1993; Finley, 1998; Finley, 1999c). Small sample sizes, sampling biases, insufficient 
comparison groups, and inadequate measures of adjustment are commonly cited as problems within adoption studies, making conclusions less generalizable (Park \& Green, 2000; Courtney, 1997). Within this context, some researchers contend that the determining whether or not adoption is a risk factor is less productive than directing investigations towards the range of specific factors associated with adoptee development (Brodzinsky, Smith, \& Brodzinsky, 1998).

\section{$\underline{\text { Transracial Adoption }}$}

\section{Historical overview}

Throughout the past few decades, the relationship between race and adoption has wrought significant debate concerning the notion of the well being of adopted children. While placing children with parents across racial lines has occurred in the United States since the 1940's, prior to World War II such practice was relatively uncommon (Curtis, 1996). However, through distinct social changes in American society, transracial placements became more commonplace in child placement (Hollingsworth, 1998). Namely, as an increasing number of white families sought to adopt, a simultaneous decreasing number of white children were being placed for adoption. In contrast, there remained a significant number of non-white children available for adoption. To this end, placing children transracially was established to enable parents to adopt children awaiting permanent homes (Brodzinsky, Smith, \& Brodzinsky, 1998; Hollingsworth, 1997).

While the term transracial adoption (TRA) denotes the joining of parents of one race and children of a different race together in adoptive families, in the United States it typically involves white families adopting minority children (Silverman, 1993).

Essentially, within the United States transracial placements involve Black, Asian, and 
South and Central American being adopted by white parents (Brodzinsky, Smith, \& Brodzinsky, 1998). Such placements account for a relatively small number of actual adoptions that occur annually. For instance, estimates show that of all adoptions that occur each year, eight percent involve children being placed with parents of a different race. Of these placements, some are domestic while others are international placements. While there are fundamental differences between these two types of adoptions that require unique methods of investigation, some scholars believe that both share commonalties deeming them sufficiently alike: a loss of biological parents and birth culture (Feigelman \& Silverman, 1984).

Yet, despite its actual prevalence, intense long-standing controversies persist within ideologies and research involving children adopted by parents of a different race. While numbers of transracial placements were increasing steadily into the 1970 's, at that time their prevalence decreased dramatically in response to rhetorical opposition from practitioners, legislatures, and researchers alike. In other words, this form of care was deemed by TRA opponents to place adopted children at a greater risk for psychological pathology with respect to behavior, self-esteem, and racial identity formation than their same-race adopted counterparts.

Specifically, as black children were being placed in white homes, groups within the black community opposed TRA based on the perspective that their culture was threatened with depletion if children were placed into white families. Consequently, at their annual conference in 1972, the National Association of Black Social Workers (NABSW) addressed concerns about the large numbers of black children who were being placed with white families. As part of their concern, the NABSW cited psychological 
maladjustment, inability to cope with racism, and cultural-genocide as likely outcomes of TRA. (Feigelman \& Silverman, 1984) Also, the development of a poor racial identity was consistently considered to be an outcome of placing children transracially. As a resolution, they issued a statement condemning white families adopting black children, which stated:

"Black children belong physically and psychologically and culturally in black families where they can receive the total sense of themselves and develop a sound projection of their future. Only a black family can transmit the emotional and sensitive subtleties of perceptions and reactions essential for a black child's survival in a racist society. Human beings are products of their environment and develop their sense of values, attitudes, and self-concept within their own family structures. Black children in white homes are cut off from the healthy development of themselves as black people...it is a blatant form of racial and cultural genocide." (Quoted in McRoy, 1989, pg. 150)

Similar to responses from black communities, some Native American communities expressed various concerns as significant numbers of Native American children were being placed with white families. Many Native Americans saw this trend as a direct threat to their cultural preservation. (Feigelman \& Silverman, 1984) Accordingly, certain groups within the Native American community worked to pass the Indian Child Welfare Act of 1978 , in attempt to prohibit the adoption of Native American children by any non-Native American. Essentially, this Act gave child-placement jurisdiction to the specific tribe to which the child belongs (Hollingsworth, 1998). As a 
result, this legal empowerment prompted further ideological resistance to TRA by the NABSW. This resistance had significant implications for adoption agencies specifically involved with placing black children with white families. Namely, many agencies established policies encouraging placing children with adoptive families of their own race (Hollingsworth, 1998).

Along with the organization-based opposition to TRA such as the NABSW and Native American communities, rhetorical opposition arose from individuals also. For instance, an investigator interested in the long-term outcomes for black children placed in white homes stated, "Until empirical studies are made of the adult personalities of whiteraised blacks, placements of black children should not proceed as if it had already been ascertained that transracial adoption is beneficial." (Chimezie, 1975 pg. 299). In this way, investigators opposing TRA practices maintained that the potentially negative effects on transracial adoptees could be avoided by placing children with families of similar race. In view of this opposition, there is documented evidence of an immediate decrease in adoptive placements across racial categorizations, as the number of such placements in 1971 was reduced by half in 1989 (McRoy, 1989).

In response to the negative claims made by the critics of TRA, many white adoptive and foster families, and researchers took offense. Specifically, potential white adoptive parents and other advocates of TRA disagreed with the assertion that whites were incapable of parenting black children. Accordingly, in response to such claims, numerous empirical investigations have been conducted to refute these ideological claims raised by the opposition. Consequently, much of the empirical research conducted on TRA, to date, examines the outcomes of various issues of psychological adjustment of 
children raised by white parents. Within this context, a large number of studies investigate satisfaction with familial relationships (Feigelman, \& Silverman, 1984; Simon \& Alstein, 1991), measures of self-esteem and racial identity (McRoy et. al., 1982; Simon \& Alstein, 1996; Vroegh, 1997), academic performance (Simon and Alstein, 1991; McRoy et. al., 1982; Brooks \& Barth, 1999), and problem behaviors (Feigelman \& Silverman, 1984; Brooks \& Barth, 1999) of transracially adopted children.

\section{$\underline{\text { Transracial Adoption Research }}$}

Although TRA can occur in several forms, the existing literature largely concentrates on black children in the United States adopted by white families. Despite a greater number of Latino and Asian children that are transracially adopted each year, white parents domestically adopting black children has elicited the greatest attention from researchers (Smith, 1996). Correspondingly, rhetorical criticism against the transracial placements of black children prompted many empirical studies that examined effects of black children growing up in non-black families. Within this context, during the late 1970's and 1980's, various studies attempted to dispel the belief that white families cannot effectively raise emotionally and socially healthy black children (Curtis, 1996). Accordingly, nearly three decades of empirical studies have sought to address issues that reflect the normative psychological adjustment of transracial adoptees.

\section{Historical Investigations of TRA}

Among the first researchers to examine various aspects of TRA were Shapiro (1974), Alstein \& Simon (1977), McRoy et al. (1982) and Feigelman and Silverman (1983). In these studies, common methods of data collection were personal interviews, as well as standardized forms of personality, cultural identity, and self-esteem tests. Many 
of these initial investigations examined adoptee adjustment with regard to the familial integration of transracially adopted children, compared to children of same-race adoptions. (Griffith, 1995) The researchers conducting these initial studies essentially agreed that with respect to overall adjustment and development, approximately $77 \%$ of transracial adoptees experience successful adjustments. (Curtis, 1996) This finding is congruent with the findings for the adjustment experiences of children adopted by families of the same race.

Specifically regarding racial identification - a major concern for TRA critics - a significant finding of Simon and Alstien's (1977) research was that transracial adoptees were aware and comfortable with their racial identity during childhood, adolescence and in adulthood. They claimed that transracial adoptees grew up to have an affirmative sense of their identity and a healthy understanding of their culture. Simon and Alstein concluded, "Our studies show that transracial adoption causes no special problems among the adoptees or their siblings. We have observed black children reared in white families and have seen them grow up with a positive sense of their black identity and a knowledge of their history and culture" (Simon \& Alstein 1977, pg. 21). However, not all investigations of racial identity confirmed these results. Some investigators found less positive racial identities in black children placed in white homes, compared to black children adopted by black parents (McRoy, et. al., 1982). Consequently, the empirical data on the racial identity of transracial adoptees remains inconclusive. However, to qualify this area of investigation, Hayes (1993) asserts that there are other developmental factors that should be considered important factors to evaluate. Consequently, these 
initial empirical studies regarding TRA supported greater use of TRA as a placement option. (Brooks and Barth, 1999).

\section{Contemporary Investigations of TRA}

Based upon findings reported from earlier studies, contemporary TRA studies have for the most part, conceptually strengthened the argument for adaptive transracial adoptee development. Accordingly, in a comprehensive studies of adoptee adjustment, Simon and Alstein (1996) reported that through multi-phased investigations, transracially adopted Black, Asian, and Native American children were found to adaptively develop a positive self-esteem as well as positive familial relationships. Similarly, Feigelman (2000) concluded that psychological adjustment for transracial adoptees is not significantly different than that experienced by same race adoptees.

\section{Contemporary Proponents of TRA}

Interestingly, some empirical investigations have suggested that for certain developmental factors, placing children transracially, may facilitate better adjustment than placing them with racially similar parents. For instance, some researchers have indicated that black children who are placed transracially have higher IQ's than their same-race adopted counterparts (Moore, 1987; Scarr \& Weinberg, 1983). Likewise, Hayes (1993) suggests that for some children, educational achievement is better facilitated by transracial placements.

Along these lines of adoptee adjustment, several longitudinal studies have reported that the long-term adjustment of transracial adoptees is favorable. Vroegh's (1997) 17-year long study of black children raised by white parents showed no significant differences between transracially adopted children and same-race adopted children along 
measures of general adjustment, racial identity, and self-esteem. Also, Simon \& Alstein (1977) conducted longitudinal analyses of transracial adoptees. Their sample, consisting of black and other minority children, were assigned interviews about their experiences. From their results taken over an 11-year period, the researchers concluded that transracially adopted children maintain an adaptive sense of self-esteem and attachment to their adoptive parents. Studies such as these consistently indicate that transracially adopted children experience adaptive developmental outcomes across the measured life span.

In addition, comparative measures of developmental outcomes of transracially adopted children versus intraracially adopted children, demonstrate significant similarities. Moreover, results from a study involving transracially adopted black adolescents and black adolescents who had been adopted by black parents indicated that both groups exhibited comparable physical health, familial relationship, and self-regard outcomes (McRoy \& Zurcher, 1983). Furthermore, to summarize the empirical data specifically comparing these two groups, Curtis (1997) suggests that without exception, no significant differences between transracial adoptees to same-race adoptees have been shown.

Overwhelmingly, the majority of published studies on transracial adoption suggest that racial differences between parents and children alone, is not harmful to the adaptive development of children (Silverman, 1993). Stated differently, the vast majority of the findings continue to suggest that black children adopted by white parents are equally as likely to experience successful adjustments to adoption as their intraracially adopted counterparts. Also, research focused on international adoptions suggests similar 
findings. For instance, in a review of the existing literature on international adoption, Tizard (1991) concluded that $75-80 \%$ of these placements are successful across various domains of measurement. In this way, internationally adopted children demonstrate adaptive behaviors, academic performances, and familial relationships (Tizard, 1991). Thus, most researchers have concluded that TRA (domestic and international) is a viable means of placing children in permanent homes.

\section{Contemporary Opposition to TRA}

Despite that, to date, there has been little empirical evidence amassed in support of damaging consequences of TRA, resistance to this practice remains alive. Namely, this resistance is rhetorical, and has primarily focused on the existing data's failure to adequately illustrate the genuine experiences of children placed across racial categorizations (Rushton \& Minnis, 1997; Park \& Green, 2000). Moreover, several scholars have claimed the standing body of literature is wrought with significant methodological limitations that distort the actual implications of transracial placements. In their review of the TRA literature, Park and Green claim, "Indeed, the methodological flaws in these studies are plentiful and suggest the need for a healthy skepticism concerning researchers' conclusions." (Park \& Green, 2000, pg. 13).

\section{Limitations of existing TRA Research}

Among the critiques on TRA research methodologies, samples used for outcome assessments and poor comparison groups are prominent (Park \& Green, 2000; Hollingsworth, 1997, Rushton \& Minnis, 1997). As much of the early research on TRA examined short-term outcomes for the children and families involved, many of these studies were conducted when the children were pre-adolescent. Therefore, a significant 
number of TRA studies say very little about how the children will adapt, as they grow older (Courtney, 1997). Critics of pre-adolescent samples have countered that the racism of a white society against the transracial adoptee is not likely to become salient until these children reach adolescence (Courtney, 1997). Within this context, there are relatively few TRA studies that specifically examine exclusively the period of development of adolescence.

In addition, with regard to critiques of poor comparison groups, several scholars have maintained that the failure to compare certain samples of adoptees to appropriate comparison groups (Hollingsworth, 1997; Rushton \& Minnis, 1997) has handicapped proponents' arguments. Effectively, many of the predominant studies used to advocate TRA compared transracial adoptees only to white adoptees, and white biological children. Consequently, same-race adopted minority children are not adequately cited as utilized comparison groups within much of the existing literature. Correspondingly, critics of TRA maintain that while comparing minority adoptees to white adoptees works to provide information concerning the adoption experience, it inherently limits the ability to compare the development of transracially adopted minorities to minorities adopted by parents of the same race (Hollingsworth, 1997). As a result, such methodological critiques throw into question many of the existing studies of TRA. Thus, controversy over the effectiveness of TRA thrives in contemporary society.

\section{$\underline{\text { Adolescence }}$}

In developmental study, adolescence is considered a transitional time involving psychological distress and confusion for individuals. Moreover, this period between childhood and adulthood often manifests complex psychological and social changes, 
which can have significant implications for developmental outcomes. Furthermore, extensive research has focused on the matriculation through different periods of adolescence. Often chronological age is often correlated with certain developmental phenomena. For instance, entry into adolescence is frequently marked by puberty (Graber \& Brooks-Gunn, 1996). In this way, transitional models of development have been utilized to qualify change in terms of unique experiences and events that individuals face. Within this context, some researchers contend that for some individuals, existing psychological conditions can be accentuated during periods of transition (Caspi \& Moffitt, 1991). In this way, the psychological dispositions manifested by individuals can be exacerbated the challenges they face as they matriculate through development.

Correspondingly, a significant amount of empirical research has been conducted to delineate various developmental patterns that occur during adolescence. A common theme within this extensive literature suggests that a primary function of adolescence is to facilitate the creation and enhancement of individuals' sense of identity. Similarly, establishing autonomy is another significant objective within adolescent development. In this way, factors such as familial relationships, self-esteem, academic competence, and psychosocial behaviors can be significantly influenced by various developmental experiences of adolescent individuals (Corbett \& Pertersilia, 1994; Berdnt \& Keefe, 1992; Fergusson \& Lynskey, 1996).

\section{$\underline{\text { Adolescence and Adoption }}$}

As adolescence is a developmental period of change for essentially all individuals, there is evidence that adoption adds complexity to this sensitive stage of life. Some researchers assert that significant developmental changes associated with adolescent 
development, such as changing relationships with parents and establishing autonomy, adoptive status is potentially a risk factor for maladjusted development in these areas for children during adolescence (Brodzinsky, Smith, \& Brodzinsky, 1998; Horner \& Rosenberg, 1991). Congruently, in regards to familial relationships, Smith and Brodzinsky (1994) have suggested that during adolescence, as children's adoptive status become more salient, they create fantasized relationships with their biological parents. As a result, adaptive adjustment toward the adoptive parents and other family members may be compromised. Sobol, Delaney, and Earn (1994) support this claim. Essentially, through investigating perceptions of familial closeness, these researchers contend that adolescent adoptees reported the least amount of closeness with their parents than at any other time of development

\section{Adolescent adoptee research}

While literature on adolescence is extensive, for adopted individuals it remains an understudied developmental component. Of the existing investigations concerning adolescent adoptee adjustment, findings are relatively inconclusive (Morgan, 1998). While some researchers contend that adopted adolescents experience favorable outcomes, others report exacerbated amounts of maladjustment compared to non-adopted adolescents. Correspondingly, one line of research within the developmental literature holds that as adopted children progress through adolescence, they experience healthy adjustment. Essentially, some researchers have suggested that the typical adolescent development of adopted children is comparable to non-adopted children, insofar that the normative developmental processes associated with adolescence are not exacerbated by an adoptive status. Moreover, longitudinal investigations tracking adoptees' 
development throughout adolescence suggest that the well being of adoptees is similar to that of non-adopted children (Bohman \& Sigvardsson, 1978, 1979).

Pertaining to specific areas of development, there is some evidence that adoptees experience outcomes more favorable than expected (Bohman \& Sigvardsoson, 1979, 1980; Tizard \& Hodges, 1978). For instance, a large study of adolescents conducted by the Search Institute (1993) compared adopted adolescents to non-adopted adolescents on various outcome variables. Results from this study show that adoptees' self esteem and overall health were comparable and sometimes significantly higher than their nonadopted peers. Furthermore, with respect to parent-child interactions, perceptions of familial closeness were reported as being healthy and consistent with reports of nonadopted adolescents. Correspondingly, Sobol, Delaney, and Earn (1994), found that adoptive children reported feeling significantly closer to their fathers than did nonadopted children. Offered as a possible interpretation of these results, the researchers argued that these findings might suggest that adoptive fathers are more actively engaged in their children's lives, than are biological fathers.

In contrast to research suggesting adaptive adolescent development for adoptees, there are data that essentially suggest a more troubled progression through this period. In this way, some researchers have suggested that adoptees become increasingly maladjusted as they matriculate through adolescence (Verhulst \& Versluis-den Bieman, 1995). To conceptually characterize the unique experience that adoption perhaps affords individuals, Verhulst (2000) states, "It is possible that with increasing age, adolescent adoptees become more and more prone to develop problem behaviors as a result of their increasing concerns over their biological parentage." (Verhulst, 2000, pg. 41). This is to 
say that acknowledging one's adoptive status, coupled with decreasing amounts of familial interaction and supervision - associated with an individual's matriculation through adolescence - could be an impetus for maladjustment. In support of this perspective, investigations of particular areas of adolescent development have evidenced maladjusted development. For example, Sharma, McGue, and Benson (1998) found that adoptees demonstrate higher substance abuse, more school adjustment problems, and more delinquent behavior than their non-adopted siblings.

Hence, within the research literature on adoptee adolescent development, a clear trend towards adaptive or maladaptive development does not yet exist. Furthermore, interpretations of negative or positive findings need to be qualified, before conclusions can be drawn. Moreover, some investigators have attempted to identify specific factors that delineate particular outcomes. For instance, reports of maladjustment in comparisons between adopted and non-adopted children fail to demonstrate significant differences in middle to late adolescence (Brodzinsky, Smith, \& Brodzinsky, 1998). Essentially, particular age groups within adolescence seem to be more sensitive to maladjustment than others. Therefore, consideration of specific age might elicit more insight regarding the adoptees' adjustment.

Correspondingly, consideration of demographic information may allow for more conclusive interpretations. For instance, Verhulst (2000) stipulated that the favorable findings of adolescent adoptee adjustment in the existing literature are perhaps due to the utilization of mostly white, domestically adopted children as sample groups.

Furthermore, Verhulst and Versluis-den Bieman (1995) contend that racial differences between children and their adoptive parents perhaps negatively influence adolescents' 
adjustment. Accordingly, international or domestic transracial placements may exacerbate stress experienced in adolescence for some individuals (Verhulst \& Versluisden Bieman, 1995). In support of this, an empirical study of international adolescent adoptees found them to have significantly worse psychological adjustment compared to their non-adopted siblings (Cohen \& Westhues, 1995). In view of these findings, consideration of various factors that may be critical to individuals' development, such race and are important to delineate underlying issues influencing adopted adolescents. 


\section{Chapter III Methods}

The present study was based upon a secondary analysis of the Wave I in-home interview of the National Longitudinal Study of Adolescent Health (Add Health).

\section{Description of database}

Add Health is a school-based study of the health-related behaviors of adolescents in grades 7-12. The National Institute of Child Health and Human Development (NICHD) and 17 other federal agencies funded this national study. There were two components of this study that were administered to adolescents: an In-school questionnaire, and an In-home interview. The In-school Questionnaire was a selfadministered instrument administered to students in grades 7 to 12 from September 1994 through April 1995. The questionnaire included topics such as the social and demographic characteristics of respondents, the education and occupation of parents, household structure, risk behaviors, expectations for the future, self-esteem, health status, friendships, and school-year extracurricular activities.

In-home interviews were conducted between April and December 1995. All participants were given the same interview, which took from one to two hours to complete depending on the respondent's experiences and age. To facilitate confidentiality, all data were recorded on computers provided by interviewers. Within the In-home interview, there were two methods of data collection. First, for less sensitive sections, the interviewer read the questions and entered the respondent's answers into the computer. For more sensitive sections, the respondent listened to pre-recorded questions through earphones and entered the answers into the computer themselves. 
Some of the topics covered by the In-home Interview were: health status, health facility utilization, nutrition, peer networks, decision-making processes, family composition and dynamics, educational aspirations and expectations, employment experience, the ordering of events in the formation of romantic partnerships, sexual partnerships, substance use, and criminal activities. Accordingly, as the In-home interview comprehensively addressed issues relevant to the current investigation, only this portion of the Add Health study was analyzed in the current study.

\section{$\underline{\text { Participants }}$}

The total number of subjects of the in-home questionnaire was 20,745 aged from 12 to 19 . Detailed analyses were conducted to determine how many of these subjects were adopted adolescents (Miller, et. al., 2001). According to their analyses, of the 20,745 adolescents representing the In-home sample, 609 were adopted. Furthermore, a sample group of 11,940 was constructed from the remaining (non-adopted adolescents) as a viable comparison group for the adopted adolescents. This comparison group of nonadopted adolescents was established by controlling for possible confounding factors, such as family form and socio-economic status. Therefore, all analyses regarding adoption status compared the 609 adopted adolescents to the 11,940 selected non-adopted adolescents. However, the valid sample size varies on different questions due to missing values (e.g., legitimate skips and refused questions).

\section{Independent Variables}

The independent variables for this study are the subjects' adoptive status (adopted or non-adopted), adoption type (transracial versus same-race), adolescent age (12-13, 1416 , or 17-19), and gender (male or female). 
Adoption status. Within the responses to the In-home interview, conflicts about true adoptive status arose between adolescents' reports and parental reports. As a result, several researchers combined numerous questions about parents, familial relationship, and household information to systematically identify the present group of adoptees $(n=$ 609) (Miller, et. al., 2001). Therefore, to measure adoptive status, the group of adoptees identified by Miller et. al. (2001) were used.

Adoption type. To measure the type of adoption, racial identification of adolescents were compared to racial identification of adoptive parents. Therefore, adolescent and parental race matches were considered same-race adoptions. Correspondingly, adolescent and parental race discrepancies were considered transracial adoptions. Additionally, each type of transracial and same-race adoptions were analysed independently. For instance, responses from black adolescents adopted by white parents, were compared to transracial adoptees of different races, as well as to same-race adopted adolescents. The racial categories regarded in the present study are Black, Native-American, Asian, White, and Other (i.e., a racial classification not represented by possible answer choices).

Age group. To measure adolescent age group, the reported age of adolescents was broken into three groups (young, middle, and old). The young age group comprised all adolescents aged either 12 or 13 years old. The middle age group comprised all adolescents aged 14 through 16 years old. The old age group comprised all adolescents between the ages of 17 and 19 years old. Preliminary analyses indicated that for the largest analyses the young age group consisted of approximately 1,090 adolescents, the middle age group consisted of approximately 5,700 adolescents, and the old age group consisted of approximately 4,255 adolescents. 
Gender. All adolescents were divided into either male or female categories based upon the single question "what is your gender?". Preliminary analyses suggested that there were approximately 5,800 females and approximately 5,200 males.

\section{Dependent Variables}

The present study investigated the implications of the independent variables described above, upon measures of academic outcomes, perceptions of familial relationships, psychological adjustment, and physical health. Scales were used to create categories within each of the dependent domains. All scales used in this study, with the exception of academic expectations category and both physical health categories were derived from the Grotevant et al. (2001) study that utilized the same data set. The categories of interest and representative questions from each category are illustrated below.

\section{$\underline{\text { Academics }}$}

To assess academic outcomes, two categories were combined. These two categories were: academic performance and academic attitudes. Academic performance measured adolescents' actual grades received in four major areas of academic study. Academic attitudes measured adolescents' perceptions of connectedness to their school, teachers, and schoolwork, as well as their expectations for future academic achievements. Also measured within academic attitudes were any academic troubles adolescents had experienced at school.

School Grades. The variables selected to measure school grades were the actual grades received in English or Language Arts, Mathematics, History or Social Studies, and Science. Accordingly, all participants were compared by their overall academic school 
grades score, which was the average of their grades across all four subjects. The Cronbach's alpa for this scale was .76.

School Connectedness. To measure the degree to which adolescents felt connected to their school, teachers, and schoolwork, six questions were compiled. All questions were measured using a five-point scale. The Cronbach's alpha value computed was .73 . The questions which make up this scale were "You feel close to people at your school", "You feel like you are part of your school", "You are happy to be at your school", "The teachers at your school treat students fairly", "You feel safe in your school", and "How much do you feel your teachers care about you".

Learning Problems. To measure the learning problems adolescents reported concerning academic involvement, four questions were combined to create a scale. The Cronbach's alpha testing this scale's reliability upon the current sample was .67. The four questions used to comprise the scale asked participants how often they had trouble doing the following: "getting along with teachers", "paying attention in school", "getting your homework done", and "getting along with other students".

Academic Expectations. To measure the adolescents' future academic expectations, two questions were combined to create a scale. The Cronbach's alpha testing this scale's reliability upon the current sample was .82 . The two questions asked were "how much do you want to go to college", and "how likely is it that you will go to college".

\section{Familial Relationships}

To measure familial relationships of the sample groups, indicators of mothercloseness, father-closeness, and overall family closeness, were investigated. Each indicator manifests a scale comprised of multiple questions. 
Mother-closeness. The scale constructed to measure perceptions of mother closeness had a Cronbach's alpha value of .86 . The five questions used to investigate adolescents' perceptions of mother closeness were the following. "How close do you feel to your mother", "How much do you think she cares about you", "Most of the time, your mother is warm and loving toward you", "You are satisfied with the way your mother and you communicate with each other", "Overall, you are satisfied with your relationship with your mother".

Father closeness. To assess perceptions of father closeness, the same questions asked about adolescents' mothers were asked about their father. Accordingly, the five questions used to create the father closeness scale were "How close do you feel to your father", "How much do you think he cares about you", "Most of the time, your father is warm and loving toward you", "You are satisfied with the way your father and you communicate with each other", and "Overall, you are satisfied with your relationship with your father". The father closeness scale had a Cronbach's alpha value of .79 .

Family closeness. As a measure of family closeness, five questions were combined to create a scale, with a Cronbach's alpha value of .75. Each of the five questions comprising this scale asked how strongly the adolescents felt about familial relationships. Specifically, the questions were, "How much do you feel that your parents care about you", "How much do you feel that people in your family understand you", "How much do you feel that you want to leave home", "How much do you feel that you and your family have fun together", "How much do you feel that your family pays attention to you". 


\section{$\underline{\text { Psychological Adjustment }}$}

To investigate different aspects of psychological development, three categories were combined to create measure psychological adjustment. For indicators of externalized-psychological adjustment, counts of delinquent behaviors were used. Correspondingly, as indicators of internalized-psychological adjustment, measures of depression and self-worth were used.

Delinquency. Delinquent behavior was measured using questions from the Delinquency Section of the Add Health In-home interview. As obtained in the interview, frequencies of delinquent behaviors were recorded as being "never", "a few times", or "often". However, for the purpose of creating a delinquency scale for the current study, participants were categorized into two groups (i.e., as having either participating in a delinquent behavior or not having participated in a delinquent behavior), per question asked. Accordingly, scores for such items were recoded as either a " 1 " for having participated in the delinquent activity "a few times", or "often", or a "0" for having participated in the delinquent activity "never". In this way, counts of " 1 ' $\mathrm{s}$ " and " 0 's" were totaled for each participant to establish their overall delinquency score. Examples of questions comprising this scale, addressed whether or not adolescents had recently: “painted graffiti or signs on someone else's property or in a public place", "deliberately damaged property", "stolen something worth less than $\$ 50$ ", "stolen something worth more than $\$ 50 "$ " "gotten into a serious fight", or "pulled a knife or gun on someone else". Depression. Assessments of depression involved the compilation of 19 questions, which sought how often the adolescents had felt certain ways. Together, these questions manifest a Cronbach's alpha value of .78. Examples of the questions comprising this 
section were, "You felt depressed", "You felt lonely", "You were bothered by things that usually don't bother you", and "You felt like life was not worth living".

Self-worth. Assessments of self-worth involved the compilation of four questions.

These questions were shown to have a Cronbach's alpha value of .79. Specifically, the questions were "You have a lot of good qualities", "You have a lot to be proud of", "You like yourself just the way you are", and "You feel like you are doing everything just about right".

\section{$\underline{\text { Physical Health }}$}

To investigate aspects of physical well-being, two categories were established. For an indicator of global physical health, an overall health scale was developed. Also, a psychosomatic scale was developed to measure counts of specific physical ailments. Overall health. Overall health was measured using the general health question administered on the Add Health interview. This question asked, "In general, how is your health? Would you say...", at which point participants are asked to choose between a range of five numbers with "1" being "excellent" and "5" being "poor".

Psychosomatic conditions. To measure psychosomatic conditions, total counts were calculated for the number of psychosomatic conditions participants indicated they had experienced in the past 12 months. There were a total of 14 possible conditions from which to choose. Examples of the possible psychosomatic conditions for selection were, "How often have you had a headache", "How often have you had chest pains", "How often have you felt tired, for no reason", and "How often have you had cold sweats". The Chronbach's alpha for this scale was .79. 


\section{$\underline{\text { Statistical Analyses }}$}

To address the hypotheses of this study three independent levels of analyses were conducted. In Analysis One, adoption status (adoptees versus non-adoptees), adolescent age, and gender were investigated. Then, in Analysis Two, only adoptees were regarded, as adoption type (transracial adoption versus same-race adoption), adolescent age, and gender were investigated. Last, Analysis Three involved three separate exploratory investigations of adoptees based upon specific parent-child racial groupings, adolescent age, and gender.

To analyze the data, several MANOVA's were conducted to investigate the relationship between independent variables, based upon the particular dependent variables listed above. For each dependent variable, mean scores were computed. In Analysis One and Analysis Two, 2 X 3 X 2 multivariate analyses of variances (MANOVAs) were utilized. Accordingly, a prototype of the design used in Analysis One is as follows:

Non-Adopted

\begin{tabular}{|c|c|c|c|c|c|}
\multicolumn{1}{c}{$12-13$} & \multicolumn{1}{c}{$14-16$} & \multicolumn{1}{c}{$17-19$} & \multicolumn{1}{c}{$12-13$} & $14-16$ & $17-19$ \\
\hline male & male & male & male & male & male \\
\hline female & female & female & female & female & female \\
\hline
\end{tabular}

Due to small sample sizes in some cells of the MANOVA, no three-way interactions were investigated, to assure adequate sample sizes of each analysis conducted. Accordingly, each MANOVA investigated three main effects and three twoway interaction effects. For significant MANOVA effects, the univariate ANOVAs were 
analysed. For significant univariate effects, Bonferroni tests were conducted on appropriate means for pairwise comparisons.

In addition, the statistical computation of Analysis Three data involved exploratory analyses for specific racial groupings, adolescent age, and gender within an adopted sample. That is, within the sample of specific racial groupings, "white parents white children", were compared to the sample of "black parents - black children", "white-parents - black children", and "white parents - Asian children", across developmental measures. Similarly, within this sample of adoptees, the three adolescent ages (i.e., 12-13, 14-16, and 17-19 year olds), as well as gender were investigated. Each of the investigations in Analysis Three were analyzed using one-way analyses of variances (ANOVAs). All tests conducted throughout the study were considered significant at $\mathrm{p}<.05$. 


\section{Chapter IV Results}

The results are reported in three sections. In the first section, multivariate analyses of variance (MANOVAs) are utilized to compare adoptees to biological children by different age groups and gender. In the second section, MANOVAs are utilized to compare transracially adopted children to same-race adopted children by different age groups and gender. For both analyses noted above, 3-way interactions were not investigated due to small sample sizes in some cells of the MANOVAs. Main effects and two-way interactions were investigated for each measure. The third section contains exploratory analyses of specific racial groupings, adolescent age, and gender of adopted children (e.g., white children with white parents, black children with black parents, black children with white parents, and Asian children with white parents). One-way ANOVAs were conducted to compare the various racial groupings, across the different dependent measures. An alpha level of .05 was used for all statistical tests.

Analysis One: Adoption Status X Adolescent Age X Gender

Adoption Status (adopted versus non-adopted) X Age (young, middle, or old adolescence) X Gender (male or female) multivariate analyses of variance were performed on four categories of adolescent adjustment: academic outcomes, familial relationships, psychological adjustment, and physical health. For significant MANOVA effects, univariate ANOVA effects tests were examined, and estimated marginal means and standard errors are given. For significant ANOVAs, Bonferroni post-hoc pairwise comparisons of means were conducted at $\mathrm{p}<.05$. 
A MANOVA was used to examine the effects of adoption status, adolescent age, and gender on the academic variables (i.e., school grades, learning problems, school connectedness, and academic expectations). Table 1 summarizes the results for this MANOVA. Table 2 contains the means and standard deviations on the dependent variables by adoption status, adolescent age, and gender.

Adoption Status. The Pillai-Bartlett multivariate test statistic indicated a significant main effect for adoption, $\underline{\mathrm{V}}=.001, \underline{\mathrm{F}}(4,8941)=2.96, \underline{\mathrm{p}}<.05$. Univariate analyses of variances (ANOVAs) for each dependent variable (see Table 3) were examined for main effects of adoption status. The ANOVAs on school grade scores and learning problems scores were significant, $\underline{\mathrm{F}}(1,8944)=4.59, \underline{\mathrm{p}}<.05$, and $\underline{\mathrm{F}}(1,8944)=7.05, \underline{\mathrm{p}}<.01$, respectively. Biological adolescents had significantly better school grades than adopted adolescents $(\underline{\mathrm{M}}=2.12, \underline{\mathrm{SE}}=.01$ for non-adopted adolescents, and $\underline{\mathrm{M}}=2.22, \underline{\mathrm{SE}}=.05$ for adopted adolescents), as well as fewer academic learning problems $(\underline{\mathrm{M}}=1.02, \underline{\mathrm{SE}}=.01$ for non-adoptees, and $\underline{\mathrm{M}}=1.14, \underline{\mathrm{SE}}=.04$, for adoptees). However, adoptees did not differ significantly from non-adoptees on measures of school connectedness and academic expectations.

Adolescent Age. The Pillai-Bartlett multivariate test statistic indicated a significant main effect for adolescent age, $\underline{\mathrm{V}}=.003, \underline{\mathrm{F}}(8,17884)=3.50, \underline{\mathrm{p}}<.01$. The univariate ANOVAs (Table 4) on the school grade scores and school connectedness were statistically significant, $\underline{\mathrm{F}}(2,8944)=6.34, \underline{\mathrm{p}}<.01$, and $\underline{\mathrm{F}}(2,8944)=5.49, \underline{\mathrm{p}}<.01$, respectively. With respect to school grades, adolescents from the young age group performed significantly better than adolescents in the middle and old age groups $(\underline{\mathrm{M}}=$ 
$2.04, \underline{\mathrm{SE}}=.06$, for young age, $\underline{\mathrm{M}}=2.26, \underline{\mathrm{SE}}=.03$, for middle age, and $\underline{\mathrm{M}}=2.20, \underline{\mathrm{SE}}=$ .03 , for old age). Also, the younger adolescents were associated with more positive school connectedness as all three age groups differed from each other $(\underline{M}=2.16, \underline{S E}=$ .05 , for young age, $\underline{\mathrm{M}}=2.29, \underline{\mathrm{SE}}=.03$, for middle age, and $\underline{\mathrm{M}}=2.36, \underline{\mathrm{SE}}=.03$, for old age). However, adolescent age was not associated with significant differences for learning problems and academic expectations.

Gender. The Pillai-Bartlett multivariate test statistic indicated a significant gender effect, $\underline{\mathrm{V}}=.005, \underline{\mathrm{F}}(4,8941)=11.90, \underline{\mathrm{p}}<.01$. Table 5 illustrates that three univariate ANOVAs (i.e., school grade scores, learning problems scores, and academic expectations) were significant, $\underline{\mathrm{F}}(1,8944)=25.56, \underline{\mathrm{p}}<.01, \underline{\mathrm{F}}(1,8944)=25.68, \underline{\mathrm{p}}<.01$, and $\underline{\mathrm{F}}(1,8944)=$ $7.26, \underline{p}<.01$, respectively. Accordingly, females $(\underline{\mathrm{M}}=2.05, \underline{\mathrm{SE}}=.03)$ performed significantly better on school grades than males $(\underline{\mathrm{M}}=2.29, \underline{\mathrm{SE}}=.04)$. Females $(\underline{\mathrm{M}}=.96$, $\underline{\mathrm{SE}}=.03)$ had significantly fewer learning problems than males $(\underline{\mathrm{M}}=1.19, \underline{\mathrm{SE}}=.04)$, and females $(\underline{M}=4.50, \underline{\mathrm{SE}}=.04)$ had significantly higher academic expectations than males $(\underline{M}=4.34, \underline{S E}=.05)$. However, a gender effect was not found for school connectedness. Interactions. Adolescent Age X Gender. The Pillai-Bartlett multivariate test statistic indicated a significant adolescent age $\mathrm{X}$ gender interaction effect, $\underline{\mathrm{V}}=.002, \underline{\mathrm{F}}(8,17884)$ $=1.94, \underline{p}<.05$. Table 6 contains the means and the standard deviations on the dependent variables for each group. The univariate ANOVA interaction effects (reported in Table 7), on learning problems, $\underline{\mathrm{F}}(2,8944)=4.77, \underline{\mathrm{p}}<.01$ and school connectedness, $\mathrm{F}(2$, $8944)=3.03, \underline{p}<.05$ were significant. Females in young adolescence $(\underline{M}=.83, S E=$ .06) had significantly fewer learning problems than females in middle adolescence $(\underline{\mathrm{M}}=$ $1.08, \mathrm{SE}=.04)$, whereas males were not significantly different across the three age 
levels. Also, females in young adolescence $(\underline{\mathrm{M}}=2.07, \mathrm{SE}=.06)$ had significantly better school connectedness than females in both middle adolescence $(\underline{\mathrm{M}}=2.32, \mathrm{SE}=.04)$ and in old adolescence $(\underline{\mathrm{M}}=2.42, \mathrm{SE}=.04)$. Males did not significantly differ on school connectedness across the three age levels. There were no significant interactions found between age and gender on school grades or on academic expectations. Also, no other Pillai-Bartlett multivariate tests for interactions were found to be significant.

\section{Familial Relationship Measures}

A MANOVA was used to examine group differences by adoption status, adolescent age, and gender in the three familial relationship variables (i.e., mothercloseness, father-closeness, and family closeness). Table 8 summarizes the results for this MANOVA. Table 9 contains the means and the standard deviations on the dependent variables by adoption status, adolescent age, and gender.

Adoption Status. The Pillai-Bartlett multivariate test statistic indicated a significant main effect for adoption status, $\underline{\mathrm{V}}=.002, \underline{\mathrm{F}}(3,7801)=5.44, \underline{\mathrm{p}}<.01$. The univariate ANOVA on mother-closeness (reported in Table 10) was significant, $\underline{\mathrm{F}}(1,7803)=5.08, \underline{\mathrm{p}}<.05$, with biological adolescents $(\underline{M}=4.50, \underline{S E}=.01)$ perceiving significantly closer relationships with their mothers than adopted adolescents $(\underline{\mathrm{M}}=4.40, \underline{\mathrm{SE}}=.05)$. Adoption status main effects were not significant for father closeness and family closeness.

Adolescent Age. The Pillai-Bartlett multivariate test statistic indicated a significant main effect for adolescent age, $\underline{\mathrm{V}}=.009, \underline{\mathrm{F}}(6,15604)=11.56, \underline{\mathrm{p}}<.01$. The univariate ANOVA main effects (reported in Table 11) were significant for: mother closeness, $\underline{\mathrm{F}}(2$, $7803)=12.79, \underline{p}<.01 ;$ father closeness, $\underline{F}(2,7803)=15.25, \underline{p}<.01 ;$ and family 
closeness, $\underline{\mathrm{F}}(2,7803)=34.37, \underline{\mathrm{p}}<.01$. For all three measures of familial relationship, all age levels significantly differed. For adolescents in the young age group, perceptions of mother-closeness $(\underline{\mathrm{M}}=4.59, \underline{\mathrm{SE}}=.06)$, father-closeness $(\underline{\mathrm{M}}=4.57, \underline{\mathrm{SE}}=.08)$, and family closeness $(\underline{\mathrm{M}}=4.34, \underline{\mathrm{SE}}=.07)$ were significantly higher than scores for middle age adolescents $(\underline{\mathrm{M}}=4.43, \underline{\mathrm{SE}}=.02$, for mother-closeness, $\underline{\mathrm{M}}=4.36, \underline{\mathrm{SE}}=.03$, for fathercloseness, and $\underline{\mathrm{M}}=4.05, \underline{\mathrm{SE}}=.02$, for family closeness). Furthermore, adolescents in the old age group had the significantly most distant perceptions of familial relationships $(\underline{\mathrm{M}}=$ $4.31, \underline{\mathrm{SE}} .02$, for mother-closeness, $\underline{\mathrm{M}}=4.19, \underline{\mathrm{SE}}=.03$, for father-closeness, and $\underline{\mathrm{M}}=$ $3.84, \underline{\mathrm{SE}}=.03$ for family closeness).

Gender. The Pillai-Bartlett multivariate test statistic indicated a significant main effect for gender, $\underline{\mathrm{V}}=.001, \underline{\mathrm{F}}(3,7801)=2.80, \mathrm{p}<.05$. Table 12 shows that the main effect of gender for mother-closeness was significant, $\underline{\mathrm{F}}(1,7803)=7.47, \underline{\mathrm{p}}<.01$, indicating that males, $(\underline{\mathrm{M}}=4.51, \underline{\mathrm{SE}}=.04)$ perceive more closeness to their mothers than do females, $(\underline{M}=4.38, \underline{\mathrm{SE}} .03)$. However, gender was not associated with significant group differences in perceptions of either father-closeness or family closeness.

Interactions. No Pillai-Bartlett multivariate tests for interactions were found to be significant.

\section{Psychological Adjustment Measures}

A MANOVA was used to examine group differences by adoption type, adolescent age, and gender on the psychological adjustment variables (depression, delinquency, and self-worth). Table 13 summarizes the results for this MANOVA. Table 14 contains the means and the standard deviations of the dependent variables by adoption status, adolescent age, and gender. 
Adoption Status. The Pillai-Bartlett multivariate test statistic indicated the main effect for adoption status was nonsignificant with, $\underline{\mathrm{V}}=.001, \underline{\mathrm{F}}(3,11,243)=2.028, \mathrm{p}=.11$.

Adolescent Age. The Pillai-Bartlett multivariate test statistic indicated a significant main effect for adolescent age, $\underline{\mathrm{V}}=.004, \underline{\mathrm{F}}(6,22848)=7.55, \underline{\mathrm{p}}<.01$. Table 15 illustrates that each of the univariate ANOVAs' main effect of age was statistically significant: for depression scores, $\underline{\mathrm{F}}(2,11425)=13.36, \underline{\mathrm{p}}<.01$; for delinquency scores, $\underline{\mathrm{F}}(2,11425)=$ $7.62, \underline{p}<.01 ;$ and for self-worth scores, $\underline{\mathrm{F}}(2,11425)=7.08, \underline{\mathrm{p}}<.01$. With respect to adolescent age, young adolescents $(\underline{\mathrm{M}}=.49, \underline{\mathrm{SE}} .03)$ tended to report significantly less depression than old adolescents $(\underline{\mathrm{M}}=.64, \underline{\mathrm{SE}}=.01)$. In addition, middle adolescents $(\underline{\mathrm{M}}$ $=.58, \underline{\mathrm{SE}}=.01)$ reported significantly less depression than old adolescents. Also, levels of delinquent behavior were significantly higher for both adolescents in the middle adolescent group $(\underline{\mathrm{M}}=.21, \underline{\mathrm{SE}}=.01)$ and the old adolescent group $(\underline{\mathrm{M}}=.19, \underline{\mathrm{SE}}=.01)$ than for participants in the young adolescent group $\underline{\underline{M}}=.15, \underline{S E}=.01)$. In addition, measures of self-worth suggest that young adolescents $(\underline{\mathrm{M}}=4.22, \underline{\mathrm{SE}}=.05)$ feel significantly more positive about themselves than both the middle adolescents $\underline{\underline{M}}=4.07$, $\underline{\mathrm{SE}}=.02)$ and the old adolescents $(\underline{\mathrm{M}}=4.03, \underline{\mathrm{SE}}=.02)$.

Gender. The Pillai-Bartlett multivariate test statistic indicated a significant main effect for adolescent age with, $\underline{V}=.008, \underline{F}(3,11243)=30.95, \underline{p}<.01$. Table 16 illustrates that main effects for gender were statistically significant: depression scores, $\underline{F}(1,11425)=$ $18.47, \underline{\mathrm{p}}<.01 ;$ delinquency scores, $\underline{\mathrm{F}}(1,11425)=24.64, \underline{\mathrm{p}}<.01$; and self-worth scores, $\underline{\mathrm{F}}$ $(1,11425)=40.77, \underline{\mathrm{p}}<.01$. Females $(\underline{\mathrm{M}}=.62, \underline{\mathrm{SE}}=.01)$ reported significantly more depression than males $(\underline{\mathrm{M}}=.52, \underline{\mathrm{SE}}=.02)$. This trend was reversed for measures of delinquent behavior, as males $(\underline{\mathrm{M}}=.21, \underline{\mathrm{SE}}=.01)$ had significantly more such instances 
than females $(\underline{\mathrm{M}}=.16, \underline{\mathrm{SE}}=.01)$. Also, males $(\underline{\mathrm{M}}=4.22, \underline{\mathrm{SE}}=.03)$ manifested significantly more positive levels of self-worth than females $(\underline{\mathrm{M}}=3.99, \underline{\mathrm{SE}}=.02)$. Interactions. No Pillai-Bartlett multivariate tests for interactions were found to be significant.

\section{Physical Health Measures}

A MANOVA was used to examine the influence of adoption status, adolescent age, and gender on the physical health variables (i.e., overall health and psychosomatic conditions). Table 17 summarizes the results for this MANOVA. The Pillai-Bartlett multivariate test statistic indicated no significant main effects for adoption status or adolescent age on physical health measures, $\underline{\mathrm{V}}=.001, \underline{\mathrm{F}}(2,11624)=2.07, \underline{p}=.13$, and $\underline{\mathrm{V}}$ $=.001, \underline{\mathrm{F}}(4,23250)=1.55, \underline{\mathrm{p}}=.19$, respectively. However, the Pillai-Bartlett multivariate test statistic indicated significant gender differences, $\underline{V}=.002, \underline{F}(2,11,624)$ $=12.98, \mathfrak{p}<.01$. Table 18 contains the means and the standard deviations of the dependent variables by adoption status, adolescent age, and gender.

Table 19 illustrates significant ANOVA gender main effects for overall health scores, $\underline{\mathrm{F}}(1,11625)=11.88, \underline{\mathrm{p}}<.01$, and psycho-somatic scores, $\underline{\mathrm{F}}(1,11,625)=20.28, \underline{\mathrm{p}}$ $<.01$. Males $(\underline{\mathrm{M}}=1.97, \underline{\mathrm{SE}}=.04)$ manifested significantly better overall physical health than did females $(\underline{\mathrm{M}}=2.14, \underline{\mathrm{SE}}=.03)$. Females $(\underline{\mathrm{M}}=.843, \underline{\mathrm{SE}}=.01)$ reported significantly more psychosomatic problems than males $(\underline{\mathrm{M}}=.74, \underline{\mathrm{SE}}=.02)$. Interactions. No Pillai-Bartlett multivariate tests for interactions were found to be significant. 
Adoption Type (transracially adopted versus same-race adopted) X Age (young, middle, or old adolescence) X Gender (male or female) multivariate analyses of variance were performed on four categories of adolescent adjustment: academic outcomes, familial relationships, psychological adjustment, and physical health. For significant MANOVA effects, univariate ANOVA effects tests were examined, and estimated marginal means and standard errors are given. For significant ANOVAs, Bonferroni post-hoc pairwise comparisons of means were conducted at $\mathrm{p}<.05$.

\section{Academic Measures}

A MANOVA was used to examine the group differences by adoption type, adolescent age, and gender on the academic variables (i.e., school grades, learning problems, school connectedness, and academic expectations). Table 20 summarizes the results for this MANOVA. The Pillai-Bartlett multivariate test statistic indicated that no significant adoption type or adolescent age effects were found for any academic variables. The statistical tests were $\underline{\mathrm{V}}=.009, \underline{\mathrm{F}}(4,360)=.78, \underline{\mathrm{p}}=.53$ for adoption type, and $\underline{\mathrm{V}}=.029, \underline{\mathrm{F}}(8,722)=1.32, \underline{\mathrm{p}}=.23$, for adolescent age. Table 21 contains the means and the standard deviations on the dependent variables by adoption type, adolescent age, and gender.

Gender. The Pillai-Bartlett multivariate test statistic indicated a significant gender difference, $\underline{\mathrm{V}}=.042, \underline{\mathrm{F}}(4,360)=3.98, \underline{\mathrm{p}}<.01$. The univariate ANOVA main effects for school grades and learning problems (reported in Table 22) were significant: $\underline{\mathrm{F}}(1,363)=$ $9.32, \underline{\mathrm{p}}<.01$, and $\underline{\mathrm{F}}(1,363)=5.23, \underline{\mathrm{p}}<.05$, respectively. While females $\underline{\underline{\mathrm{M}}}=1.85, \underline{\mathrm{SE}}$ $=.10)$ have significantly higher grades than males $(\underline{\mathrm{M}}=2.31, \underline{\mathrm{SE}}=.11)$, they also report 
significantly report fewer learning problems than males $\underline{\underline{\mathrm{M}}}=.97, \underline{\mathrm{SE}}=.09$, for females and $\underline{\mathrm{M}}=1.27, \underline{\mathrm{SE}}=.10$, for males). There were no significant gender differences found for school connectedness or academic expectations.

Interactions. No Pillai-Bartlett multivariate tests for interactions were found to be significant.

\section{$\underline{\text { Familial Relationship Measures }}$}

A MANOVA was used to examine the effects of adoption type, adolescent age, and gender on familial relationship variables (i.e., mother-closeness, father-closeness, and family closeness). Table 23 summarizes the results for this MANOVA. Table 24 contains the means and the standard deviations on the dependent variables by adoption type, adolescent age, and gender. The Pillai-Bartlett multivariate test statistic indicated no significant adoption type, adolescent age, or gender differences for any familial relationship variables. The statistical tests were $\underline{\mathrm{V}}=.009, \underline{\mathrm{F}}(3,351)=1.05, \underline{\mathrm{p}}=.37$ for adoption type, $\underline{\mathrm{V}}=.025, \underline{\mathrm{F}}(6,704)=1.48, \underline{\mathrm{p}}=.18$ for adolescent age, and $\underline{\mathrm{V}}=.005, \underline{\mathrm{F}}(3$, $351)=.47, \mathfrak{p}=.70$, for gender. Furthermore, no Pillai-Bartlett multivariate tests for interactions were found to be significant.

\section{$\underline{\text { Psychological Adjustment Measures }}$}

A MANOVA was used to examine the influence of adoption type, adolescent age, and gender on the psychological adjustment variables (i.e., depression, delinquency, and self-worth). Table 25 summarizes the results for this MANOVA. Table 26 contains the means and the standard deviations on the dependent variables by adoption type, adolescent age, and gender. The Pillai-Bartlett multivariate test statistic indicated that there were no significant differences between transracially adopted adolescents and same- 
race adopted adolescents, was $\underline{\mathrm{V}}=.003, \underline{\mathrm{F}}(3,479)=.53, \underline{\mathrm{p}}=.66$, or between adolescents at different ages, $\underline{\mathrm{V}}=.009, \underline{\mathrm{F}}(6,960)=.75, \underline{\mathrm{p}}=.61$, on any psychological adjustment variables.

Gender. The Pillai-Bartlett multivariate test statistic indicated a significant gender effect, $\underline{\mathrm{V}}=.030, \underline{\mathrm{F}}(3,479)=4.94, \underline{\mathrm{p}}<.01$. Table 27 illustrates the univariate main effects for depression and self-worth scores were significant, $\underline{\mathrm{F}}(1,481)=7.73, \underline{\mathrm{p}}<.01$, and $\underline{\mathrm{F}}(1$, $481)=5.56 \underline{\mathrm{p}}<.05$, respectively. Males $(\underline{\mathrm{M}}=.51, \underline{\mathrm{SE}}=.06)$ are depressed significantly less often than females $(\underline{\mathrm{M}}=.72, \underline{\mathrm{SE}}=.05)$. Also, males $(\underline{\mathrm{M}}=4.17, \underline{\mathrm{SE}}=.09)$ reported significantly higher self-worth than females $(\underline{\mathrm{M}}=3.89, \underline{\mathrm{SE}}=.07)$. No significant main effect of gender was found for delinquency scores.

Interactions. No Pillai-Bartlett multivariate tests for interactions were found to be significant.

\section{Physical Health Measures}

A MANOVA was used to examine group differences of adoption type, adolescent age, and gender on the physical health variables (i.e., overall health and psychosomatic conditions). Table 28 summarizes the results for this MANOVA. Table 29 contains the means and the standard deviations for the dependent variables by the adoption type, adolescent age, and gender. The Pillai-Bartlett multivariate test statistic indicated no significant main effects were found for adoption type, $\underline{V}=.002, \underline{F}(2,486)=.38, p=.68$, or adolescent age, $\underline{V}=.005, \underline{F}(4,974)=.65, \underline{p}=.63$, for physical health variables.

Gender. The Pillai-Bartlett multivariate test statistic indicated a significant gender effect, $\underline{\mathrm{V}}=.017, \underline{\mathrm{F}}(2,486)=4.31, \mathrm{p}<.05$. Table 30 illustrates the univariate main effect of gender were significant for overall physical health, $\underline{\mathrm{F}}(1,487)=6.89, \underline{\mathrm{p}}<.01$. Males $(\underline{\mathrm{M}}$ 
$=1.80, \underline{\mathrm{SE}}=.12)$ had significantly better overall physical health than their female counterparts $(\underline{\mathrm{M}}=2.21, \underline{\mathrm{SE}}=.10)$. The univariate main effect for gender on psychosomatic scores was marginally significant, $\underline{F}(1,487)=3.735, \underline{p}=.054$. Males $(\underline{\mathrm{M}}$ $=.76, \underline{\mathrm{SE}}=.06)$ reported fewer psychosomatic conditions than females $(\underline{\mathrm{M}}=.91, \underline{\mathrm{SE}}=$ $.05)$.

Interactions. No Pillai-Bartlett multivariate tests for interactions were found to be significant.

Analysis Three: Exploratory Analyses

To further analyze the implications of being adopted upon adolescent development, exploratory investigations were conducted across the four domains of adolescent development investigated in Analysis One and Analysis Two. However, exploratory one-way ANOVAs were performed for specific racial groupings, adolescent age, and gender. First, four different racial groupings of adopted families (white child white parents, black child - black parents, black child - white parents, and Asian child white parents) were examined. Second, three adolescent age groups (12-13, 14-16, and 17-19) were examined. Lastly, gender was examined. For all three independent variables, four categories of adolescent adjustment were utilized as dependent variables. These four dependent measures were academic outcomes, familial relationships, psychological adjustment, and physical health. For significant ANOVAs, Bonferroni post-hoc pairwise comparisons of means were conducted at $\underline{\mathrm{p}}<.05$.

\section{Specific racial groupings}

Associations between the four specific racial groupings of adopted adolescents and various developmental outcomes were explored. With respect to these specific racial 
groupings, Table 31 illustrates the means, standard deviations, and the results of the significance tests for all measures investigated.

Academic Measures. Four one-way ANOVAs were conducted to determine the association between four specific adoptive parent-child racial groupings on adolescents' school grades, learning problems, school connectedness, and academic expectations. The results for learning problems, school connectedness, and academic expectations failed to show significant differences between any of the four adoptive parent-child groupings. By contrast, for school grades, the one-way ANOVA indicated a significant difference in the means between the group of Asian children adopted by white parents and both white children adopted by white parents and black children adopted by black parents, $\underline{\mathrm{F}}(3,338)$ $=5.25, \underline{\mathrm{p}}<.01$. Accordingly, Asian children adopted by white parents $(\underline{\mathrm{M}}=1.72, \underline{\mathrm{SE}}=$ .14) had better grades than both white children adopted by white parents $(\underline{M}=2.25, \underline{S E}=$ $.05)$ and black children adopted by black parents $(\underline{\mathrm{M}}=2.47, \underline{\mathrm{SE}}=.09)$ and yet, Asian children adopted by white parents did not significantly differ from black children adopted by white parents $(\underline{\mathrm{M}}=2.67, \underline{\mathrm{SE}}=.35)$. Beyond this, no other significant adoptive parentchild groups significantly differed.

Familial Relationships. Three one-way ANOVAs were conducted to determine the effect of four specific adoptive parent-child racial groupings on adolescents' perceptions of mother-closeness, father-closeness, and family closeness. No significant differences were found among any of the specific racial groupings.

Psychological Adjustment. Three one-way ANOVAs were conducted to determine the effect of four specific adoptive parent-child racial groupings on adolescents' reports of depression, delinquency, and self-worth. For delinquency and self-worth, there were no 
significant differences found between any of the four adoptive parent-child groupings. However, for depression, the one-way ANOVA indicated a significant difference in the means among the four groups, $\underline{\mathrm{F}}(3,450)=3.18, \underline{\mathrm{p}}<.05$. Black children adopted by black parents $(\underline{\mathrm{M}}=.73, \underline{\mathrm{SE}}=.05)$ reported significantly greater depression in comparison to white children adopted by white parents $(\underline{\mathrm{M}}=.57, \underline{\mathrm{SE}}=.02)$. No other adoptive parent-child groups significantly differed.

Physical Health. Two one-way ANOVAs were conducted to determine the effects of four specific adoptive parent-child racial groupings on adolescents' overall physical health and psychosomatic conditions. No significant group differences were found on the overall physical health measure. However, for psychosomatic conditions, the one-way ANOVA indicated a significant difference in the means among the four groups, $\underline{F}$ (4, $452)=2.79, \underline{p}<.05$. Asian children adopted by white parents $(\underline{\mathrm{M}}=.99, \underline{\mathrm{SE}}=.07)$ reported significantly more psychosomatic conditions black children adopted by black parents $(\underline{\mathrm{M}}=.73, \underline{\mathrm{SE}}=.04)$.

\section{Adolescent Age}

Specifically for the adopted adolescents under investigation, associations between three adolescent age groups and various developmental outcomes were explored. With respect to these adolescent age groups, Table 32 illustrates the means, standard deviations, and the results of the significance tests for all measures investigated. Academic Measures. Four one-way ANOVAs were conducted to determine the influence of adolescent age on adolescents' school grades, learning problems, school connectedness, and academic expectations. No significant differences were found among the adolescent age groups. 
Familial Relationships. Three one-way ANOVAs were conducted to determine the effect of four specific adoptive parent-child racial groupings on adolescents' perceptions of mother-closeness, father-closeness, and family closeness. For father-child relationships, there were no significant differences found between any of the three adolescent age groups. However, there were significant differences found for mother-closeness, $\underline{F}(2$, $402)=4.36, \underline{p}<.05$, and for family-closeness, $\underline{F}(2,418)=10.88, \underline{p}<.01$. Individuals in old adolescence $(\underline{\mathrm{M}}=4.21, \underline{\mathrm{SE}}=.06)$ reported significantly less closeness with their mother than both young adolescents $(\underline{\mathrm{M}}=4.51, \underline{\mathrm{SE}}=.09)$ and middle adolescents $(\underline{\mathrm{M}}=$ $4.40, \underline{\mathrm{SE}}=.05)$. With respect to family-closeness, all three adolescent age groups significantly differed from each other. The young adolescents $(\underline{\mathrm{M}}=4.31, \mathrm{SE}=.07)$ reported the highest family-closeness, while the middle adolescents $(\underline{\mathrm{M}}=3.95, \underline{\mathrm{SE}}=.05)$ reported the second highest family-closeness, and the old adolescents $\underline{\underline{M}}=3.76, \underline{\mathrm{SE}}=$ .06) reported the least family-closeness.

Psychological Adjustment. Three one-way ANOVAs were conducted to determine the influence of three adolescent age groups upon individual's reports of depression, delinquency, and self-worth. For depression and self-worth, there were no significant differences found between any of the four adoptive parent-child groupings. However, for delinquency, the one-way ANOVA indicated a significant difference, $\underline{F}(2,421)=3.46, \underline{p}$ $<.05$. The young group of adolescents $(\underline{\mathrm{M}}=.14, \underline{\mathrm{SE}}=.01)$ reported delinquency significantly less often than individuals in middle adolescence $(\underline{\mathrm{M}}=.22, \underline{\mathrm{SE}}=.01)$. No other adolescent age groups significantly differed.

Physical Health. Two one-way ANOVAs were conducted to determine the association between three adolescent age groups and individuals' overall physical health and 
psychosomatic conditions. No significant differences were found among the three adolescent age groups.

\section{$\underline{\text { Gender }}$}

Specifically for the adopted adolescents under investigation, associations between gender and various developmental outcomes were explored. With respect to these adolescent age groups, Table 33 displays the means, standard deviations, and the results of the significance tests for all measures investigated.

Academic Measures. Four one-way ANOVAs were conducted to determine the influence of adolescent age on adolescents' school grades, learning problems, school connectedness, and academic expectations. For school connectedness and academic expectations, no significant differences were found for gender. However, there were significant gender differences on school grades, $\underline{\mathrm{F}}(1,340)=9.47, \underline{\mathrm{p}}<.01$, and learning problems, $\underline{\mathrm{F}}(1,448)=6.25, \underline{\mathrm{p}}<.05$. Females $(\underline{\mathrm{M}}=2.14, \underline{\mathrm{SE}}=.01)$ had significantly better grades than males $(\underline{\mathrm{M}}=2.39, \underline{\mathrm{SE}}=.01)$. Also, females $(\underline{\mathrm{M}}=1.04, \underline{\mathrm{SE}}=.01)$ had significantly fewer learning problems than males $(\underline{\mathrm{M}}=1.20, \underline{\mathrm{SE}}=.01)$.

Familial Relationships. Three one-way ANOVAs were conducted to determine the influence of gender on adolescents' perceptions of mother-closeness, father-closeness, and family-closeness. No significant gender differences were found. Psychological Adjustment. Three one-way ANOVAs were conducted to determine the influence of three adolescent age groups upon individual's reports of depression, delinquency, and self-worth. The one-way ANOVAs on depression, $\underline{F}(1,452)=12.74$, $\mathrm{p}<.01$, delinquency, $\underline{\mathrm{F}}(1,450)=11.59, \underline{\mathrm{p}}<.01$, and self-worth, $\underline{\mathrm{F}}(1,454)=20.80, \underline{\mathrm{p}}<$ .01 all revealed significant gender effects. Females $(\underline{\mathrm{M}}=.67, \underline{\mathrm{SE}}=.03)$ reported 
depression significantly more often than males $(\underline{\mathrm{M}}=.53, \underline{\mathrm{SE}}=.02)$. Males $(\underline{\mathrm{M}}=.23, \underline{\mathrm{SE}}$ $=.01)$ however, were significantly more delinquent than females $(\underline{\mathrm{M}}=.17, \underline{\mathrm{SE}}=.01)$. Also, males $(\underline{\mathrm{M}}=4.20, \underline{\mathrm{SE}}=.04)$ reported having significantly higher self-worth than females $(\underline{M}=3.93, \underline{S E}=.05)$.

Physical Health. Two one-way ANOVAs were conducted to determine the association between three adolescent age groups and individuals' overall physical health and psychosomatic conditions. Both overall physical health, $\underline{\mathrm{F}}(1,454)=13.75, \mathrm{p}<.01$, and psychosomatic conditions, $\underline{\mathrm{F}}(1,454)=19.11, \underline{\mathrm{p}}<.01$ revealed significant gender effects. Males $(\underline{\mathrm{M}}=1.90, \underline{\mathrm{SE}}=.05)$ had significantly better overall physical health than females $(\underline{\mathrm{M}}=2.20, \underline{\mathrm{SE}}=.06)$. Also, males $(\underline{\mathrm{M}}=.74, \underline{\mathrm{SE}}=.02)$ reported fewer psychosomatic conditions than females $(\underline{\mathrm{M}}=.91, \underline{\mathrm{SE}}=.03)$. 


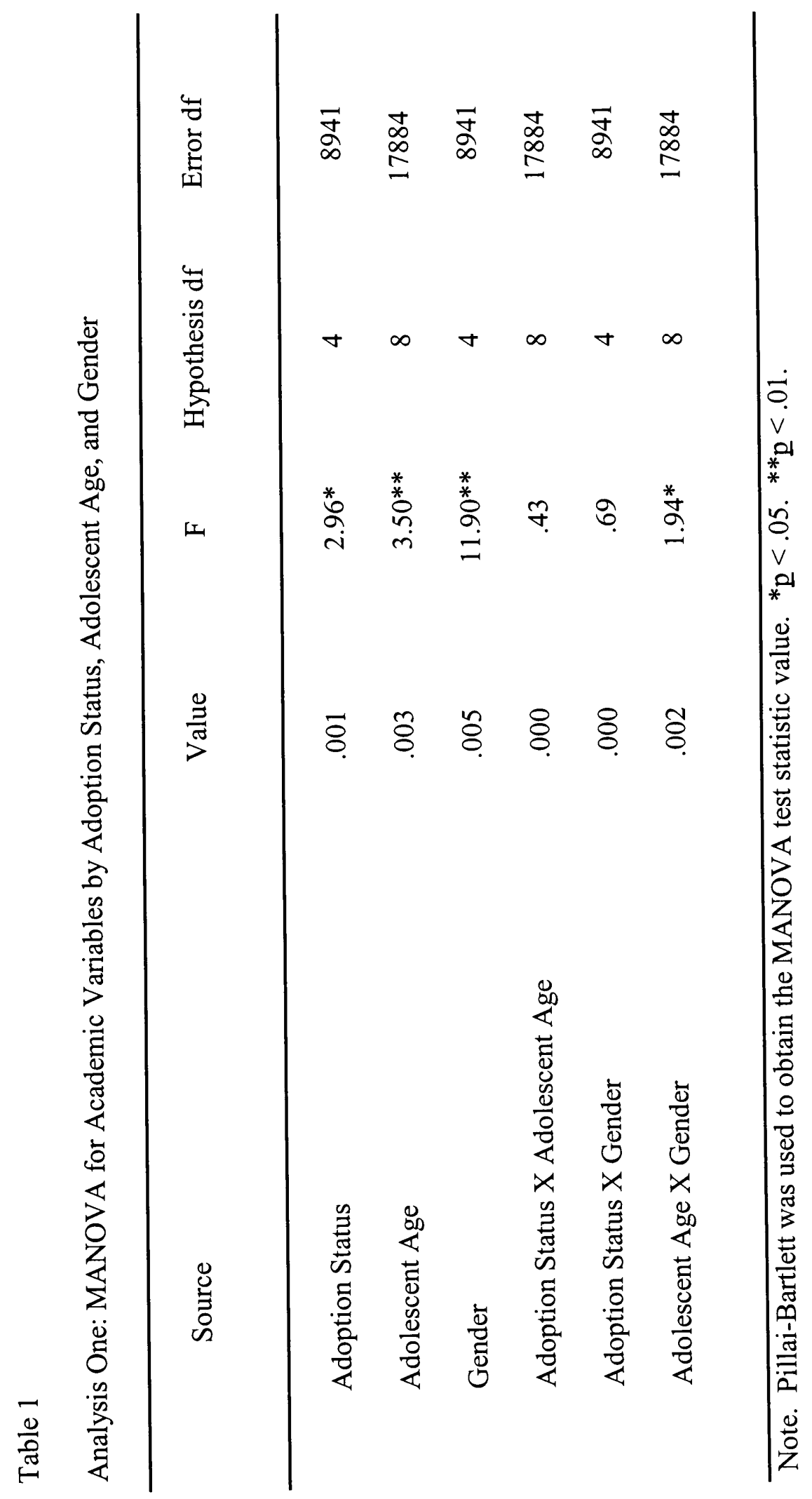

$n$ 


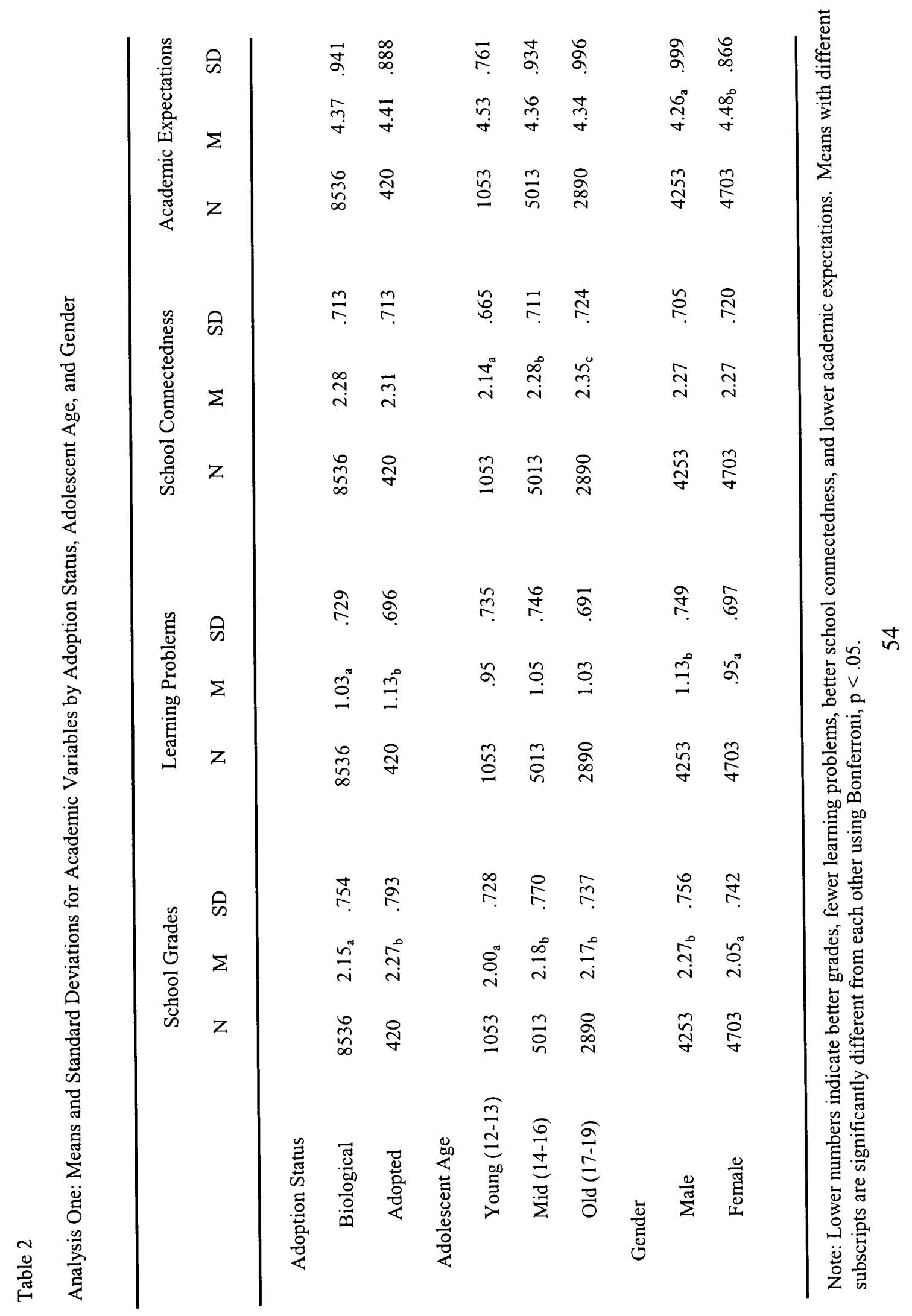




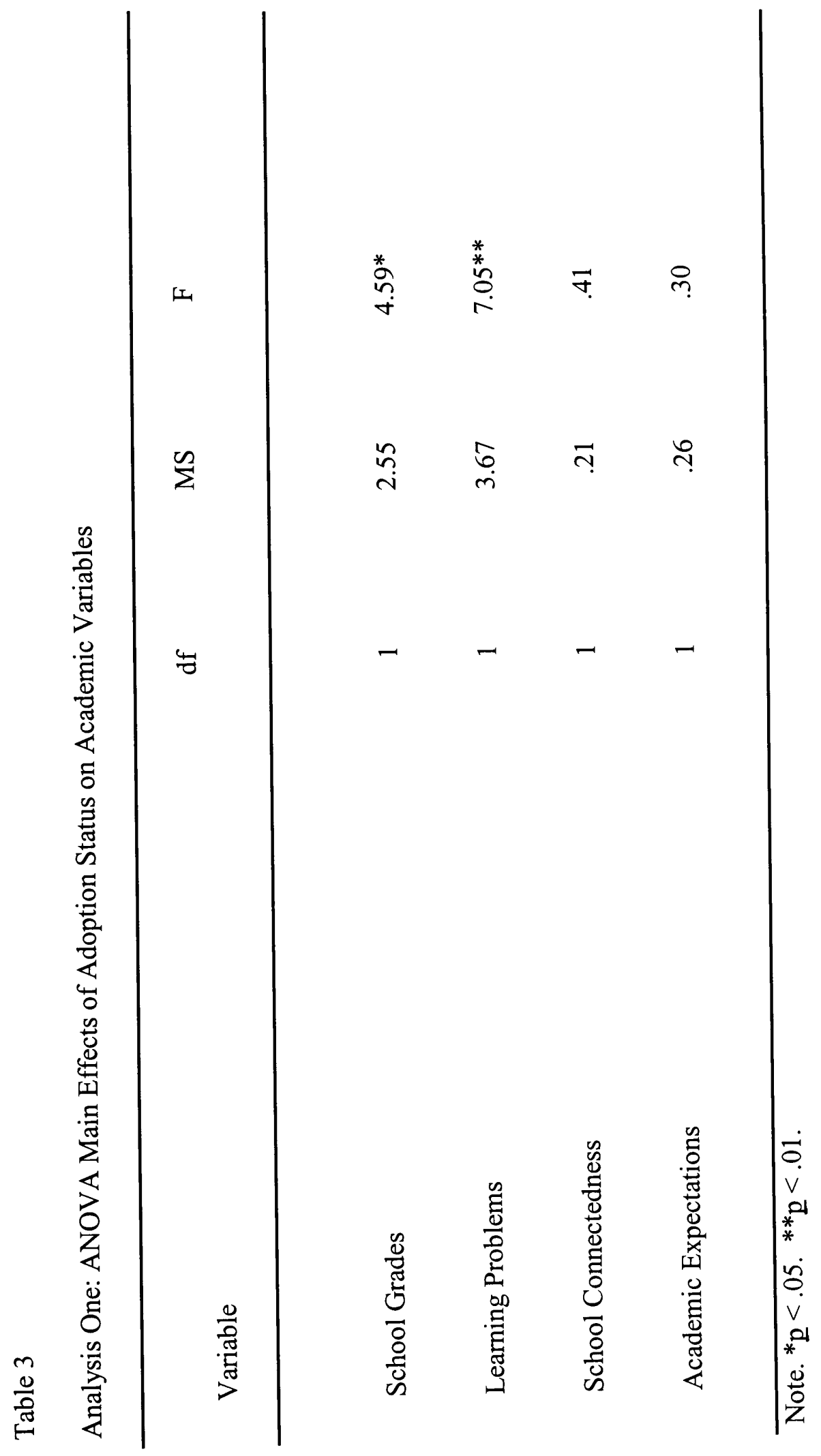

n 


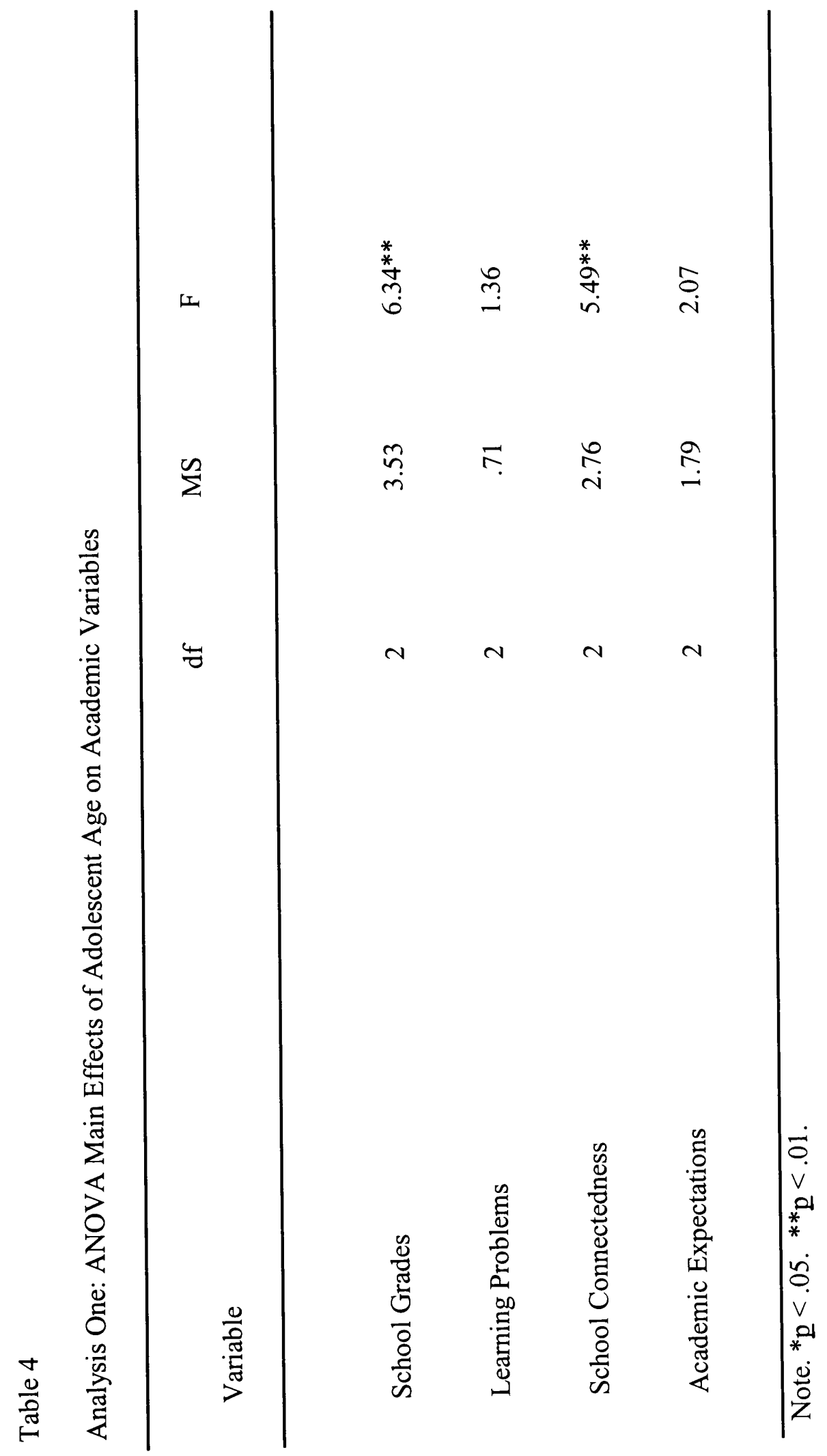

n 


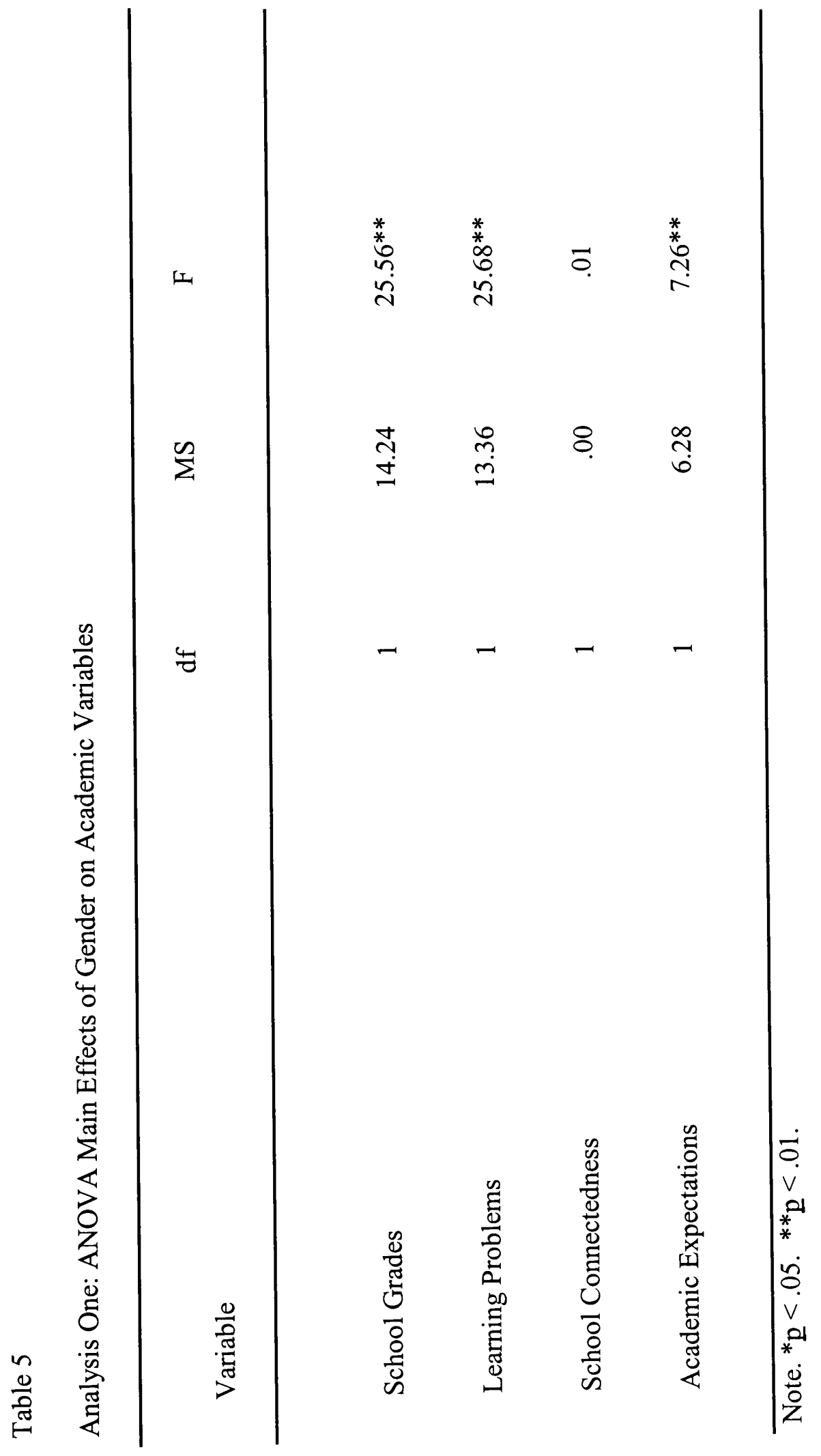

in 


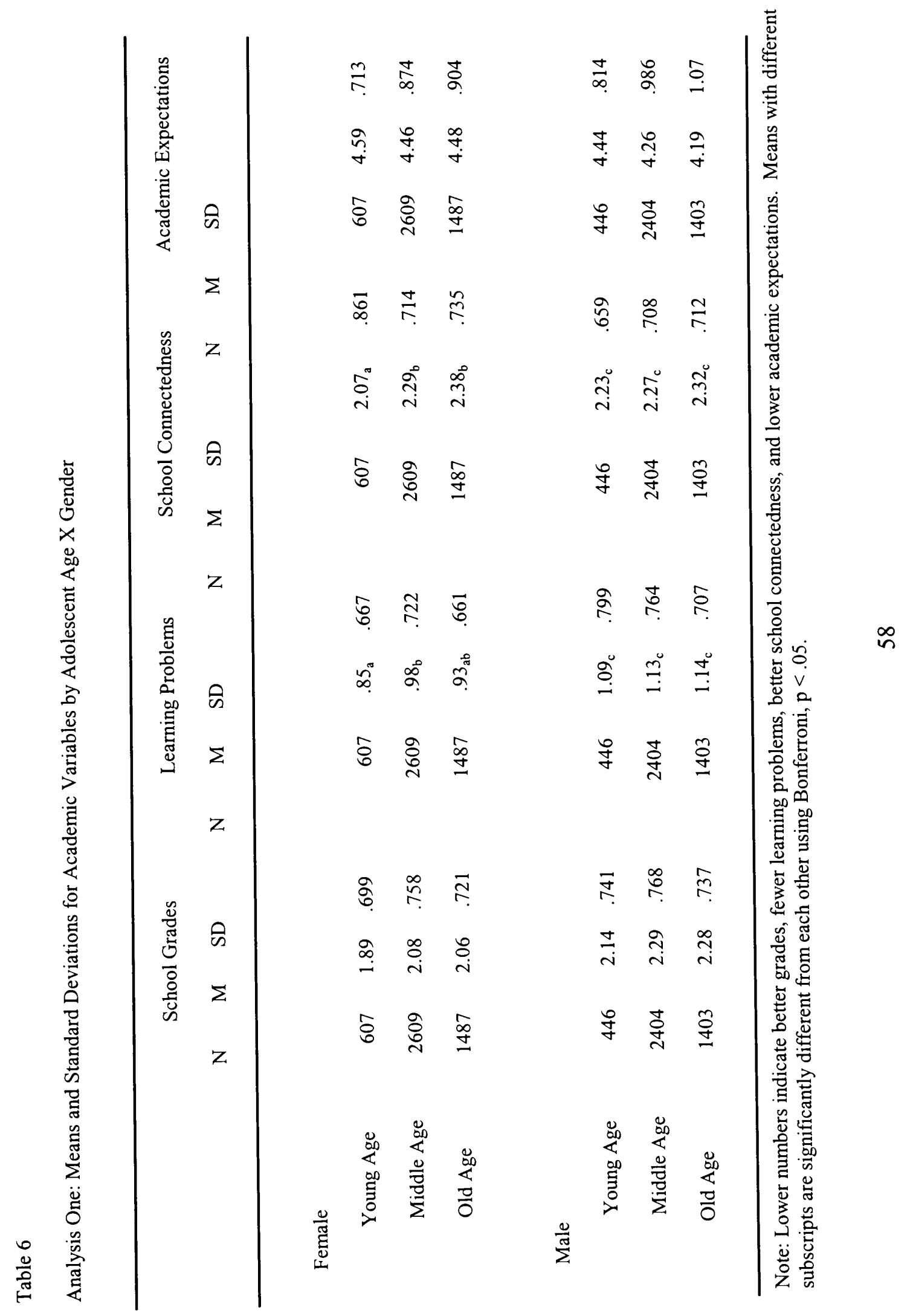




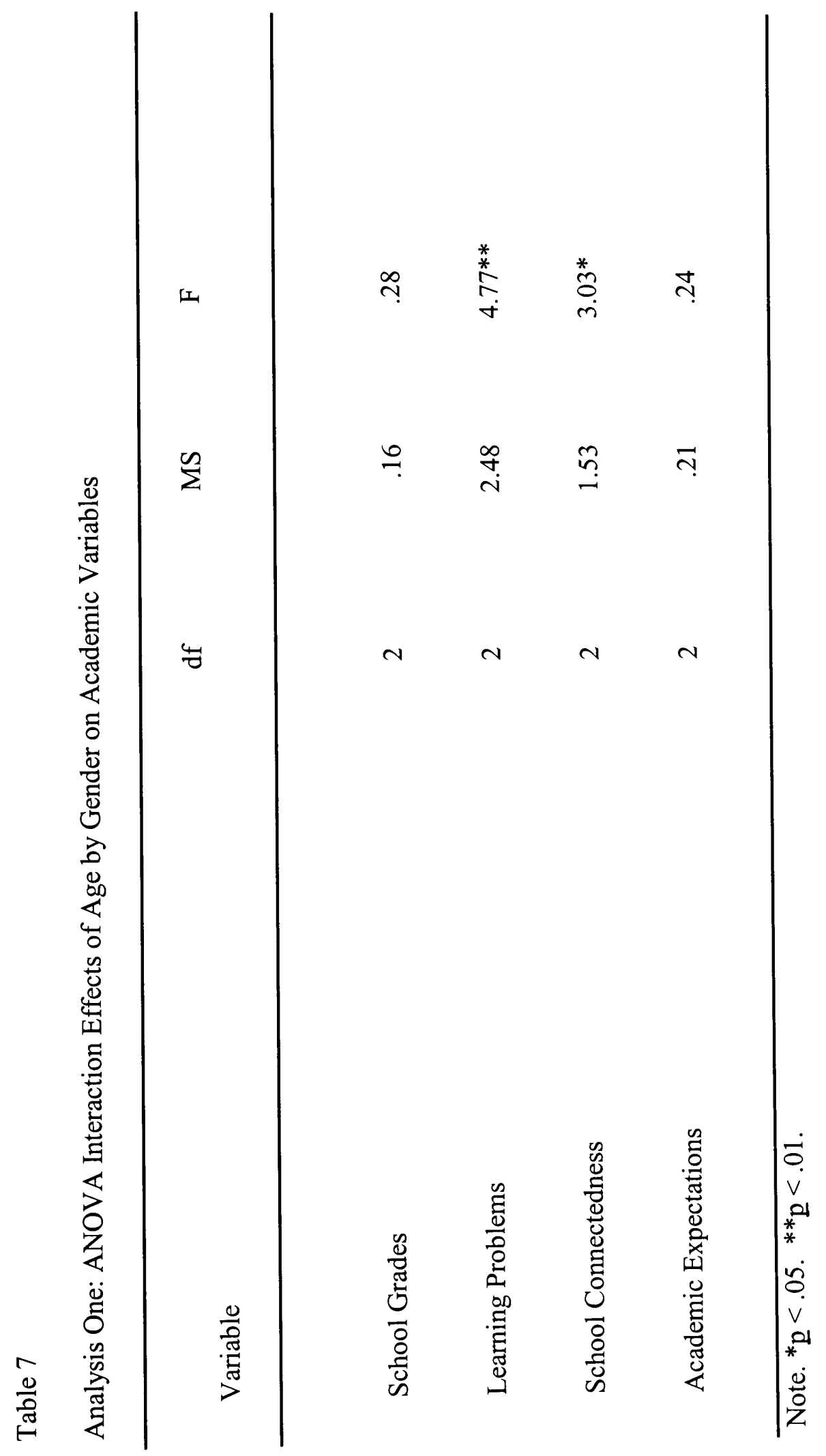

a 


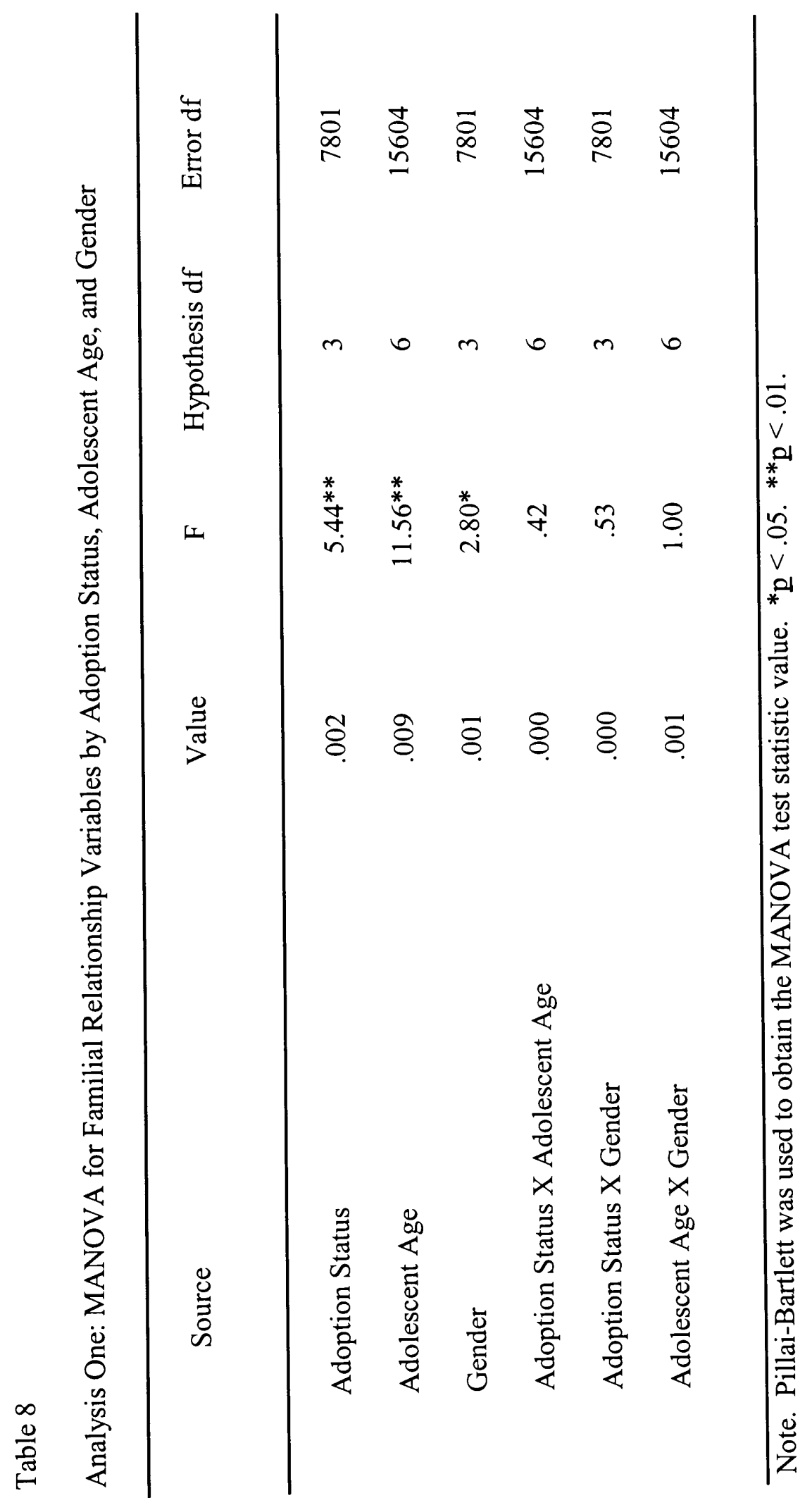




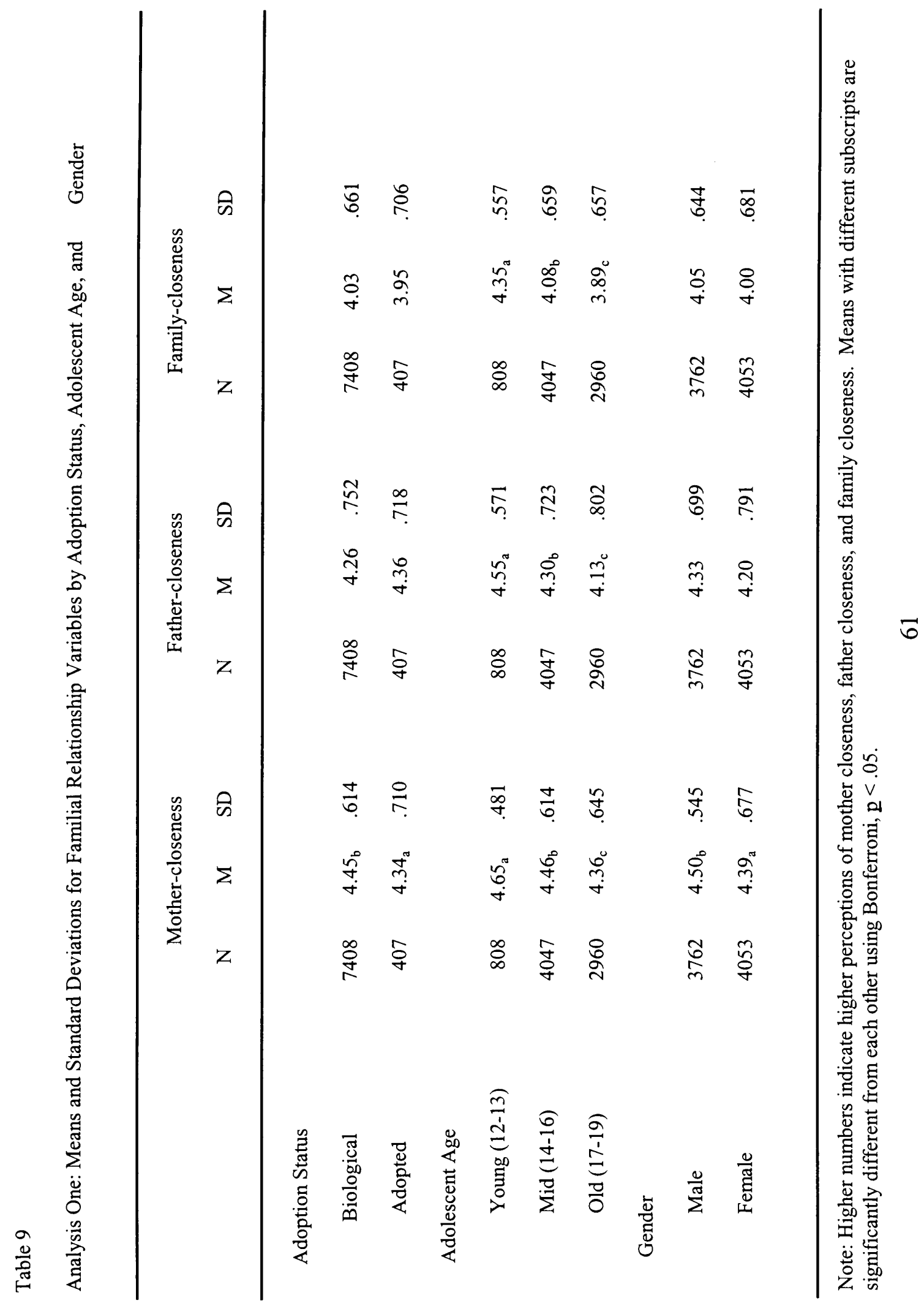




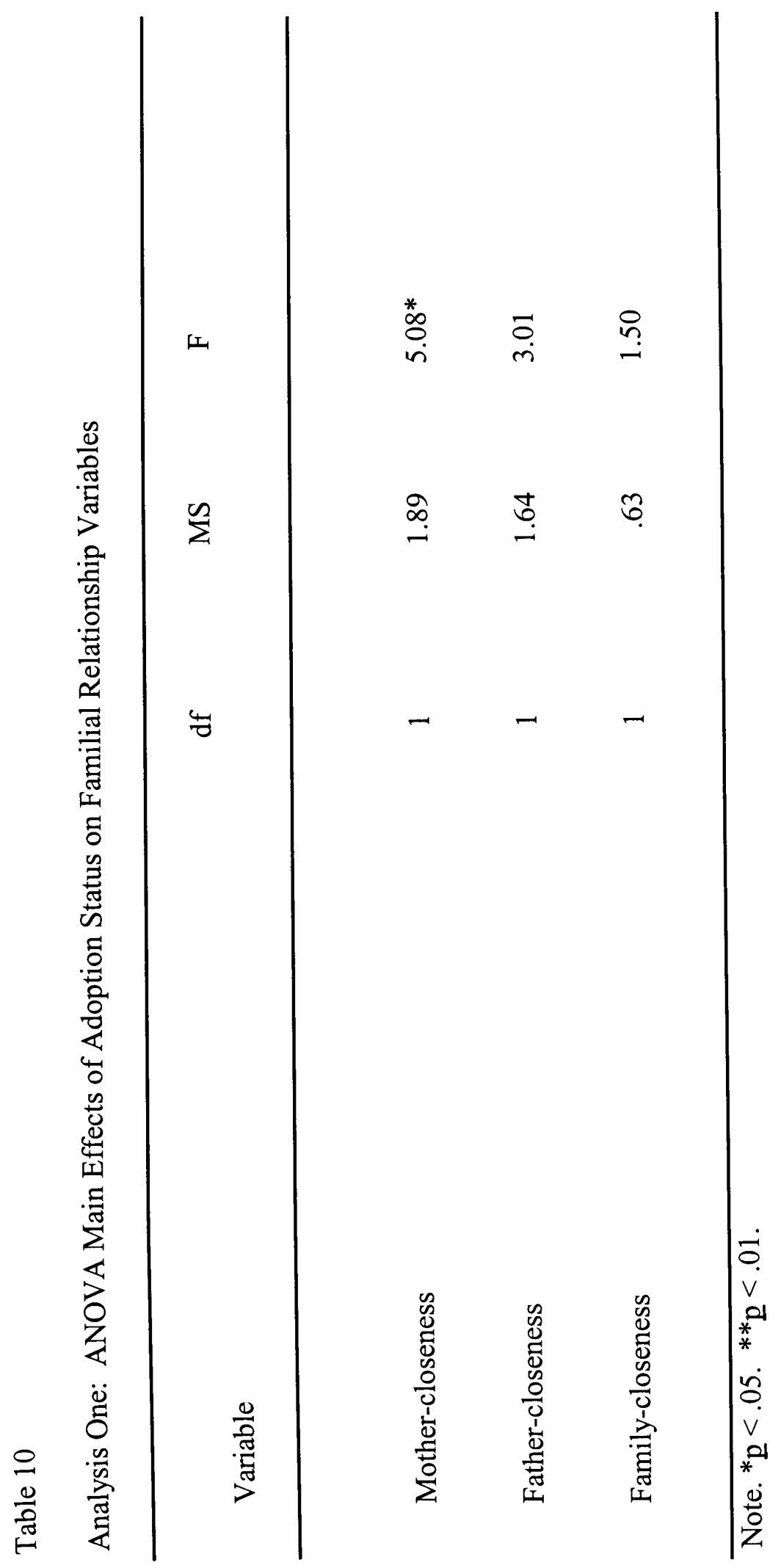

ธิ 


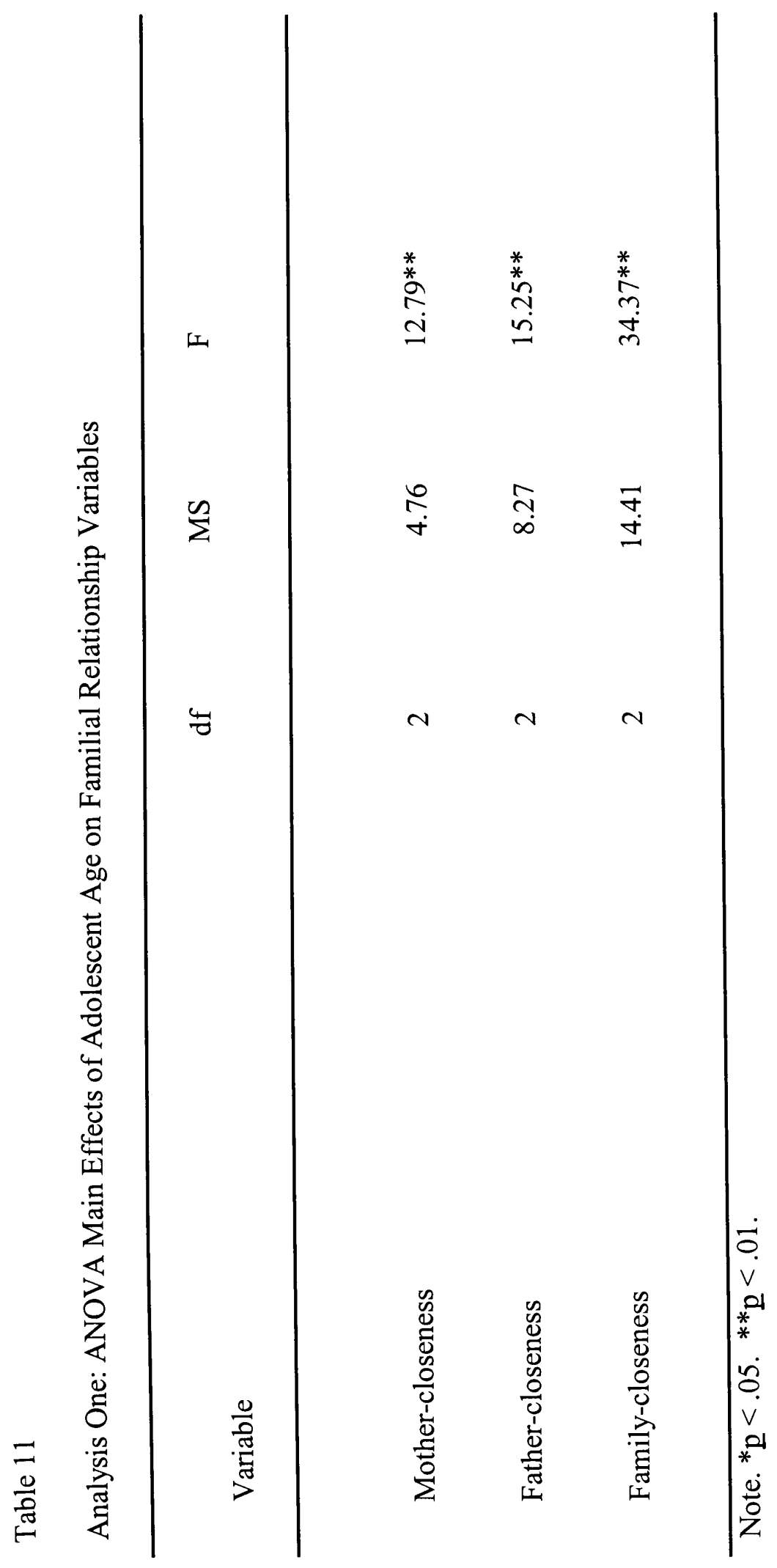




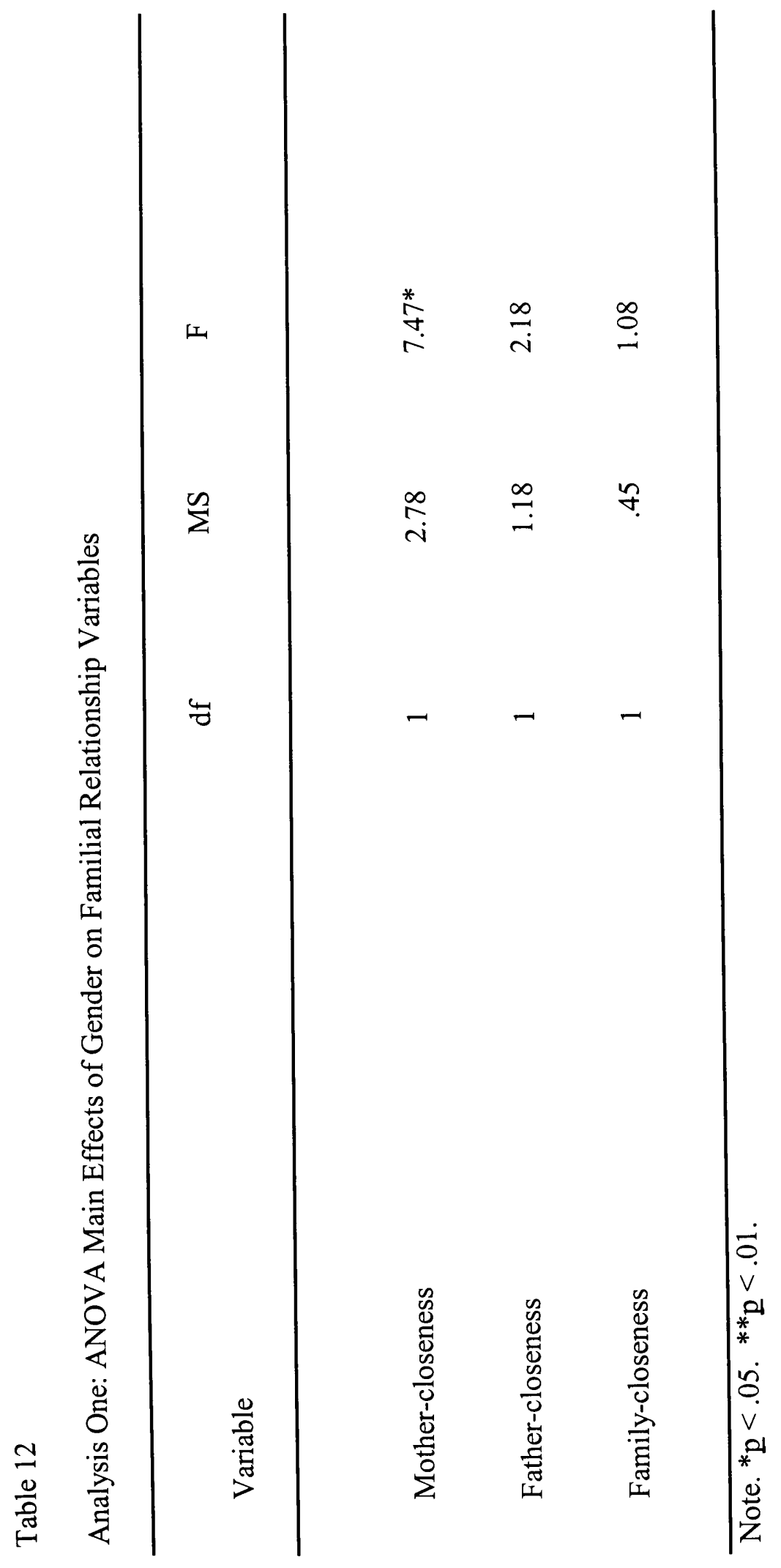

J 


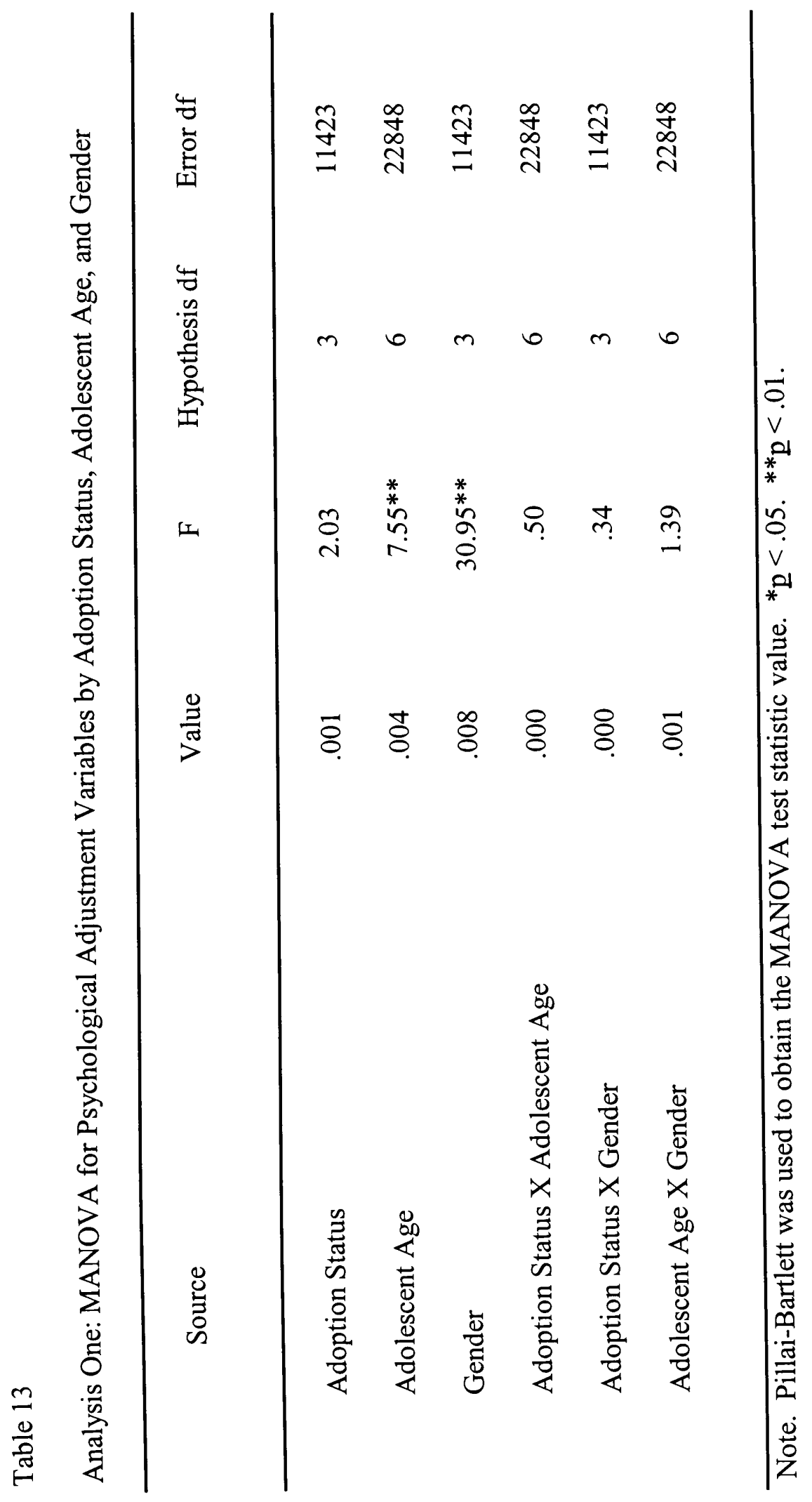

3 


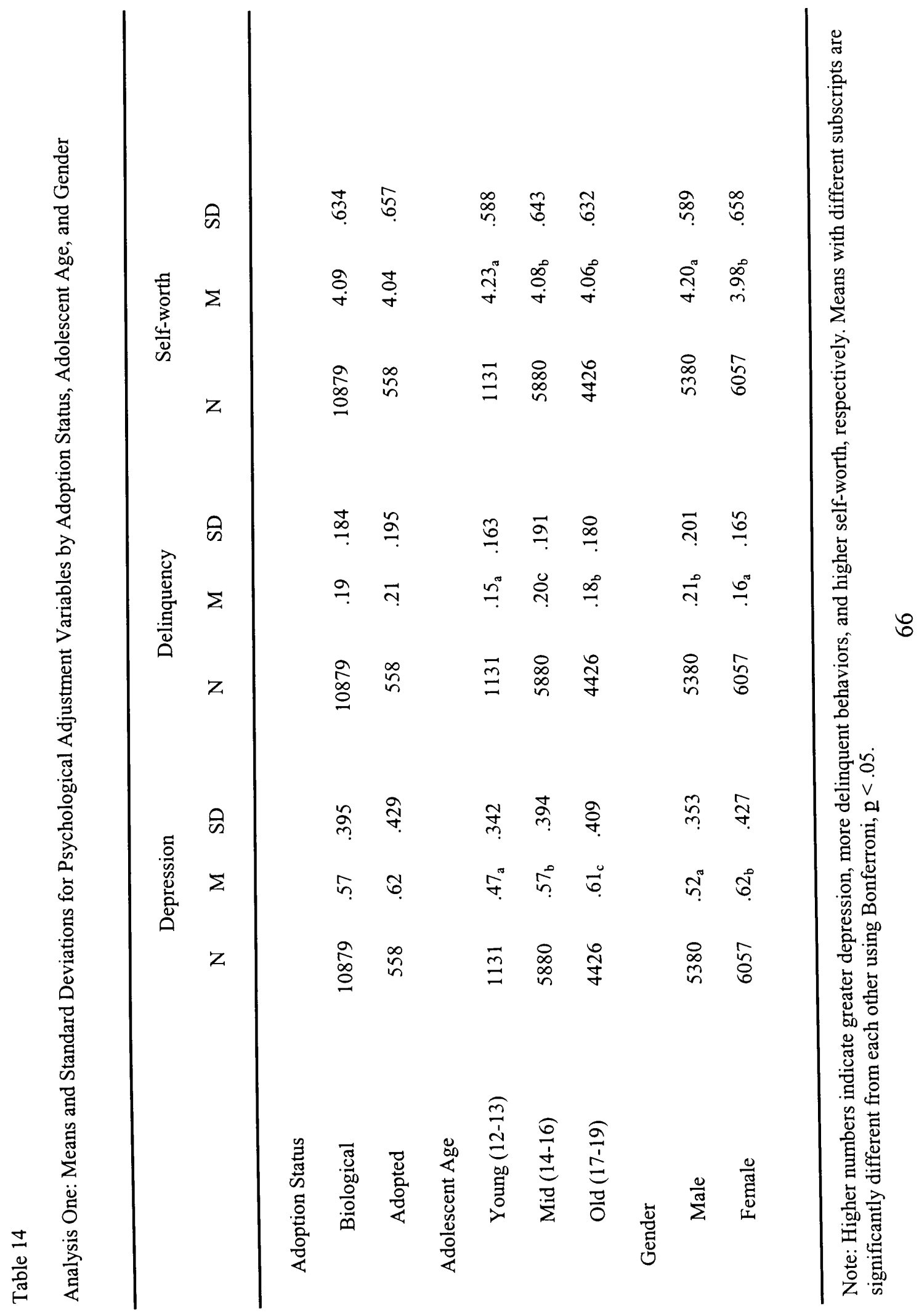




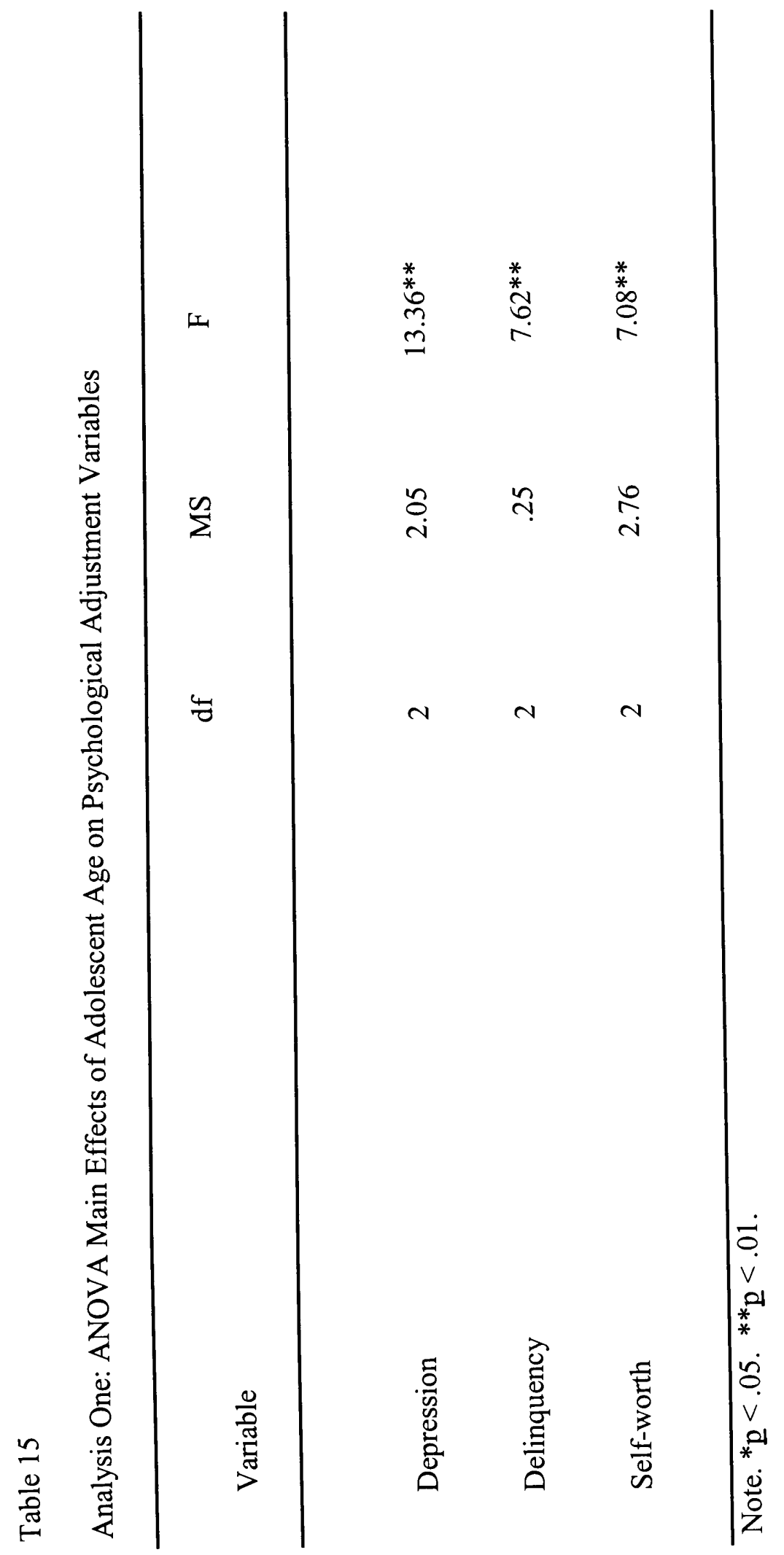

5 


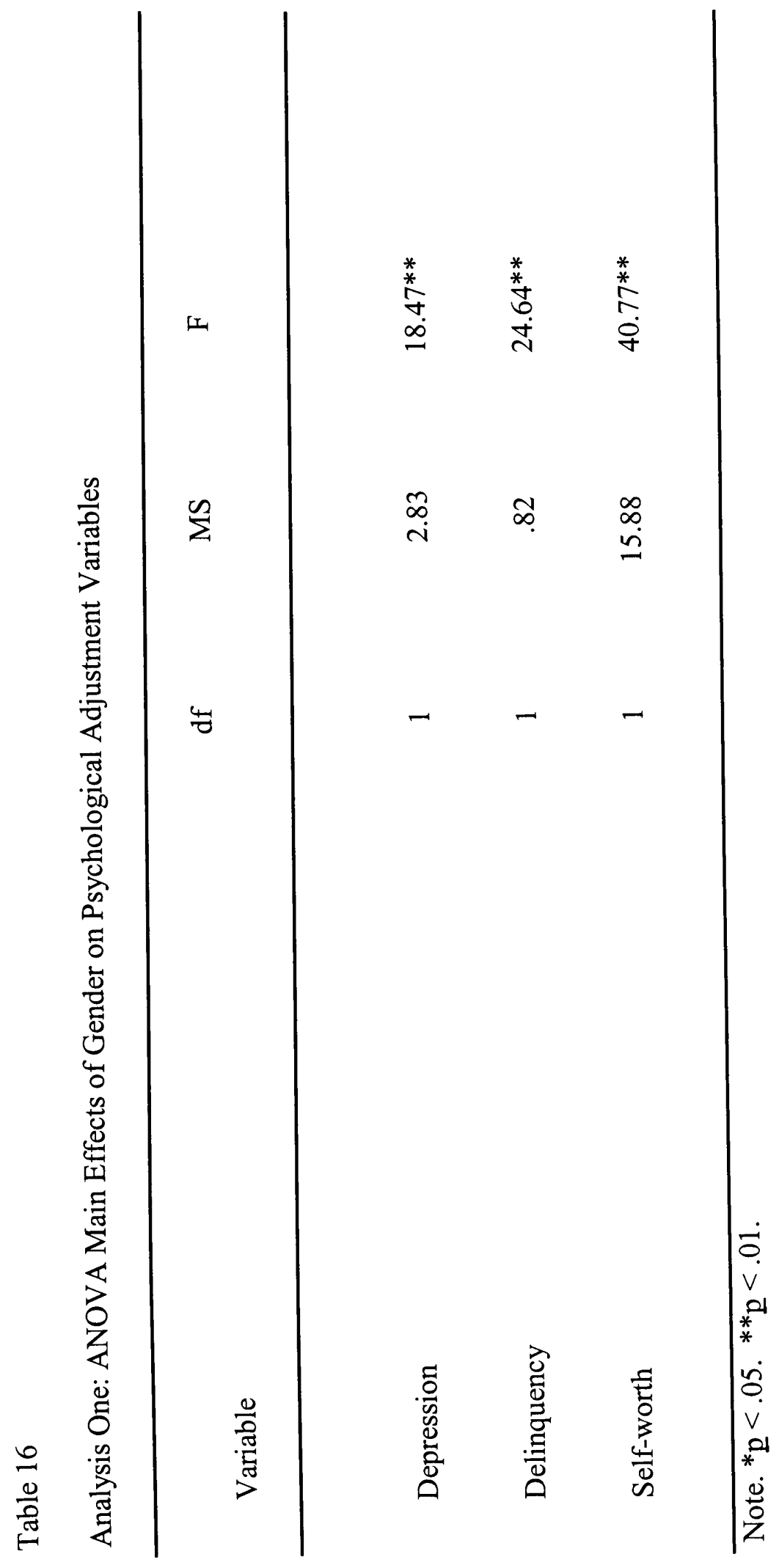




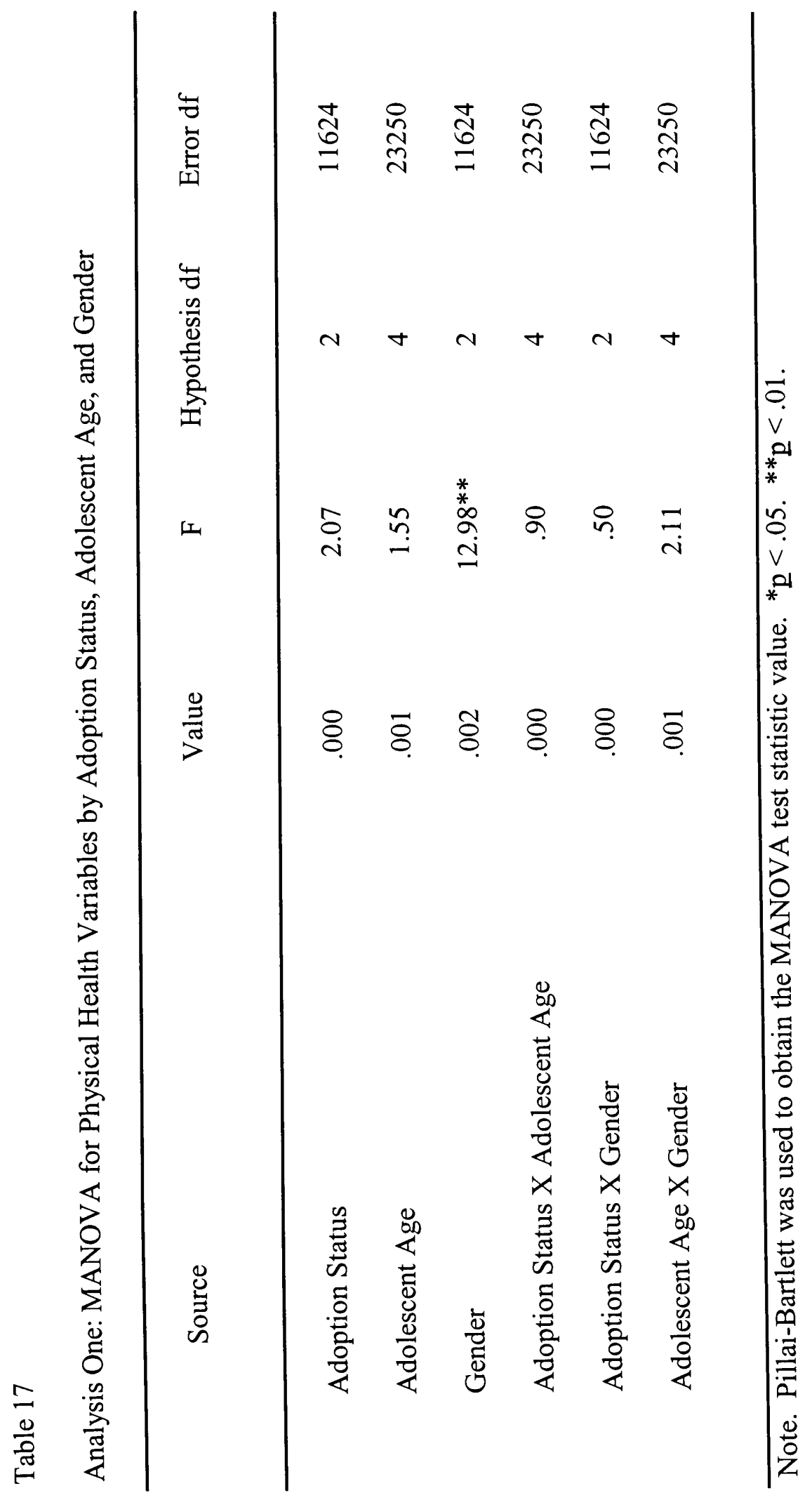




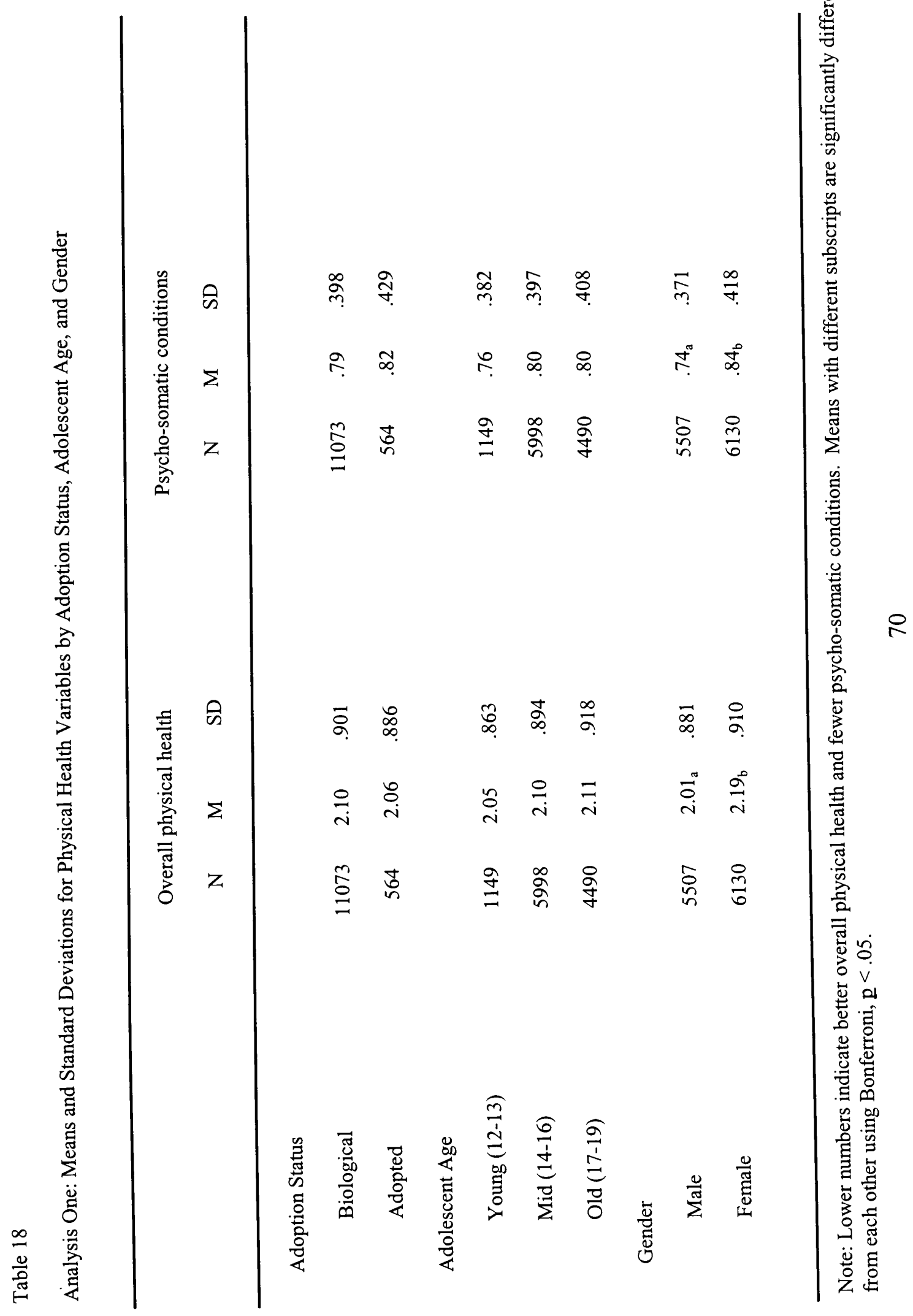




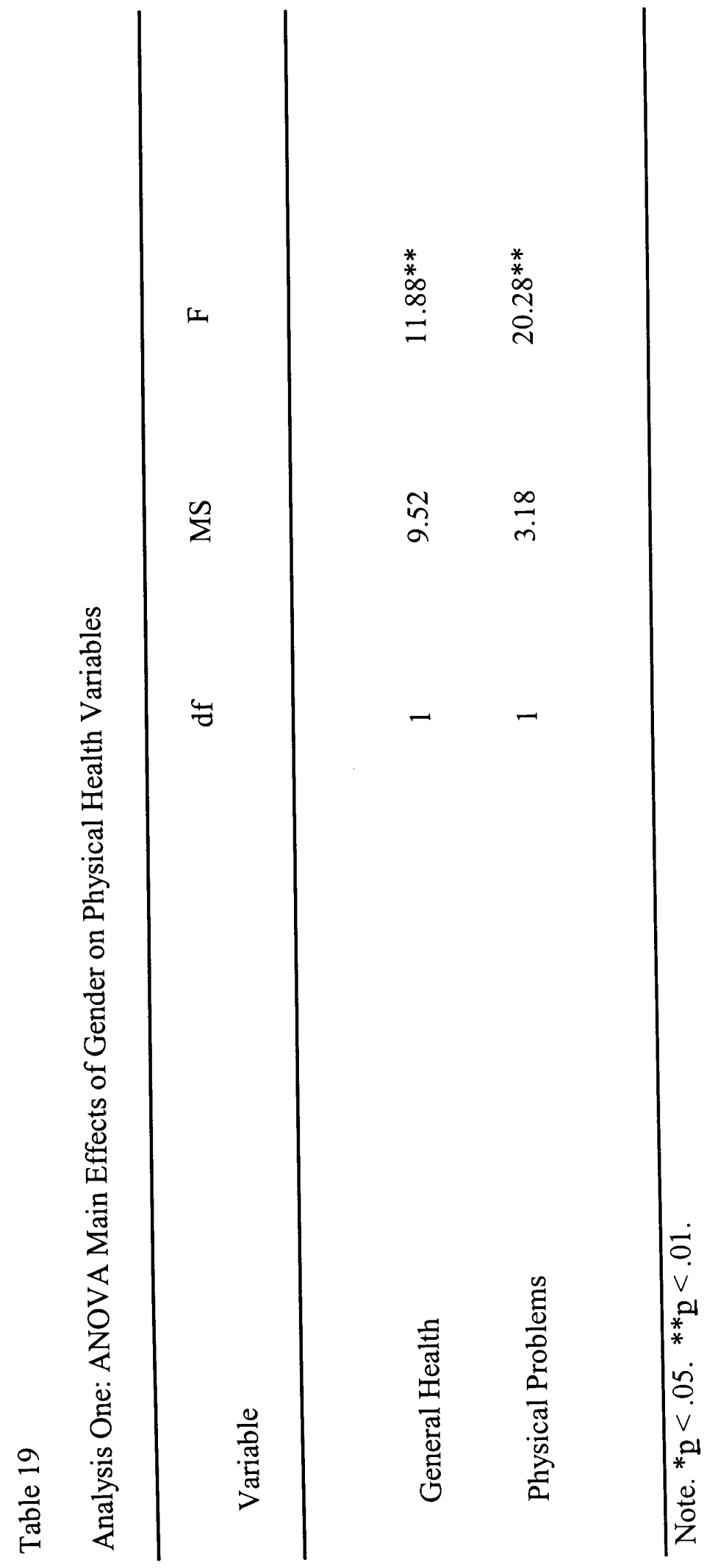




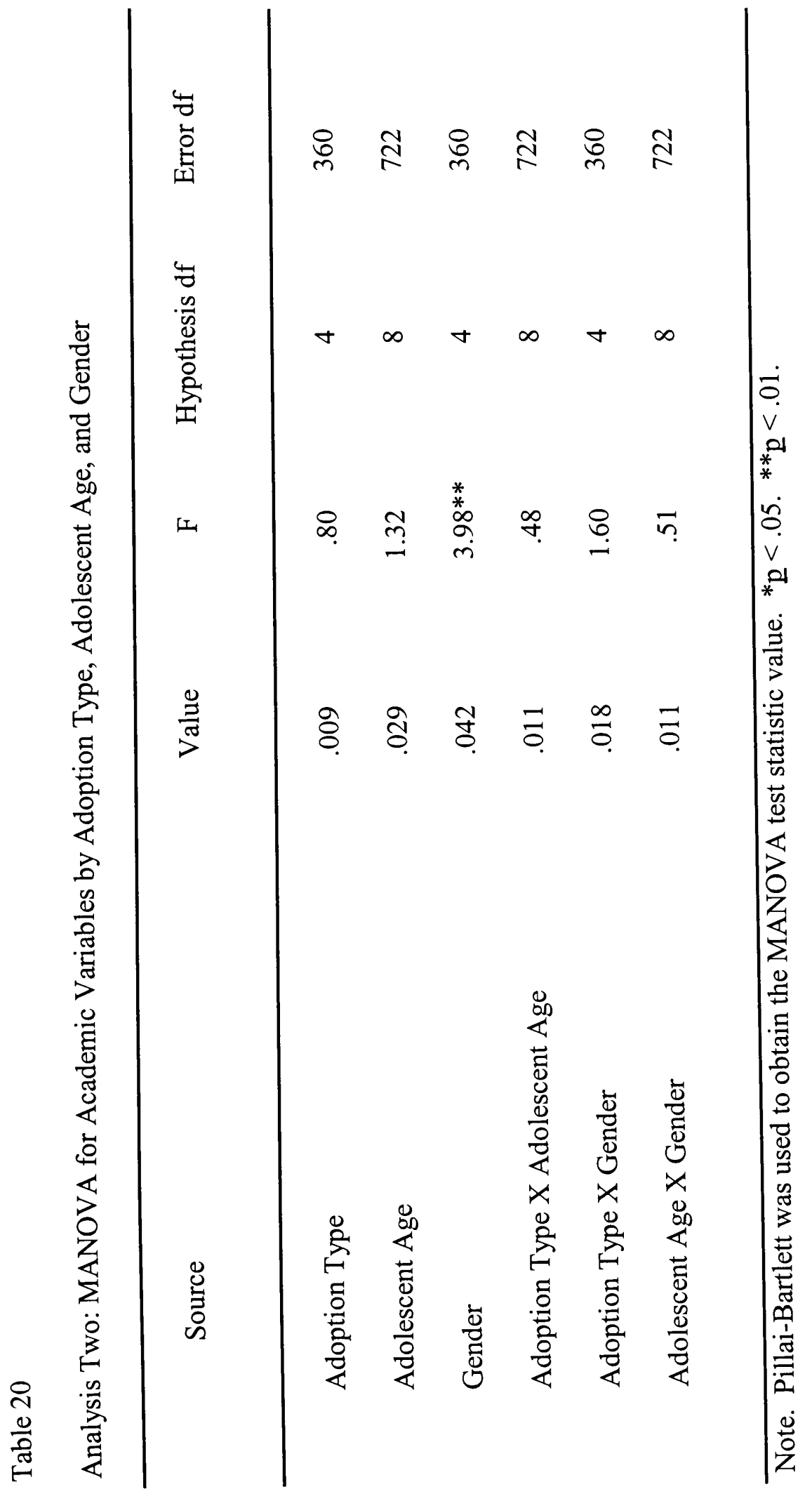

$\approx$ 


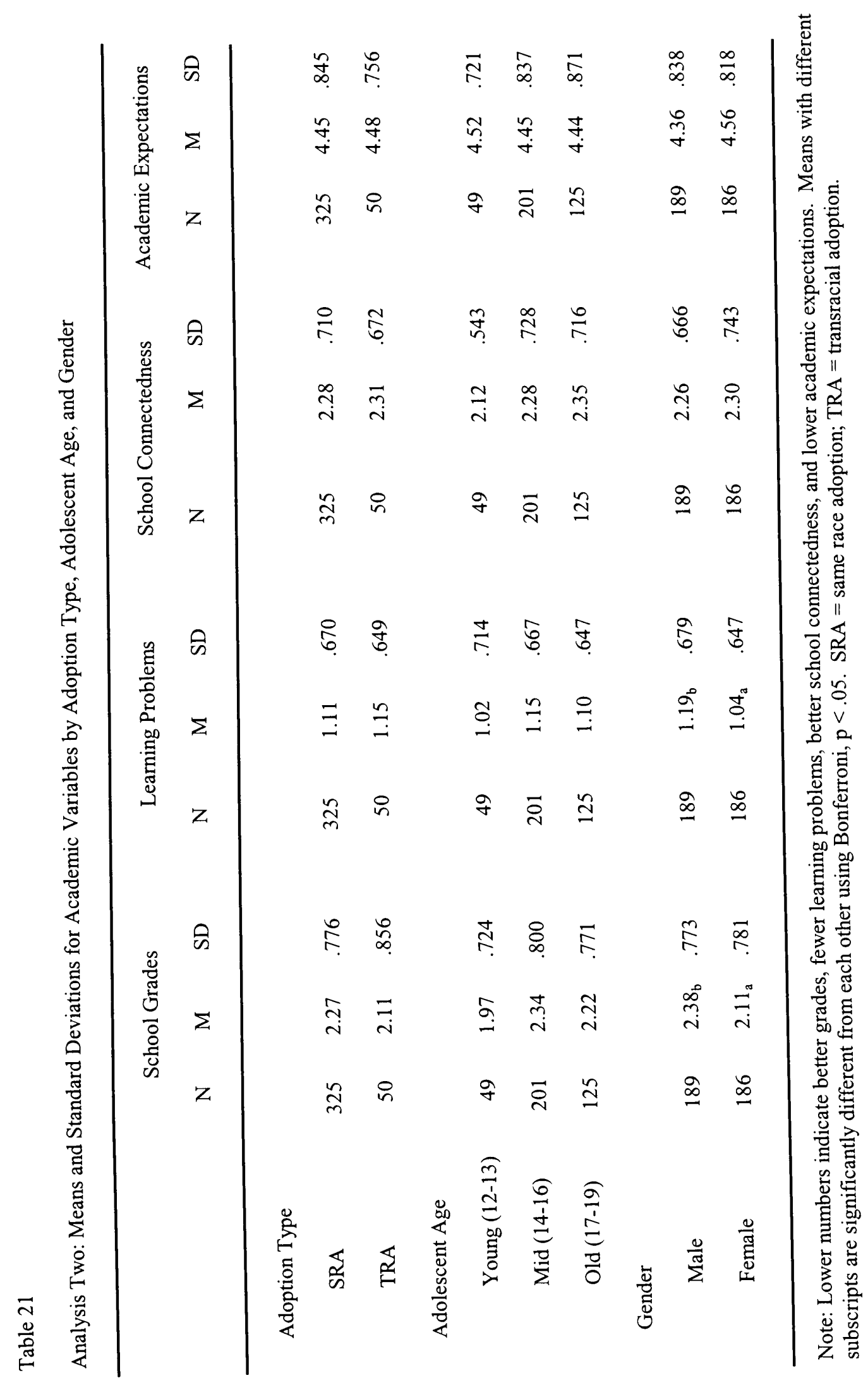




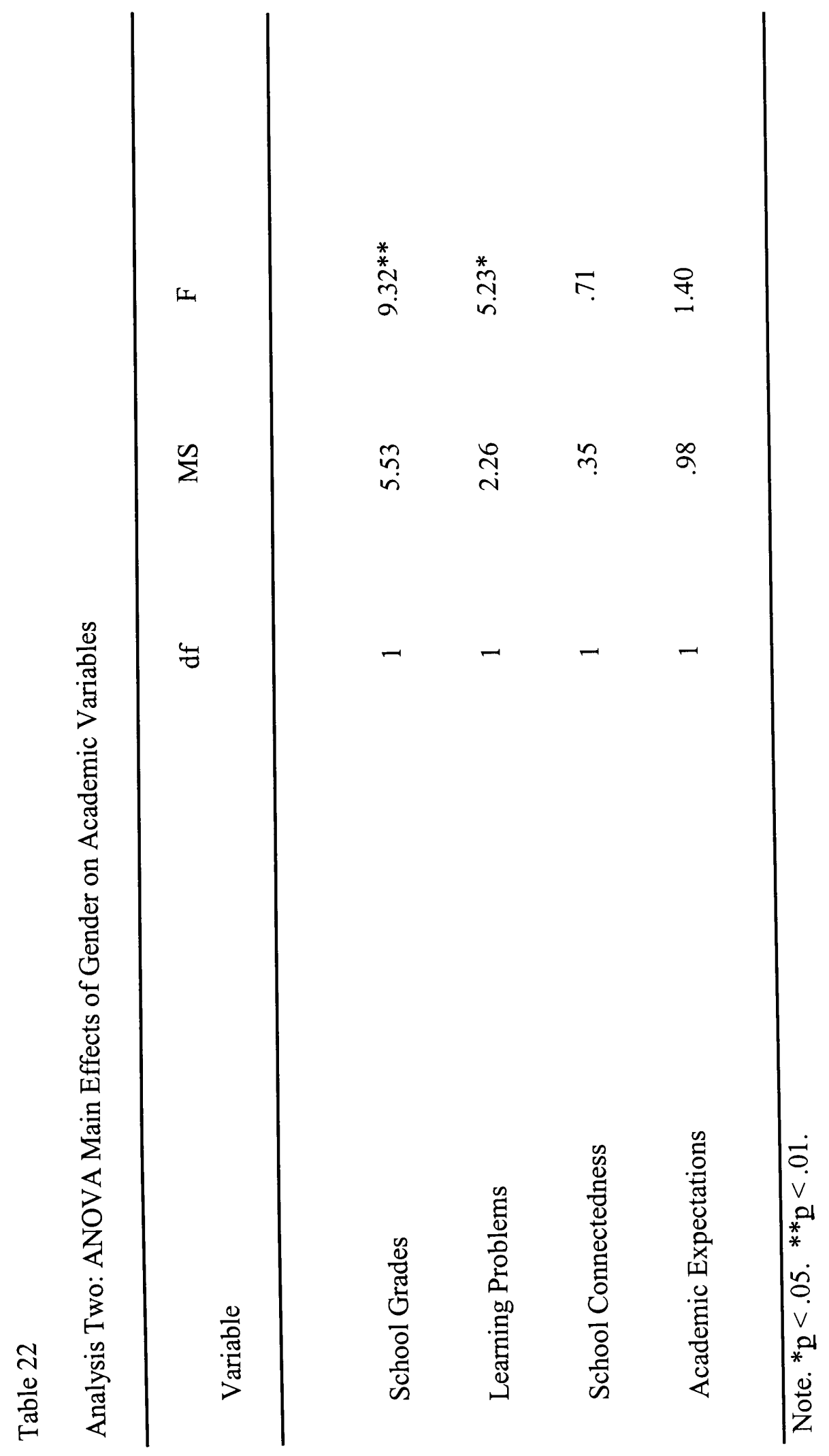

I 


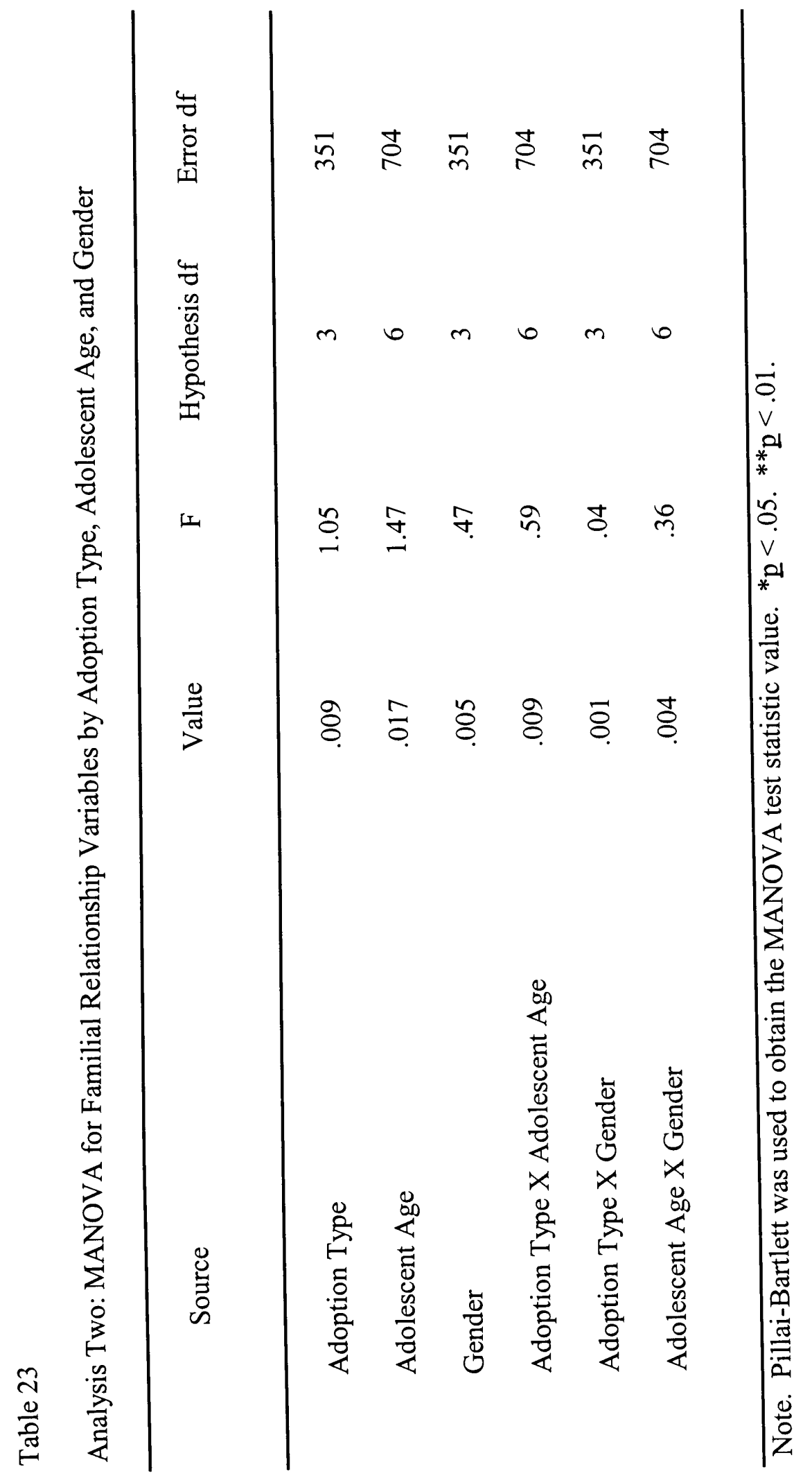




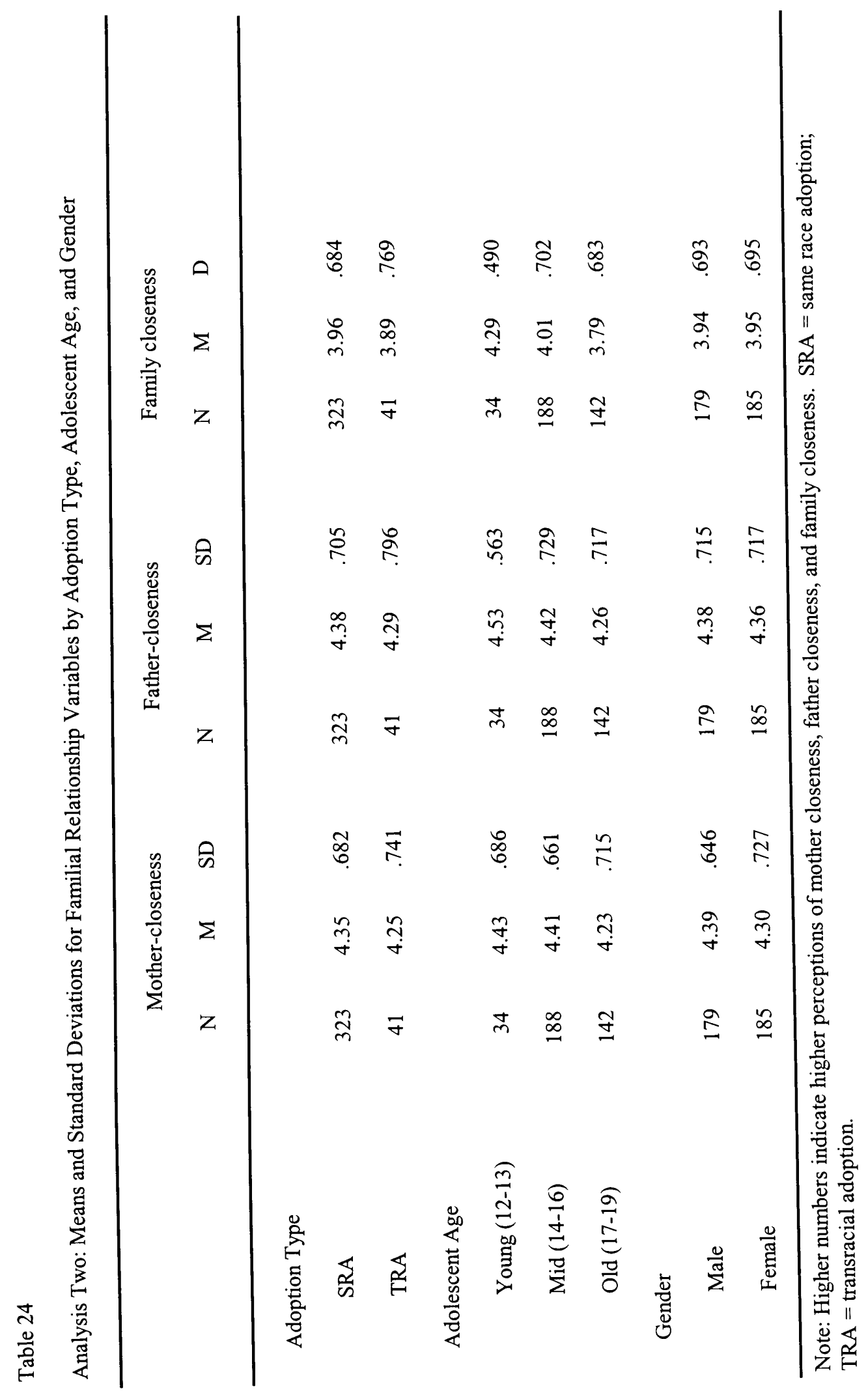




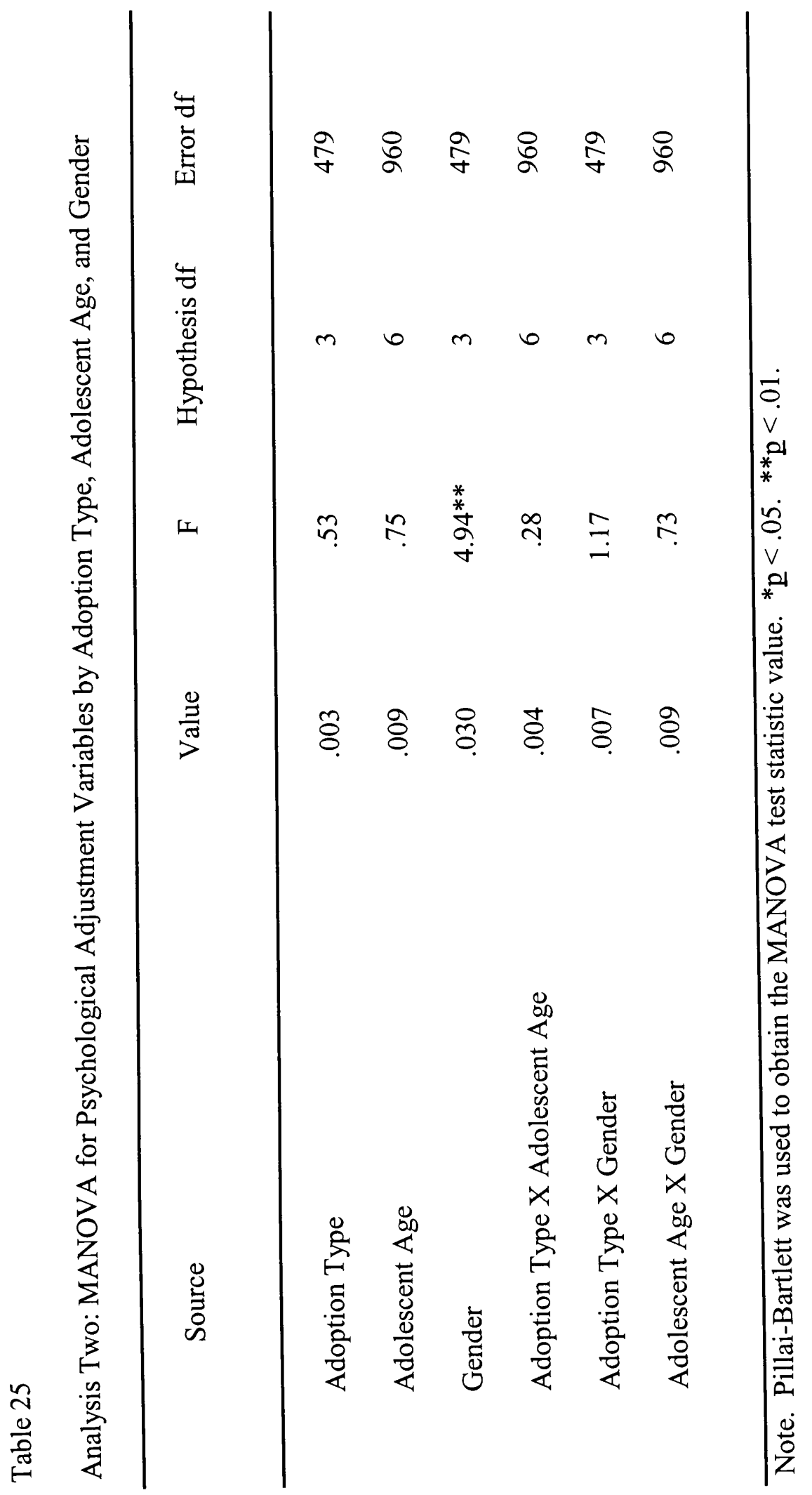

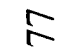




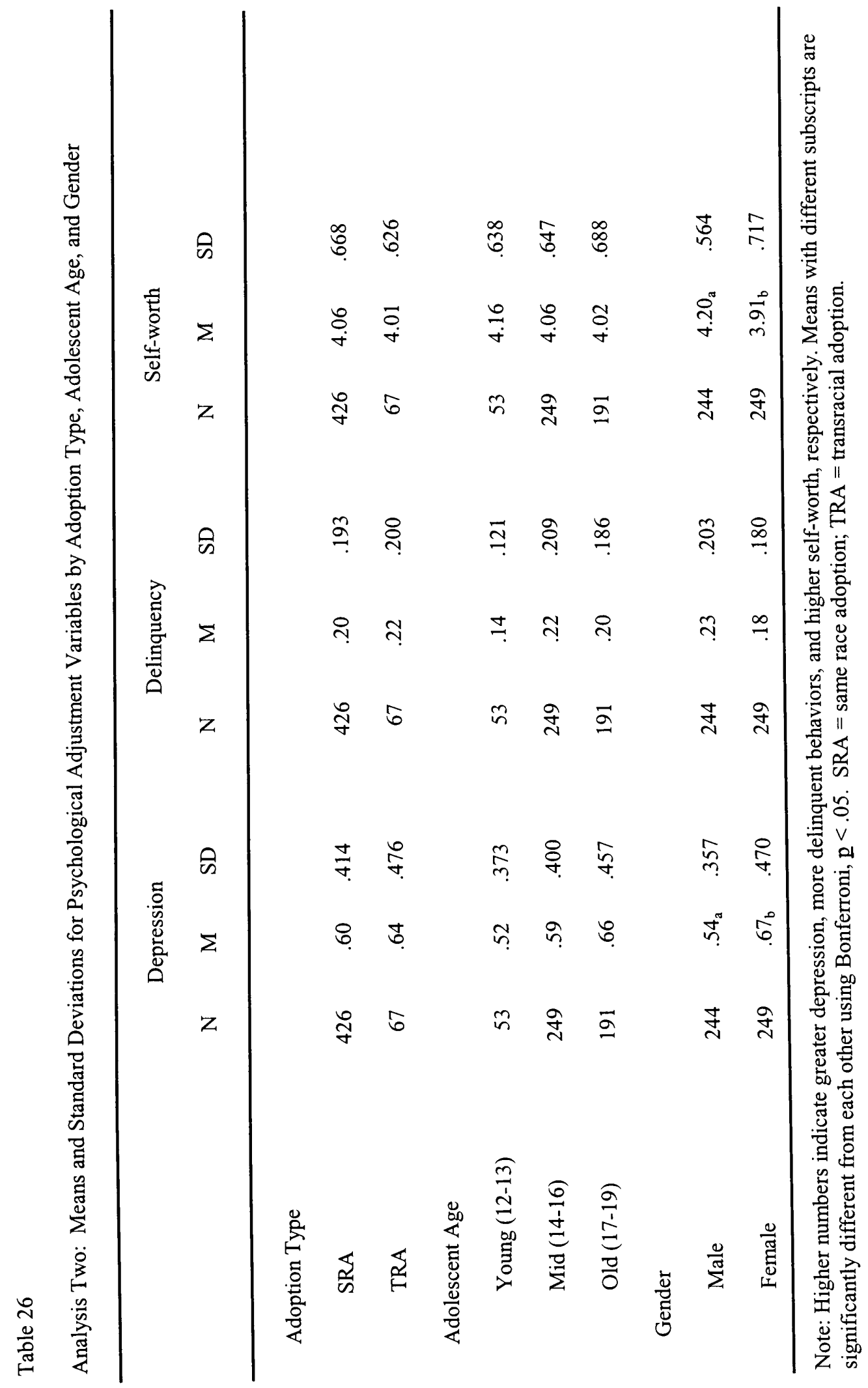




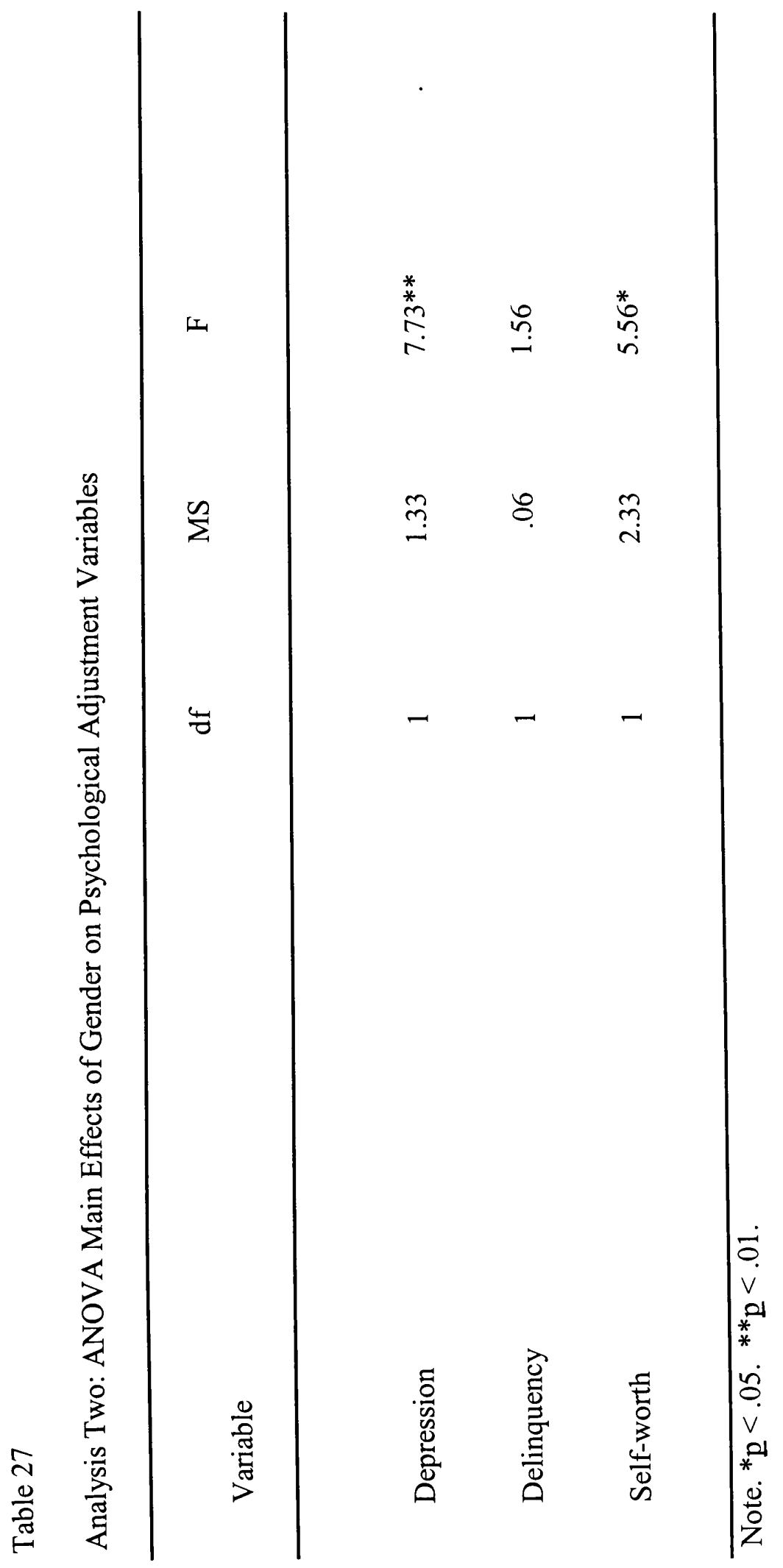

2 


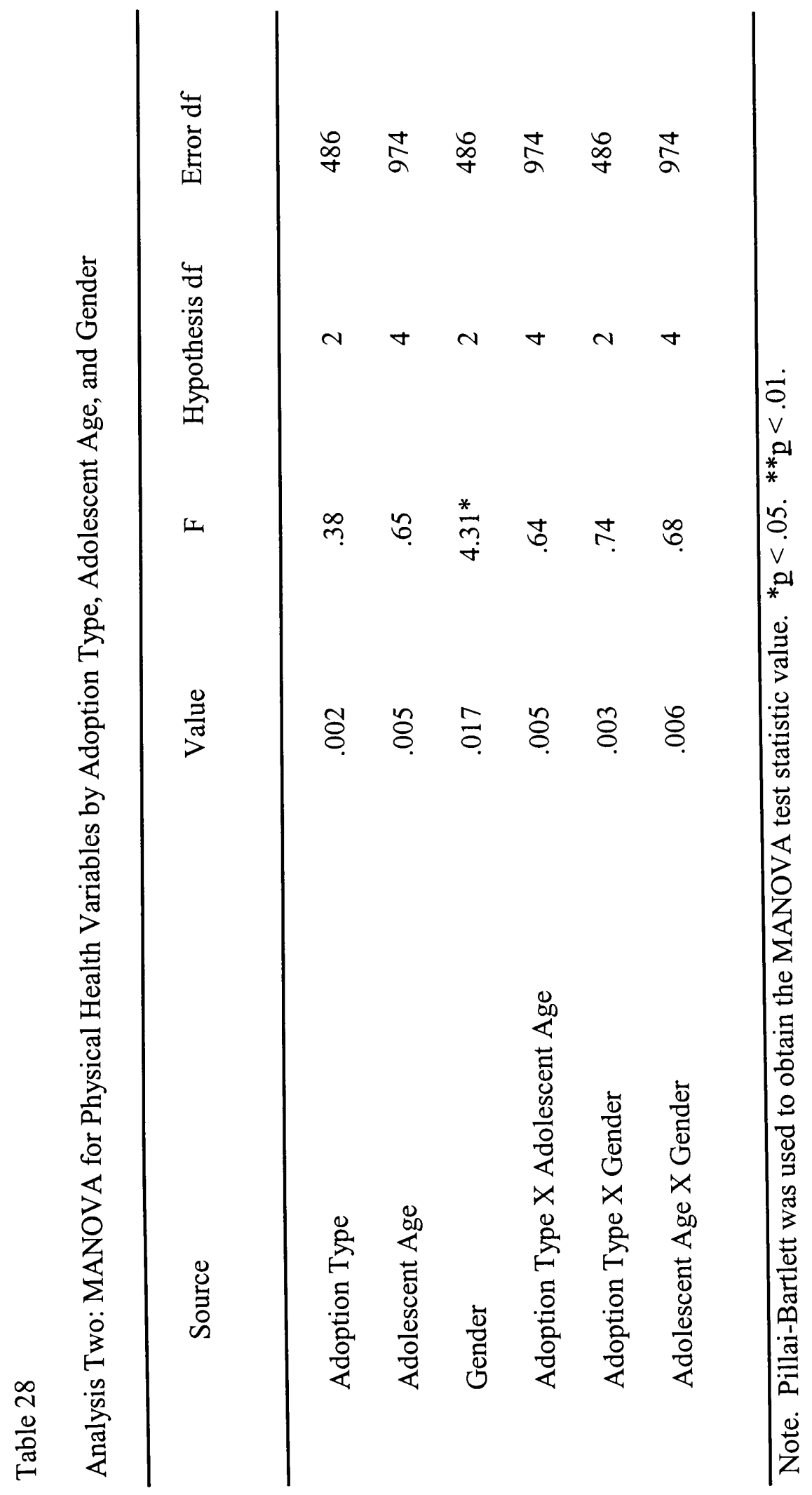




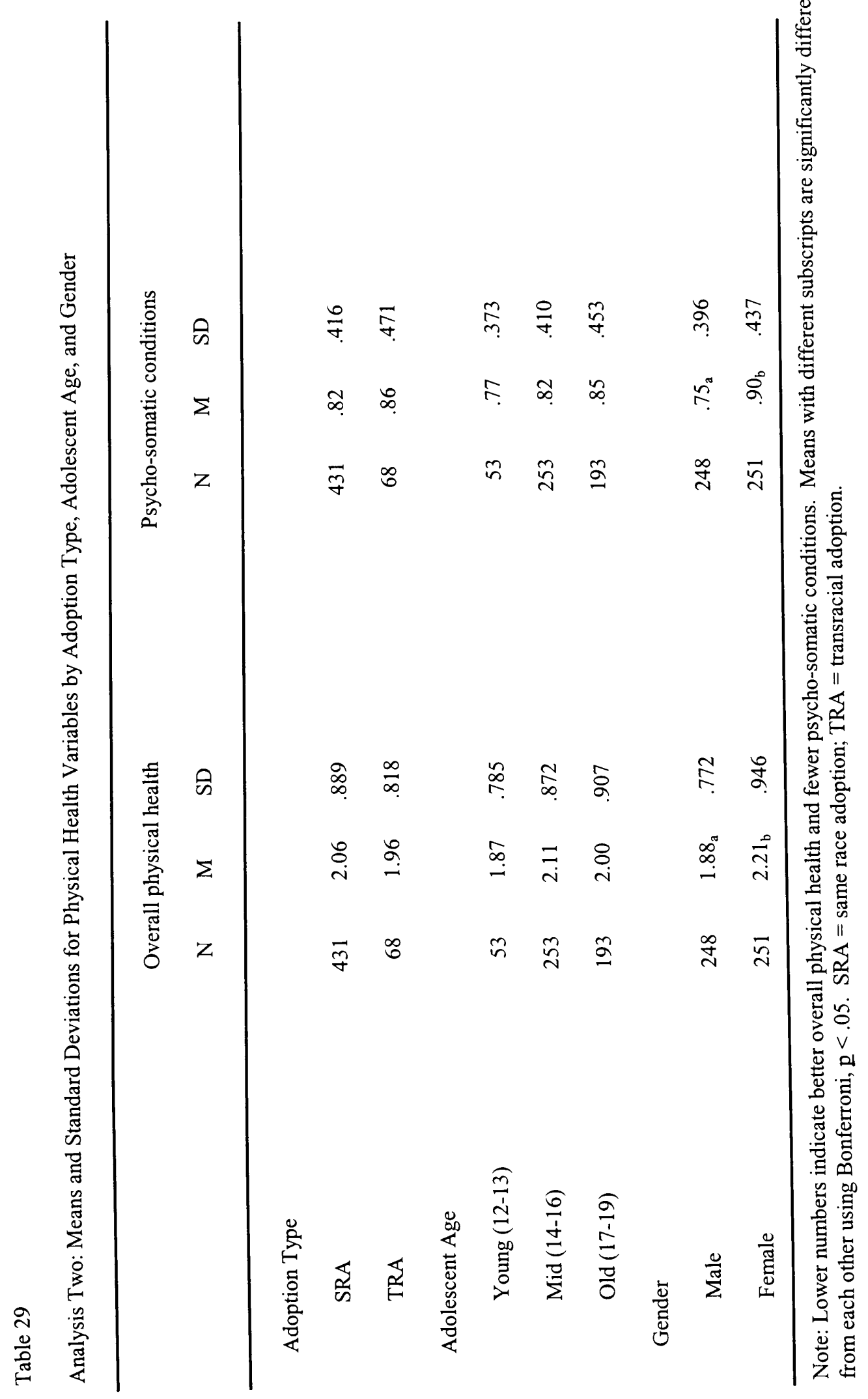




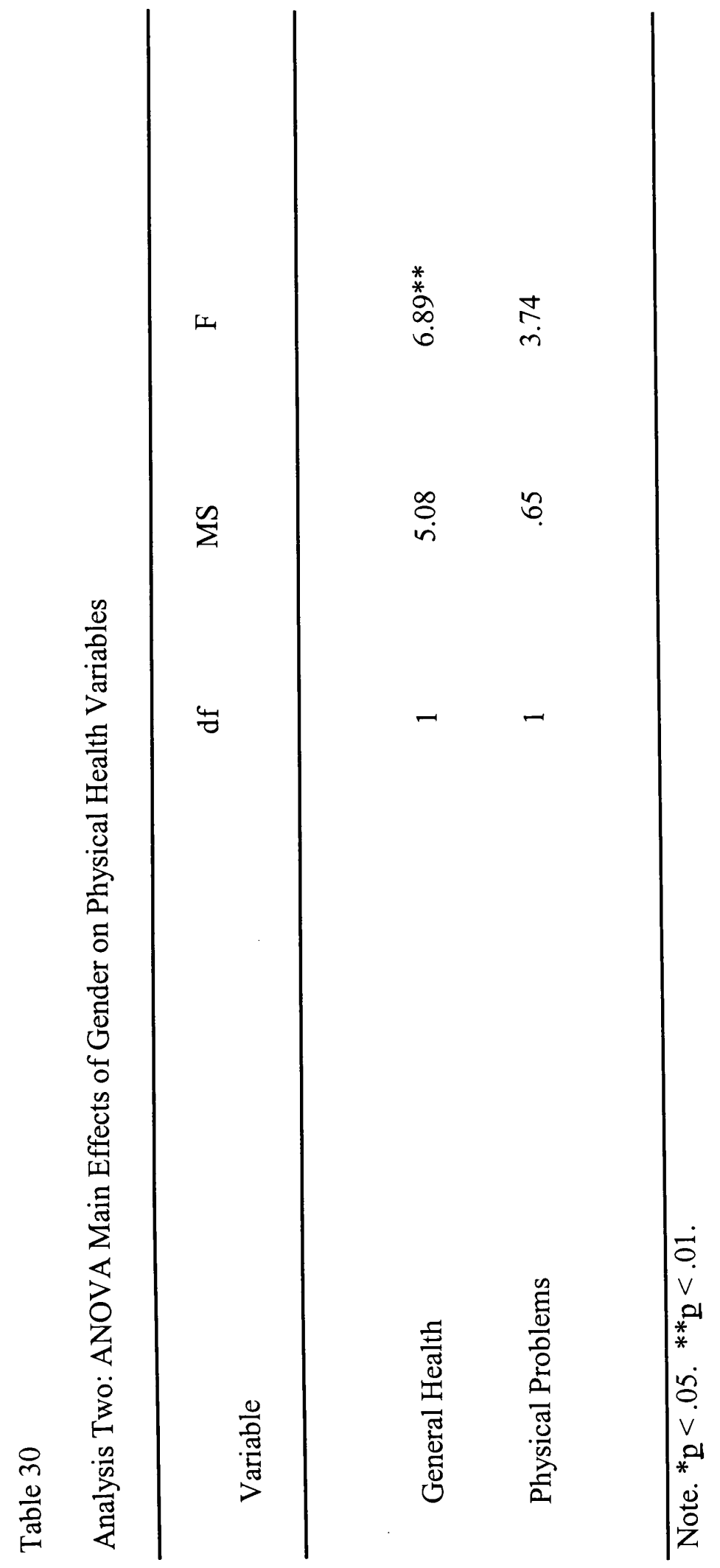

$\infty$ 


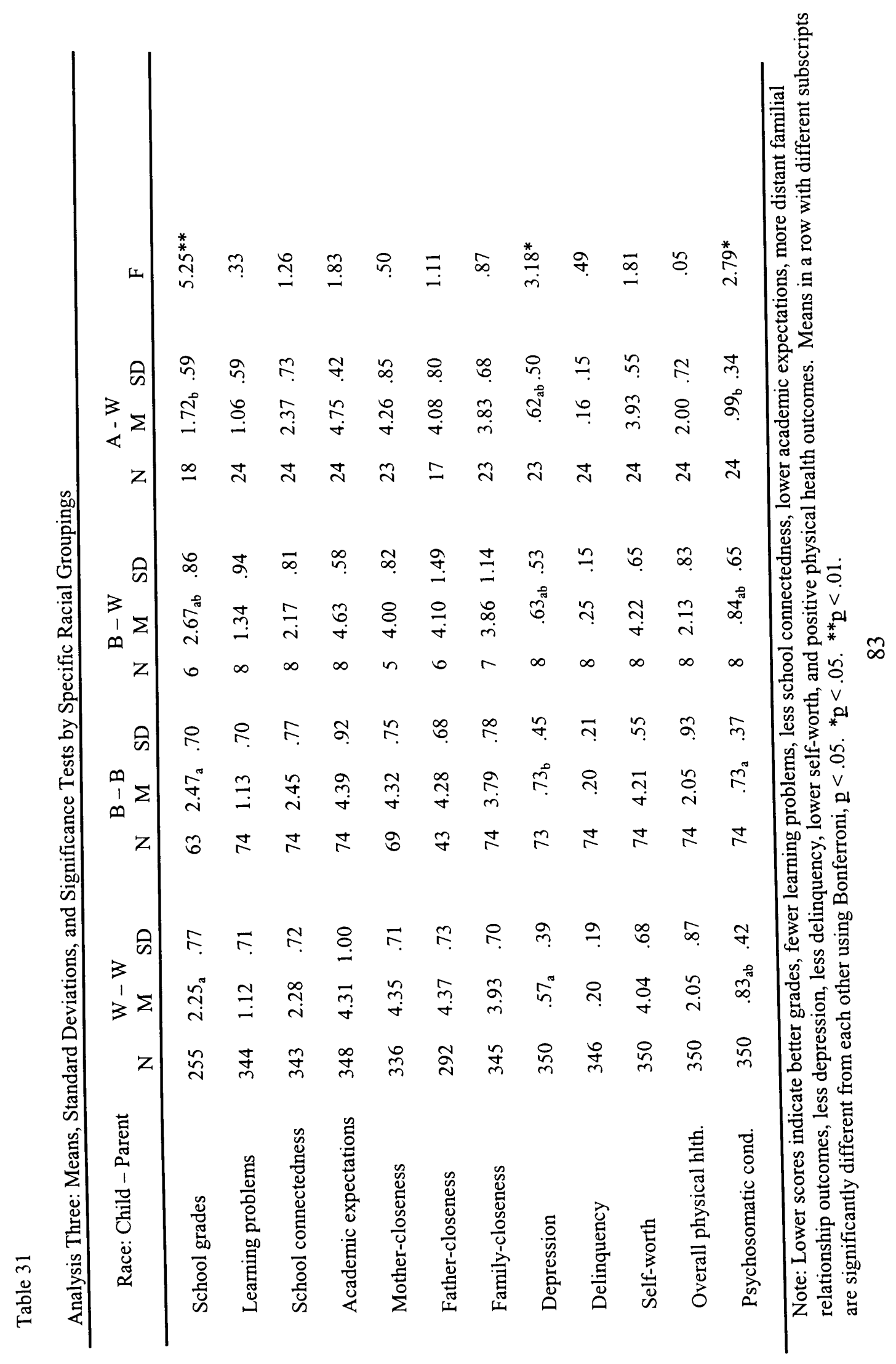




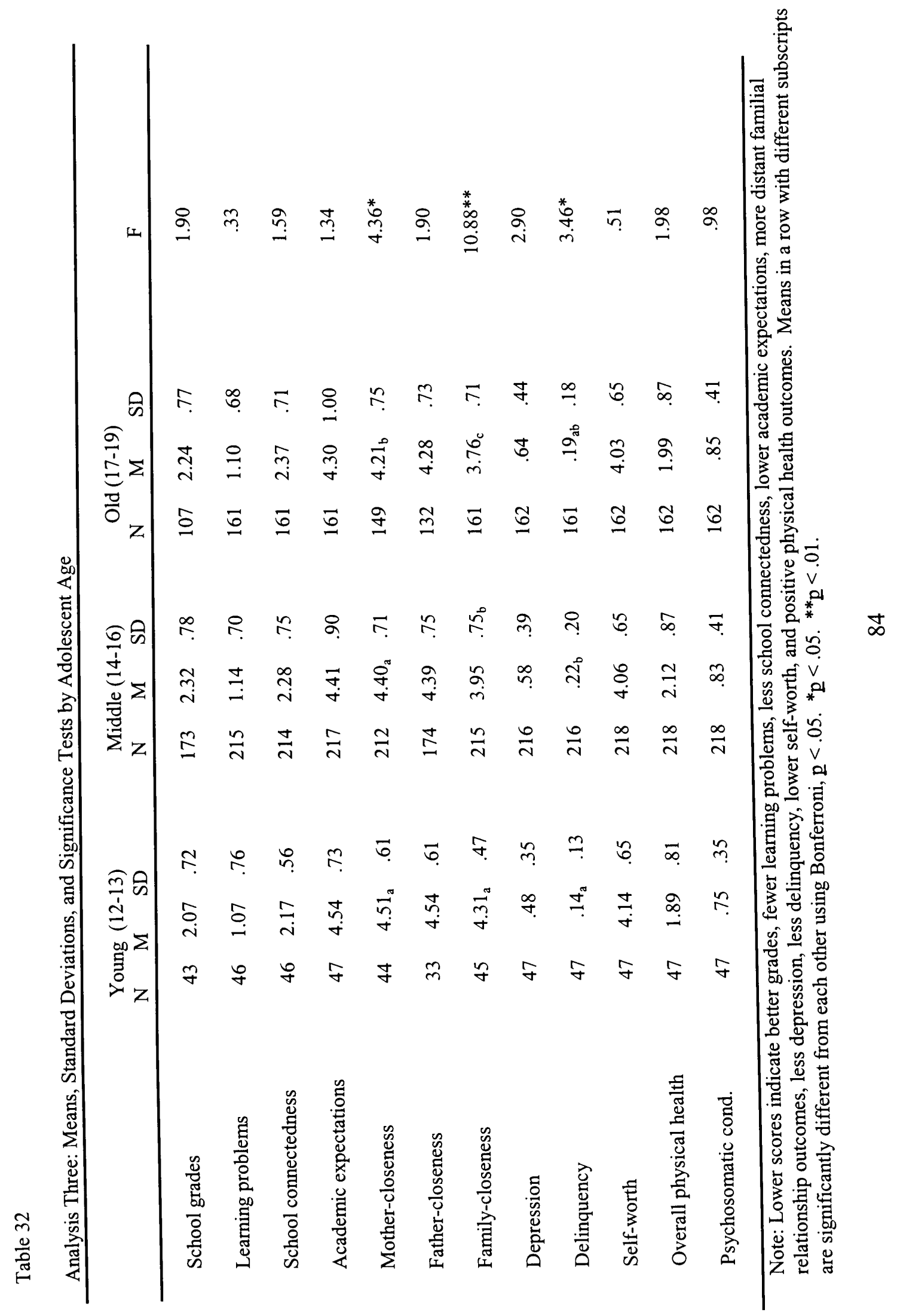




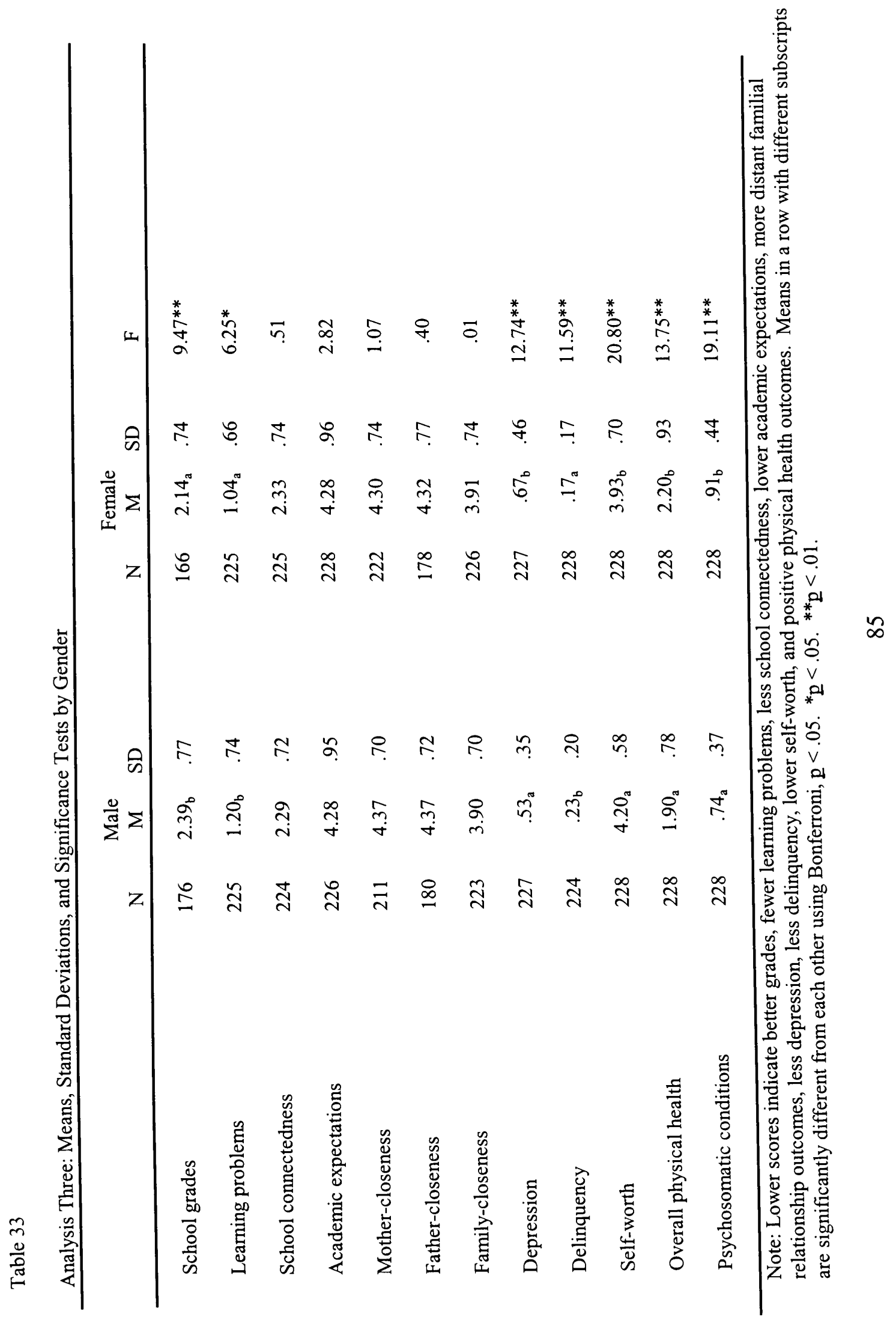




\section{Chapter V Discussion}

\section{Summary of Results}

This study was both consistent with and added to the existing body of research on adoption. Three levels of analyses were conducted in this study to evaluate the implications of 1) adoption status, 2) adoption type, and 3) specific adoptive child-parent racial groupings upon adolescent outcome. The findings are particularly significant because they focus exclusively on adolescence, a developmental period that has gone understudied in previous adoption studies. Taken together, the three analyses illustrate the need to consider various domains of adjustment when comprehensively assessing development, as unique patters of influences were found across the different domains of adjustment were investigated. This study clearly suggests that investigating associations between adoption statuses, adoption types, age, and gender within adolescence requires comprehensive perspectives that consider the whole child.

The research area in which the present study has the most potential to contribute to is that of transracial adoption. The three levels of analysis utilized by this study allow for direct and indirect comparisons of transracial adoptees to same-race adoptees and non-adopted adolescents. Also, the investigations undertaken in Analysis Three provide insight into associations between specific subtypes of transracial adoption and same-race adoption. In addition, while the findings derived from the assessments of adolescent age and gender mainly resonate with the existing literature, they place the adoption investigations into meaningful perspectives.

The major hypothesis of this study that transracial adoption type would interact with adolescent age across the selected adjustment domains was not supported. 
Basically, very few differences were detected between transracially adopted and samerace adopted adolescents across the adolescent ages investigated. Moreover, although there were some comparative differences associated with age, they did not interact with adoption type. Accordingly, based upon the measures used in this study these findings suggest that alone, racial differences between adoptive parents and their children are not associated with maladaptive adjustment across adolescent ages.

In Analysis One, evaluations between adopted and non-adopted adolescents (i.e., by adoption status) delineated some significant differences favoring non-adopted adolescents. However, the consistency of greater maladjustment for adoptees was not shown to be uniform across the investigated adjustment domains. The MANOVAs indicated that being adopted was associated with significantly worse academic performance and familial relationships, however, it had no significant influence upon psychological adjustment or physical health. In addition, MANOVA analyses illustrated that adolescent age was associated with significant differences in several measures of adjustment. Specifically, 12-13 year-olds faired better than 14-16 year-olds, who often times faired better than 17-19 year-olds. Based on these findings, it is clear that progress through adolescence is consistently associated with increasingly worse academic performance, more distant familial relationships, and poorer psychological adjustment.

Furthermore, in Analysis One, MANOVAs illustrated that gender influenced outcomes across each of the four investigated adjustment domains. Specifically, females were shown to have better academic performance and less delinquency than males. However, males were shown to have more positive familial relationships, less depression and higher self-worth, and better physical health than females. Also in this analysis, age 
and gender were found to interact significantly. In this interaction, young adolescent females were shown to differ from middle and old adolescent females on some measures of academic performance. In contrast, young adolescent males were not significantly different than males in middle or old adolescence on any academic variables.

In Analysis Two significant differences between adolescent transracial adoptees and same-race adoptees (i.e., by adoption type) were not found. Moreover, the results of this study indicated that differences in adoption type were not associated with different academic, familial relationship, psychological adjustment, or physical health outcomes for adolescents. Likewise, evaluations among the adolescent age group also failed to identify significant differences. However, within this analysis, gender differences were shown to be associated with some of the adjustment outcomes. Specifically, MANOVAs indicated differences between males and females on measures of academic performance, psychological adjustment, and physical health, but not for familial relationships.

Using smaller samples of adoptees in Analysis Three, significant differences were found within three areas: specific racial groupings of parents and children, adolescent age, and gender. First, significant differences were found among the specific racial groupings on measures of academic performance and psychological adjustment. Second, for the different age groups, significant differences were found on measures of familial relationships and psychological adjustment, such that younger adolescents were shown to fair better than older adolescents. Third, comparisons by gender within this analysis found that females performed better academically, but were worse off both psychologically and physically. 
Synthesis of Literature Review and Results

\section{Analysis One: Adoption as a risk factor}

Adoption Status within Analysis One. As illustrated in the literature review of this study, whether or not adoption is a risk factor for adolescent's developmental outcomes is debated in the existing literature. It is important to note, as many previous studies have used enrollment in psychological clinics as a measure of psychopathology, some researchers have perhaps erroneously assumed that the elevated enrollment rates for adoptees compared to non-adoptees implies more maladjustment. However, Warren (1992) characterized the danger in this assumption by suggesting that the use of clinical samples may reflect referral biases on behalf of adoptive parents, and not any inherent psychopathology of the adopted individuals. To this end, the use of a non-clinical sample in this study eliminated the possibility of parental referral biases and assumptions of existing psychopathology.

To some degree, support for the maladjustment of adoptees was found in the present study. Moreover, other investigations of the development of adolescents by adoption status indicated some significant differences in the areas of academic performance and familial relationships. To be specific, adopted adolescents had significantly worse grades and greater learning problems than non-adopted adolescents. Findings in the current study related to academic performance are consistent with previous literature. Sharma, McGue, and Benson (1998) using a sample of 715 families (a comparable size to the current study) detected similar results. Comparing adoptees to non-adoptees, these researchers found that adopted children demonstrated more school adjustment problems than their non-adopted counterparts. 
Also, within the current study, non-adopted adolescents reported significantly more closeness with their relationships with their mothers than adopted adolescents did. This resonates with previous studies which concluded that some adopted children may feel less attached to their parents than non-adopted children, thereby compromising positive familial relationships and closeness (Yarrow \& Goodwin, 1973; Yarrow, Goodwin, Manheimer, \& Milowe, 1973). Despite this finding of perceptions of lower mother-closeness, however and importantly, the present study found no differences between adoptees and non-adoptees on perceptions of father closeness or overall familial closeness. The failure to find significant differences between perceptions of fathercloseness between the two groups may be explained by findings suggesting that adoptive fathers are more involved with their children's lives than are biological fathers (Finley, $1999 a, b)$

There are some discrepancies however, between the existing literature and the findings of the current study with regard to the implications of adoption status. The current study failed to find any significant group differences in psychological adjustment or physical health between adoptees and non-adoptees. Such discrepancies may be explained by the current study's use of a large, non-clinical sample of adolescents, wherein many previous studies that found significant differences used small, clinically referred samples of pre-adolescent children. Indeed, such differences in research methods have been postulated as potentially leading to different findings with respect to adoptee outcome (Park \& Green, 2000; Courtney, 1997). Accordingly, some researchers contend that determining whether or not adoption in general is a risk factor is less meaningful than identifying the specific conditions that are associated with 
maladjustment for adoptee development (Brodzinsky, Smith, \& Brodzinsky, 1998; Finley, 1998).

Adolescent age within Analysis One. The findings concerned with adolescent age were, for the most part, consistent with existing literature. The younger adolescents clearly manifested better outcomes than older adolescents. In particular, adolescents in the younger group consistently reported better adjustment across academic, familial relationships, and psychological domains than their older counterparts. This trend was best illustrated within the familial relationship realm, wherein each adolescent age group uniformly differed from each other, where 12-13 year-olds reported the most positive familial relationships, followed by 14-16 year-olds, and the 17-19 year-olds who reported the least positive familial relationships. This pattern continued with the psychological adjustment measures of depression, delinquency, and self-worth. In addition, the young adolescents reported the best school grades and school connectedness, compared to older adolescents. This is one of the most consistent patterns in the present results.

Some scholars have explained that because searching for autonomy is a primary developmental task during adolescence, academic performance, relationships with family members, and adaptive psychological adjustment often suffer during this period (Corbett \& Pertersilia, 1994). Furthermore, as transitions models of adolescent development assert, individuals progressing through adolescence are constantly maneuvering between important biological, psychological, and physical contexts that can disrupt adjustment (Graber \& Brooks-Gunn, 1996). Since the current study includes individuals ranging in age across adolescence, transitions such as moving from middle school to high school and encountering new sets of friends are likely captured by the different age groups in the 
current investigation. Therefore, significant differences in maladjustment are not surprising with respect to adolescent age differences.

Gender within Analysis One. Generally consistent with previous literature, significant differences by gender were found for all four measures of adolescent adjustment in Analysis One. Within the academic domain, females performed better than males. They had higher grades, fewer learning problems, and higher academic expectations. This finding was expected as common findings in gender research point towards females performing better than males academically (e.g., Pomerantz et. al., 2002). However, for familial relationships, males were shown to have more positive relationships with their mothers than did females.

Significant gender differences were also found for psychological adjustment as males significantly reported less depression and better self-worth than females. In contrast, females had fewer instances of delinquency than males. For physical health measures, males reported better overall health and fewer psychosomatic conditions than females. To explain such results, social interest in physical activity investigated in previous studies has been shown to reveal gender differences. For instance, researchers have found greater interest by males to participate in athletic activity and physical health classes in school than by females (Mandingo et. al., 1999).

Furthermore, within this analysis, adolescent age was found to interact with gender for two of the academic variables. For females, young adolescence is associated with fewer learning problems and better school connectedness. However, this trend was not supported for males, as levels of these variables did not differ across adolescent age groups for males. One possible explanation for this finding might be that early academic 
expectations are much higher for females than they are for males. However, as females progress through adolescence, their academic performance grows significantly worse as they age, although oftentimes still outperforming males.

\section{Analysis Two: Transracial Adoption as an additional risk factor}

Adoption Type within Analysis Two. As adoption has been shown to be a possible risk factor for adolescent development, other factors may exacerbate risk for adverse outcomes among adoptees. As widely speculated by existing literature, one such possible risk factor is racial differences between parent and child (i.e., transracial adoption). The prevailing controversy concerning transracial adoption is no doubt fueled by domainspecific debates of adaptive development. In other words, biases in the selection of dependent outcomes enables constituents of both sides of the controversy to strengthen their argument by demonstrating differences in outcomes of particular variables at the exclusion of others. Therefore, the current study's multi-domain investigation allows for more comprehensive interpretation of adjustment of transracial adoptees than has been offered in the past.

Based upon the findings of the present study, transracial adoption was not shown to be a significant risk factor for adverse developmental outcomes. Stated differently, the results of this analysis failed to indicate significant differences between transracially adopted adolescents and same-race adopted adolescents across measures of academics, familial relationships, psychological adjustment, and physical health. Accordingly, the results manifested by the current study can be interpreted in several ways. For instance, perhaps racial differences between adoptees and their parents are inconsequential and do not promote additional risk factors with regards to adaptive development. Another 
possible explanation may be that any risk factors that are associated with transracial adoption do not express themselves in the period of adolescence. In any case, the evidence detected in this study mitigates strong rhetorical opposition to the practice of placing adopted children across racial lines. Due to the nature of the transracial adoption debate in our society, findings of studies either supporting or refuting its validity are equally important. Thus, consideration of various explanations of particular findings from these studies is critical, as they are likely to have strong implications for social policy, child-placement institutions, and academic research.

Adolescent Age within Analysis Two. Within this analysis of adoption type, no significant differences were found between the selected adolescent age groups across any measure of adolescent adjustment. Stated differently, the 12-13 year-olds, 14-16 yearolds, and the 17-19 year-olds were not found to significantly differ on measures of academic performance, familial relationships, psychological adjustment, or physical health. This finding differs from the results comparing adolescent ages in Analysis One. However, there are a number of explanations for not finding significant differences between the age groups in Analysis Two. One explanation might be methodological, insofar that the smaller sample sizes used in this analysis compared to Analysis One, resulted in less statistical power. Alternatively, as all of the adolescents included in this analysis were adopted, another possible explanation might point towards more uniform life experiences manifested by different types of adopted adolescents.

Gender within Analysis Two. Despite finding no significant differences by adoption type and adolescent age in this analysis, gender was associated with a number of differences in adolescent adjustment. Moreover, the results of this analysis suggest that academic 
performance, psychological adjustment, and physical health are all influenced by gender. Specifically, females received better grades and manifested fewer learning problems than males. Males reported more delinquency than females, yet reported depression less often and had higher self-worth. In addition, males had better overall physical health, as well as fewer psychosomatic conditions than females. Again, these findings parallel existing literature on gender differences in adolescent development.

\section{Analysis Three: Exploratory Investigations of Adopted Adolescents}

As noted above, the exploratory investigations in Analysis Three likely have the most to contribute to adoption literature. The sample of adoptees used in this analysis allowed for evaluation of implications of specific racial groupings, adolescent ages, and gender upon measures of adjustment. However, the small sample sizes utilized in this analysis deem the findings exploratory.

Specific Racial Groupings within Analysis Three. When examining specific racial groupings, the current study found that transracial adoptees, at a minimum, fair as well as their same-race adopted counterparts across various measures of adjustment; and in some instances they fair better. However, there were some differences detected between the specific racial groupings that are noteworthy. Specifically, the results for school grades show that Asian children adopted by white parents received higher grades in school than same-race adopted white and black children. Correspondingly, near significant findings suggest a corresponding trend insofar that Asian children adopted by white parents reported the highest levels of academic expectations. These findings may suggest a racial or cultural bias held by white adoptive parents that Asian children are inherently academically inclined, and therefore reinforce such values upon their children; while this 
is not done by white parents of non-Asian children. An alternative explanation of the higher grades received by Asian children may be due to genetic disposition. To qualify these findings though, measures of physical health revealed that Asian children adopted by white parents reported the greatest number of psychosomatic problems, significantly more than the other racial groupings. Perhaps, success in the areas in which Asian children adopted by white parents are flourishing comes at the expense of the physical health.

The most striking finding was that within measures of psychological adjustment, comparisons for depression showed that black children adopted by black families reported significantly more depression than white children adopted by white parents. By contrast, the near significant findings with respect to psychological adjustment showed that black children adopted by either black or white parents had the highest levels of selfworth compared to both white and Asian children adopted by white parents. As depression and self-worth are associated with internalized psychological functioning, further research on emotional development of adoptees is needed to better understand these contradictory findings.

Adolescent Age and Gender within Analysis Three. The findings for adolescent age and gender investigated in Analysis Three matched the patterns described in Analysis Two for these variables. The implications of adolescent age and gender upon the small sample of adoptees utilized in this analysis parallel the existing body of literature on these respective domains as mentioned above. 


\section{$\underline{\text { Limitations }}$}

Due to the nature of secondary analyses, the current research was unable to address questions that were not included in the original questionnaire design. Therefore, further analyses of interesting findings were not possible. For instance, follow-up investigations of sample members could not identify descriptive details such as special needs adoptions or individuals' age at time of adoption. Such level of detail might have helped to better characterize the implications of adoption status and adoption type on adolescent adjustment. Furthermore, the aim of this study was to investigate adolescent adjustment outcomes. Due to this aim, however, only speculation can be drawn about implications for pre-adolescent or adult individuals. The generalizability of this study may be limited to the adolescent period.

In addition, the present study only investigated academic, familial, psychological, and physical domains of adjustment. While these domains reflect the most prevalent in adoption research, they are not exhaustive. In addition to these, other plausible domains of investigation might include racial or cultural identity formation, peer relationships, substance abuse, and sexual activity. In the absence of many of these other areas of investigation, the present study cannot claim to completely describe the adjustment of adolescent adoptees.

Furthermore, key comparisons examined in the current study utilized small sample sizes, which may limit the external reliability of the present results. While still providing an opportunity for investigation, such small sample sizes reduced the statistical power to detect reliable group differences. In this way, the insights drawn from the exploratory investigations undertaken in Analysis Three, may only suggest trends that 
require replication from additional studies using larger samples. Also due to sample size limitations, no three-way interactions were investigated in Analysis One or Analysis Two. Accordingly, the present study was unable to detect any adoption by adolescent age by gender interactions for adolescent development.

\section{Directions for Future Research}

In light of the limitations of this study, there are several suggestions for future research. First, a whole-child approach may provide the most meaningful illustration of developmental outcomes for adopted adolescents. In other words, investigating multiple domains relevant to adolescent adjustment works towards uncovering different patterns of adoptee adjustment. As demonstrated by the current results, comparisons between same-race adoptions and transracial adoptions can be meaningfully understood in terms of identifying the conditions under which adoption can influence adjustment in substantial ways. This promotes the inclusive assessment of holistic development. In this way, perhaps the whole-child approach to mapping developmental outcomes may work to clarify key debates in the transracial adoption literature.

To this end, additional domains need to be considered in future studies to promote the more comprehensive measurement of adjustment. For instance, along with the domains utilized by this study, future research might include aspects of peer relationships, substance abuse, and sexual activity to better account for unique patterns of adoptee adjustment. Also, measurement of family form (i.e., living with two parents, parental divorce, living with biological or adopted siblings, etc.) and socio-economic status information may work to better characterize selected samples. Along these lines, specific adolescent ages and gender should be included within any comprehensive 
investigation of adoptee adjustment. As they were shown to have significant relations with adjustment, the current study supports their consideration in future studies. In addition, incorporation of Afri-centric dependent variables and instrumentation would work to provide insight into potential limitations of current models of development, and the instruments used to measure the development of adopted black children.

Also, especially in the area of adoption research, longitudinal investigations of adjustment would contribute greatly to current knowledge. Perhaps by focusing on progress through adolescence, insight could be gained as to group differences in developmental processes associated with adoption. Once group differences in developmental processes have been delineated, specific risk and protective factors can be identified. Correspondingly, potential prevention methods can be devised to counter maladjustment, and promote more adaptive development for adopted individuals. 


\section{List of References}

Berndt, T. J. \& Keefe, K. (1992). Friends' influence adolescents' perceptions of themselves at school. In D. H. Schunk and J. L. Meece, Eds. Student Perceptions in the Classroom (pp. 51-68). Hillsdale, NJ, Lawrence Erlbaum.

Bohman M., \& Sigvardsson, S. (1980). A prospective, longitudinal study of children registered for adoption: a 15-year follow-up. Acta. Psychiatr. Scand. 61, 339-355.

Bohman, M. \& Sigvardsson, S. (1990). Outcome in adoption: Lessons from longitudinal studies. In D. Brodzinsky \& M. Schechter, (Eds.), The psychology of adoption, NY: Oxford University Press.

Brodzinsky, D (1990): A stress and coping model of adoption adjustment. I: Brodzinsky (Ed): The Psychology of Adoption. New York: Oxford University Press.

Brodzinsky, D. .M. (1993). Long-term outcomes in adoption. In R. E. Behrman (Ed.) The future of Children: Adoption (pp. 153-166). Los Altos, CA: Center for the Future of Children, The Packard Foundation.

Brodzinsky, D. M, \& Brodzinsky, A. B. (1992). The impact of family structure on the adjustment of adopted children. Child Welfare, 71, 69-75.

Brodzinsky, D., Lang, R. \& Smith, D. (1995). Parenting adopted children. En M.H. Bornstein (ed.): Handbook of parenting, 3. New Jersey: Lawrence Erlbaum Associates, Inc.

Brodzinsky, D. M., Smith, D. W., \& Brodzinsky, A. B. (1998). Children's Adjustment to Adoption. Developmental and Clinical Issues. Developmental Clinical Psychology and Psychiatry, 38, 10-20.

Brooks, D., \& Barth, R. P. (1999). ADULT TRANSRACIAL AND INRACIAL ADOPTEES: Effects of Race, Gender, Adoptive Family Structure, and Placement History on Adjustment Outcomes. American Journal of Orthopsychiatry, 69 (1), 87-99.

Burrow, A. L., \& Finley, G. E. (2001). Issues in Transracial Adoption and Foster Care. Adoption Quarterly, 5, (2), 1-4.

Caspi, A., \& T. E. Moffitt. (1991). Individual Differences are Accentuated during Periods of Social Change: The Sample Case of Girls at Puberty. Journal of Personality and Social Psychology, 61, 157-68.

Chestang, L. (1972). The dilemma of bi-racial adoption. Social Work, 17, 100-105. 
Chimezie, A. (1975). Transracial adoption of black children. Social Work, 20, 296-301.

Cohen, J.S. \& Westhues, A. (1995). A Comparison of Self-esteem, School Achievement and Friends Between Intercountry Adoptees and their Siblings. Early Child Development and Care, 1, (1), 205-224.

Corbett, R.P. \& Petersilia, J. (1994). What works with juvenile offenders: A synthesis of the literature and experience. Federal Probation, 58, (4), 63-67.

Courtney, M. E. (1997). The Politics and Realities of Transracial Adoption. Child Welfare, $56(6), 749-779$.

Curtis, C. M. (1996). The Adoption of African American Children by Whites: A Renewed Conflict. Families in Society: The Journal of Contemporary Human Services, 156-163.

Feigelman, W. (2000). Adjustments of Transracially and Inracially Adopted Children. Journal of Child and Adolescent Social Work, 17, (3), 165-184.

Feigelman, W. \& Silverman, A. (1984). The Long-Term Effects of Transracial Adoption. Social Service Review, 588-602.

Fergusson, D. M., \& Lynskey, M. T. (1996). Adolescent resiliency to family adversity. Journal of Child Psychology and Psychiatry and Allied Disciplines 37, (3), 281292.

Finley, G. E. (2002). The best interest of the child and the eye of the beholder. [Review of C. Panter-Brick \& M.T. Smith (Eds.) Human ecology: An encyclopedia of children, families, communities, and environments]. Santa Barbara: AMC-Clio.

Finley, G. E. (2000). Adoptive families: Dramatic changes across generations. National Council on Family Relations Report, 45 (2), F10-F12. [Special section on "Visions for families: Continuity and change across cohorts and generations."]

Finley, G. E. (1999a). Adoptive and Biological Fathers' Enjoyment of First-time Fathering. National Council on Family Relations.

Finley, G. E. (1999b). Unheard Voices: Adoptive Fathers on the Adoption Process and Adoptive Fatherhood. International Conference on Adoption Research.

Finley, G. E. (1999c). Children of adoptive families. In W.K. Silverman \& T.H. Ollendick (Eds.). Developmental issues in the clinical treatment of children and adolescents. (pp. 358-370) Boston: Allyn and Bacon. 
Finley, G. E. (1998). On individual difference, choice, selection, and complexity in adoption research. Adoption Quarterly, 1 (4), 83-91.

Graber, J.A., \& Brooks-Gunn, J. (1996). Growing up female: Navigating body image, eating, and depression. Journal of Emotional and Behavioral Problems, $\underline{5}$, (2), 7680 .

Griffith, E. E. (1995). Forensic and Policy Implications of the Transracial Adoption Debate. Bull Am Acad Psychiatry Law, 24 (4), 501-512.

Grow, L. J., \& Shapiro, D. (1974). Black children-white parents. New York: Child Welfare League of America.

Hayes, P. (1993). Transracial adoption: Politics and ideology. Child Welfare, 72, 301310.

Hollingsworth, L. D. (1998). Promoting Same-Race Adoption for Children of Color. Social Work, $43(2), 104-116$.

Hollingsworth, L. D. (1997). Effect of Transracial/Transethnic Adoption on Children's Racial and Ethnic Identity and Self-Esteem: A Meta-Analytic Review.

Families and Adoption, 25 (1/2), 99-130.

Hollingsworth, L. D. (1996). An Africentric Perspective for the Teaching and Practice of Family Science. Family Science Review, 9 (1), 35-48.

Horner, T., \& Rosenberg, E. (1991). Birthparent Romances and Identity Formation in Adopted Children. American Journal of Orthopsychiatry, 61(1), 70-77.

Howe, D. (1997) Parent-reported problems in 211 adopted children: some risk and protective factors. Journal of Child Psychology \& Psychiatry, 38, 401-412.

Kirk, H. D (1964). Shared fate: A theory of adoption and mental health. New York: Free Press.

Mandigo, J. L., Spence, J. C., Poon, P. P. L., \& and Mummery, W. K. (1999). Physical Education Enrolment at the Secondary Level in Alberta. Vol. 6, No. 3. 77-90.

Maughan, B. \& Pickles, A. (1990).Adopted Children Growing Up in Robins, L. \& Rutter, M. (eds.) Straight and Devious Pathways from Childhood to Adolescence. CUP.

Miller, B. C., Fan, X., Christensen, M., Bayley, B., Grotevant, H., van Dulmen, M., Dunbar, N., \& Coyl, D. (2001). Who is adopted: Measuring adoption status using national survey data. Adoption Quarterly, 5 (1), 7-31. 
McRoy, R. G. (1989). An Organizational Dilemma: The Case of Transracial Adoptions. The Journal of Applied Behavioral Science, 25 (2), 145-160.

McRoy, R \& L.A Zurcher (1983): Transracial adoptees: The adolescent years. Springfield: Thomas Publishers.

McRoy, R. G., Zurcher, L. A., Lauderdale, M. L. \& Anderson, R. E. (1982). Self-esteem and racial identity in transracial and inracial adoptees. Social Work, 57 522-526.

Moore, E. G. J. 1986. Family socialization and the IQ test performance of traditionally and transracially adopted black children. Developmental Psychology. 22, (3), $317-26$

National Association of Black Social Workers. (1994). Preserving African-American families (position statement). Washington, D.C.: NABSW.

Park, S. M. \& Green, C. E. (2000). Is Transracial Adoption in the Best Interest of Ethnic Minority Children?: Questions Concerning Legal and Scientific Intepretations of a Child's Best Interests. Adoption Quarterly, 3 (4), 5-34.

Pomerantz, E. M., Altermatt, E. R., Saxson, J. L. (2002). Making the Grade but Feeling Distressed: Gender Differences in Academic Performance and Internal Distress Journal of Educational Psychology, Vol. 94, (2), 396-404.

Rushton, A., \& Minnis, H. (1997) Annotation: Transracial Family Placements. Journal of Child Psychology \& Psychiatry, 38,147-159.

Scarr, S. \& Weinberg, R.A. (1983). The Minnesota Adoption Studies: Genetic differences and malleability. Child Development, 54, 260- 267.

Schorr, A. L. (2000). The Bleak Prospect for Public Child Welfare. Social Service Review, 74, 125-136.

Silverman, A.R. (1993). Outcomes of transracial adoption. The Future of Children, 3(1), 104-118.

Simon, R. J. (1998). Adoption and the Race Factor: How Important Is It? Sociological Inquiry, 68 (2), 274-279.

Simon, R. J., \& Alstein, H. (1996). The Case for Transracial Adoption. Children and Youth Services Review, 18, 5-22.

Simon, R. \& Alstein, H. (1992). Adoption, Race, and Identity: From Infancy through Adolescence. New York: Praeger. 
Simon, R. J., Alstein, H. (1977). Transracial Adoption. New York: John Wiley \& Sons.

Smith, J. F. (1996). Analyzing Ethical Conflict in the Tranracial Adoption Debate: Three Conflicts Involving Community. Hypatia, 11, (2), 1-33.

Sokoloff, B. Z. (1993). Antecendents of American Adoption. The Future of Children, 3 (1), 17-25.

Stein, L. \& J. Hoopes (1985). Identity Formation in the Adopted Adolescent. New York, Child Welfare League of America.

Stolley, K. S. (1993). Statistics on Adoption in the United States. The Future of Children, 3(1),26-42.

Tizard, B. (1991). Intercountry adoption: a review of the evidence. Journal of Child Psychology and Psychiatry 32, 743-756.

Tizard, B., \& Rees, J. (1974). A comparison of the effects of adoption, restoration of the natural mother, and continued institutionalization on the cognitive development of four-year-old children. Child Development, 45, 92-99.

Triseliotis, J., Shireman, J. \& Hundleby, M. (1997). Adoption theory, policy and practice. London: Cassell.

Verhulst, F. C. (2000). Internationally Adopted Children: The Dutch Longitudinal Adoption Study. Adoption Quarterly, 4, (1), 27-44.

Verhulst, F. C., \& Versluis-den Bieman, H. J. M. (1995). Developmental Course of Problem Behaviors in Adolescent Adoptees. Journal of the American Academy of Child and Adolescent Psychiatry, 34, (2) 151-159.

Vroegh, K. S. (1997). Transracial Adoptees: Developmental Status After 17 Years. Journal of Orthopsychiatry, 67 (4), 568-575.

Warren, S. B. (1992). Lower threshold for referral for psychiatric treatment for adopted adolescents. Journal of the American Academy of Child and Adolescent Psychiatry, 31, 512-517.

Weiss, A. (1985). Symptomatology of adopted and nonadopted adolescents in a psychiatric hospital. Adolescence, 19, 77-88.

Werner, E. (1989). High-risk children in young adulthood: A longitudinal study from birth to 32 years. American Journal of Orthopsychiatry, 59, 72-81. 
Wierzbicki, M. (1993). Psychological adjustment of adoptees: A meta-analysis. Journal of Clinical Child Psychology, 22(4), 447-454.

Yarrow, L. J., \& Goodwin, M. S. (1973). The immediate impact of separation: Reactions of infants to a change in mother figure. In Stone, L., Smith, H., \& Murphy, L. (Eds.). The competent infant. New York: Basic Book.

Yarrow, L. J., Goodwin, M. S., Manheimer, H., \& Milowe, I. D. (1973). Infancy experiences and cognitive and personality development at 10 years. In Stone, L., Smith, H., \& Murphy, L. (Eds.). The competent infant. New York: Basic Book. 